\title{
PEER GROUPS AND OPERATIONAL CYCLE ENHANCEMENTS TO THE PERFORMANCE INDICATOR REPORT
}

\author{
H. M. Stromberg \\ M. S. DeHaan \\ C. D. Gentilion \\ G. E. Wilson \\ L. N. Vanden Heuvel, ORNL
}

December 1, 1992
Idaho National Engineering Laboratory
EG\&G Idaho, Inc.
Idaho Falls, Idaho 83415

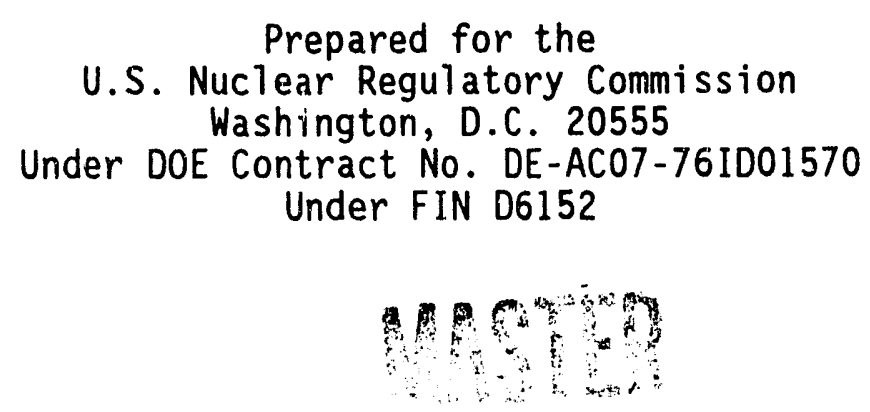




\begin{abstract}
Accurate performance evaluation and plant trending by the performance indicator program are integral parts of monitoring the operation of commercial nuclear power plants. The presentations of the NRC/AEOD performance indicator program have undergone a number of enhancements. The diversity of the commercial nuclear plants, coupled with cont inued improvements in the performance indicator program, has resulted in the evaluation of plants in logical peer groups and highlighted the need to evaluate the impact of plant operational conditions on the performance indicators. These enhancements allow a more meaningful evaluation of operating commercial nuclear power plant performance.

This report proposes methods to enhance the presentation of the performance indicator data by analyzing the data in logical peer groups and displaying the performance indicator data based on the operational status of the plants. Previously, preliminary development of the operational cycle displays of the performance indicator data was documented. This report extends the earlier findings and presents the continued development of the peer groups and operational cycle trend and deviation data and displays.

This report describes the peer groups and enhanced PI data presentations by considering the operational cycle phase breakdowns, calculation methods, and presentation methods.
\end{abstract}




\section{CONTENTS}

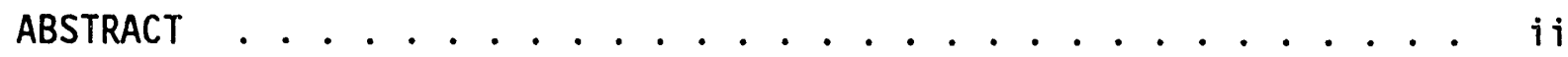

ACKNOWLEDGMENTS ...................... . . .

EXECUTIVE SUMMARY .................... . . vi

1. INTRODUCTION .................... 1

1.1 Background $\ldots \ldots . . . \ldots 1$

1.2 The Current PI Program $\ldots$

1.3 Performance Indicator Report Enhancements ....... 2

2. PEER GROUPS ..................... . . . 4

2.1 Background ................. 4

2.2 Methodology ................ 4

2.2.1 Design Characteristics ............4

2.2.2 Regulatory Issues ............ 4

2.3.3 Organizational Issues ............ 4

2.2 .4 Peer Group Size ................ 5

2.3.5 Input from Other Organizations ........ 5

2.3 Results ................... 5

3. OPERATING CYCLE ..................... 6

3.1 Phase Profile ............... 6

3.1.1 Operational Profile Background ......... 6

3.1 .2 Startup (I) .............. . . 6

3.1.3 Power Operations (II) . . . . . . . . . . . 8

3.1 .4 Pre-Refueling (IV) ............ . . 9

3.1 .5 Refueling (V) ............. . . 9

3.1 .6 Non-Refueling Outage (VI) ........ 10

3.2 Phase Type ................. . . 12

3.2.1 Operations Phase Type ............ 12

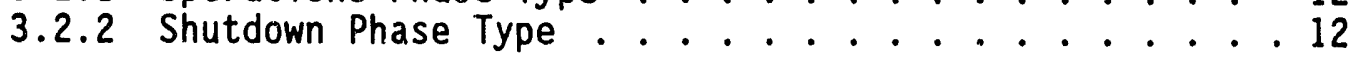

4. CALCULATION AND DISPLAY METHODS ............. 15

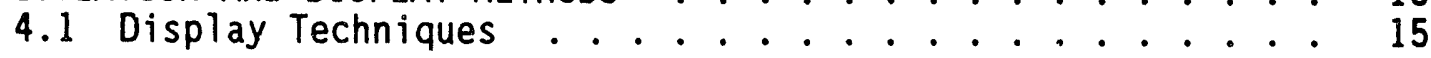

4.1.1 Quarterly Data Display ............ 15

4.1 .2 Trends and Deviations Display . . . . . . . 17

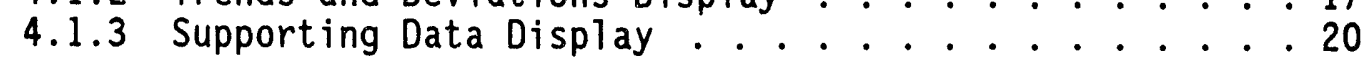

4.2 Calculational Techniques . . . . . . . . . 22

4.2.1 Plant, Peer Group, and Industry Trend

Presentations 


\section{PONTENTS}

4.2.2 Plant Self-Trend ............... 23

4.2.3 Plant Deviations from Peer Group . . . . . . . . . 27

4.2.4 Statistical Significance ........... 29

5. PEER GROUP AND OCM ASSESSMENT . . . . . . . . . . . . . . . 32

5.1 Peer Group Assessment . . . . . . . . . . . . . . 32

5.1.1 Similarities in the Reporting Patterns

of Peer Groups .... . . . . . . . . . . 32

5.1.2 Analysis Methodology for Evaluation of Peer Group Reporting Patterns . . . . . . . . 32

5.1.3 Summary of ANOVA Evaluations . . . . . . . . . . . 34

5.1.4 Potential Problems with Combining Peer Groups . . . . 34

5.1.5 Peer Group Size... . . . . . . . . . . . . 35

5.1.6 Conclusions of Peer Group Assessment . . . . . . . 35

5.2 Assessment of the Effects of Operating Cycles . . . . . 35

5.2.1 Observation of Cyclic Behavior of

Cause Code Data................ . 35

5.2.2 Implications of Cyclic Behavior of

Cause Code Data . . . . . . . . . . . . 39

5.2.3 Qual itative Assessment of the Operational

Cycle Calculation Methodology ........... . 43

5.2.4 Statistical Significance Test Assessment . . . . 45

5.3 Pilot Program .................. 45

5.3.1 September 12, 1991 ITG Meeting . . . . . . . . . 45

5.3.2 May 27, 1992 ITG Meeting .. . . . . . . . . . . 48

5.3.3 August 26, 1992 ITG Meeting . . . . . . . . . . . 48

5.3.4 Summary of Pilot Program . . . . . . . . . . . 50

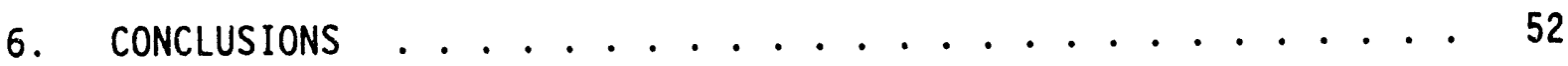

7. REFERENCES . . . . . . . . . . . . . . . . . . . . 54

APPENDIX A. PERFORMANCE INDICATOR PROGRAM . . . . . . . . . . . A-1

APPENDIX B. PEER GROUP ANALYSIS . . . . . . . . . . . . . . B B-1

APPENDIX $C . \quad$ SUMMARY OF INPUT FROM OTHER ORGANIZATIONS $\ldots . . \cdots$

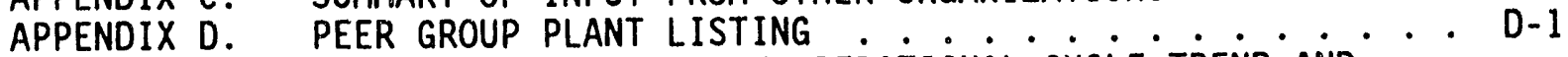

APPENDIX E. FURTHER DEVELOPMENT OF OPERATIONAL CYCLE TREND AND

DEVIATION MEASURES FOR THE PERFORMANCE INDICATORS . . E-1 


\section{FIGURES}

1. Hypothetical operational cycle phase diagram . . . . . . . 7

2. Phase diagram for operational cycle ............ 7

3. PI event rate .................. 8

4. Cause code PI rate ................ 8

5. Illustration of reporting during startup ........ 9

6. Illustration of reporting frequency during pre-refueling . . . 10

7. Illustration of reporting frequency for outage duration ..... 11

8. Illustration of the number of outages having a specific duration .................. 11

9. Illustration of phases and phase types ........... 13

10. Illustration of $\mathrm{OCM}$ plant specific PIs ......... 16

11. Illustration of $\mathrm{OCM}$ plant specific self-trend and . . ..... 18

12. Illustration of phase type time partitioning ........ 24

13. Multiplying Factors of the standard deviation for confidence intervals ..................... 36

14. Illustration of peer group trends for the scrams and SSA $\ldots . . .37$
Indicators . . . . . . . . . . . 37

15. Plant A maintenance error cause code generation rate vs plant age 38

16. Plant $B$ maintenance error cause code generation rate vs plant age 38

17. Plant C maintenance error cause code generation rate vs plant age 39

18. Maintenance error cause code generation rate vs plant age for plant D ................... 40

19. Maintenance error cause code generation rate vs plant age for plant E ...................... 41

20. Maintenance error cause code generation rate vs plant age ..... 42

21. Illustration of PI trend significance ............ 46

\section{TABLES}

1. Table of PI Event Phase Rates ................ 14

2. Summary of changes in OCM quarterly presentations of PI data . . 17

3. Table of significant changes in OCM for reporting PI self-trends and deviations from the peer group ............ 19

4. Summary of significant changes in OCM for reporting plant $\ldots 21$

5. Number of days in shutdown for the most recent 3 year period . 25

6. Summary of threshold values used for assigning statistical .... 31

7. Peer groups used for the OCM deviation analysis ........ 33

8. PIs used in evaluation of peer group combinations ....... 34

9. Correlation between plants of greater concern and outliers

10. Correlation between plant sites of greater concern and out lier

11. plant sites from both methods ............ 44

11. Illustration of PI trend significance ............ 46

12. Table of significance levels from 92-2 OCM PI report ..... 47

13. Modifications to OCM from September 12, 1991 ITG meeting. . . . . 49

14. Modifications to OCM from May 27, 1992 ITG meeting ...... . 49

15. Modifications to OCM from August 26, 1992 ITG meeting ..... 51 


\section{ACKNOWLEDGMENTS}

This work would not be possible without the ongoing support of personnel in the U.S. NRC's Office for Analysis and Evaluation of Operational Data, Trends and Patterns Branch. Support and suggestions from the technical monitor, D. Hickman, and other members of the Trends and Patterns Branch staff including, B. Brady, T. Wolf, and R. Prato, are gratefully acknowledged.

W. P. Poore and R. Schmoyer from Oak Ridge National Laboratory are acknowledged for proposing methods for evaluating the significance of the performance indicator trends and deviations and for supplying the threshold values for the significance assessments. They are also acknowledged for their portions of performing and presenting the peer group analysis.

J. H. Bryce, R. C. Clark, T. W. Smith from EG\&G Idaho, Inc. are thanked for their helpful suggestions and review comments. 


\section{EXECUTIVE SUMMARY}

\section{Background and Introduction}

The Nuclear Regulatory Commission (NRC) started the development of the Performance Indicator Program in May of 1986. The purpose of the NRC's Performance Indicator Program has been to provide an additional view of operational performance and enhance the NRC's ability to recognize areas of poor and/or declining safety performance of operating plants. The Performance Indicators (PIs) are intended to augment the Systematic Assessment of Licensee Performance (SALP) process and to provide for a more timely identification of declining performance. Consequently, the PIs are trended on a more frequent basis than SALP to detect symptoms of declining performance and to provide more objective input into SALP.

In 1989, as documented in SECY-89-046 and SECY-89-211, the NRC staff proposed the cause code performance indicator. Through Staff Requirements Memoranda (SRM) dated March 15, 1989, and August 10,1989, the Commission approved the cause codes as a new singular performance indicator. The Secretary's memorandum of August 10,1989, also requested that the NRC staff assess the validity of comparing $\mathrm{PI}$ data across the industry. Since December 1989, the impact of the peer groups has been under development and consideration.

During the peer group development and assessment, it became evident that a plant's operating status has an impact on the performance indicators and the frequency with which the events are experienced. To understand the plant operating condition impact on the performance indicators, the operating cycle effects have been evaluated. A methodology for presenting the performance indicators using the selected peer group breakdown and adjusting the displays for the impact of plant operating conditions has been developed and is being presented for consideration.

\section{Proposed Enhancements to the Performance Indicator Program}

As a result of the peer group and plant operating conditions analyses, two enhancements are being proposed to the performance indicator program: implementation of the peer group breakdown of the commercial nuclear power plants and operating cycle adjustments to the performance indicator displays.

\section{Peer Groups}

As presented in SECY-92-083, dated March 12 , 1992, nine peer groups were developed. All operating commercial light-water reactors were assigned to one of the nine groups. The peer groups reflect design differences among the NSSS vendors, class and product line differences among plants of each NSSS vendor, and age difference among these plants. The nine peer groups are as follows:

- Babcock and Wilcox Plants,

- Combustion Engineering Plants - Without Core Protection Calculators,

- Combustion Engineering Plants - With Core Protection Calculators,

- Westinghouse Electric Plants - Two-Loops,

- Westinghouse Electric Plants - Older ThreeLoops,

- Westinghouse Electric Plants - Older FourLoops,

- Westinghouse Electric Plants - Newer ThreeLoops and Four-Loops,

- General Electric Plants - BWR/2, BWR/3 and Older BWR/4, and

- General Electric Plants - BWR/5, BWR/6 and Newer BWR/4.

These nine peer groups have been used in the analysis of data during evaluation and assessment efforts. The evaluation and assessment found the nine peer groups to effectively differentiate between the operations of the various types of plants. 
Operating Cycle Adjustments to the Performance Indicators

The operating cycle for commercial nuclear power plants was analyzed and classified in five operating phases. The phases are listed below:

- Startup,

- Power Operations,

- Non-Refueling Outages,

- Pre-Refueling, and

- Refueling Outages.

The operating cycle phases were subsequently combined into two operating phase types: operations and shutdowns. These phase types are used in the performance indicator displays.

To optimize the operating cycle methods display of the performance indicators the following changes are proposed for the performance indicator displays:

The Plant Quarterly Data displays

- Twelve quarters of data presented rather than the current eight quarters,

- The count of the quarterly cause code events presented rather than a six-quarter moving average,

- Plant status time line added showing major operation and shutdown periods rather than critical hours,

- Industry average linear regression trend line presented rather than a six-quarter moving average,

- Peer group average linear regression trend line added based on the plant's peer group data,

- Plant linear regression trend line without regard to phase or phase type, and

- Shading added to the event bars to differentiate between events occurring in operation, shutdown, and startup.

The Trends \& Deviations Display changes include the following:

- Trends and deviations separated for operating and shutclown periods and forced outages,
- Cause code deviations added,

- The deviations from the peer group substituted for deviations from the industry. Each plant compared to the peer group median instead of being compared to the industry average,

- The plant self-trends based on slopes of a linear regression trend line overlayed through the event counts as a replacement for comparing plant event rates for different periods of time,

- Shading added to the trends and deviations presentations to indicate their statistical significance, or the likelihood that ar. observed trend or deviation could be due to a real change in plant performance rather than due to random event count variation, and

- The time periods for the trend and deviation calculations changed to those listed in the following table.

These proposed changes have been evaluated and assessed. Based on these efforts, the changes effectively present the peer group information and the operational cycle impact on the performance indicators.

\section{Conclusions and Recommendations}

Nine peer groups were developed based on design factors, plant class, model, and plant age. The nine peer groups have been demonstrated to be a more equitable method for comparing operating data from plants with similar operations and tuipment. These nine peer groups are recommended for use to facilitate comparisons of plant performance among similar plants.

The operating cycle methodology for adjusting performance indicator trends and deviations for the impact of changing operating conditions at a commercial nuclear power plant has been developed. The adjustments account for changes in plant operations from shutdown to power operations. The displays presenting the adjusted information have been demonstrated to be an improvement over the current display techniques. The use of the operating cycle methodology is recommended. 


\begin{tabular}{||l|c|c|c|c|c|c||}
\hline & \multicolumn{2}{|c|}{ OPERATIONS } & \multicolumn{2}{c|}{ SHUTDOWNS } & \multicolumn{2}{c|}{$\begin{array}{c}\text { FORCED } \\
\text { OUTAGE RATE }\end{array}$} \\
\cline { 2 - 7 } & Trend & Deviation & Trend & Deviation & Trend & Deviation \\
\hline Total Number of Days & 270 & 540 & 90 & 180 & 270 & 540 \\
\hline $\begin{array}{l}\text { Minimum Number of } \\
\text { Days }\end{array}$ & 90 & 90 & 30 & 30 & 90 & 90 \\
\hline $\begin{array}{l}\text { Maximum Number of } \\
\text { Calendar Quarters }\end{array}$ & 4 & 12 & 6 & 12 & 4 & 12 \\
\hline $\begin{array}{l}\text { The Equipment Forced Outages per 1000 Critical Hours of Commercial Reactor Operation trend and } \\
\text { deviation calculations use the same time frames and time limits as the operations trend and deviation } \\
\text { calculations. }\end{array}$ &
\end{tabular}




\section{PEER GROUP AND OPERATING CYCLE ENHANCEMENTS TO THE PERFORMANCE INDICATOR REPORT}

\section{INTRODUCTION}

\subsection{Background}

The NRC's quarterly Performance Indicator (PI) Report was first published in February of 1987, containing data from the first quarter of 1985 through the fourth quarter of 1986 on 101 operating commercial nuclear power reactors. The indicators included in this first report were (1) unplanned automatic scrams while critical, (2) safety system actuations (SSA), (3) significant events (SE), (4) safety system failures (SSF), (5) forced outage rate (FOR), and (6) equipment forced outages per 1000 commercial critical hours (EFO). Quarterly collective radiation exposure (CRE) was added as a new indicator beginning with the report for the first quarter 1989. Also in 1989, the NRC staff recommende: and the commission approved the inclusion of cause codes into the PI Report. This new in t cator was first incorporated into the report for the second quarter of 1989.

The Performance Indicator Program provides an additional view of operational performance and enhances the NRC's ability to recognize areas of poor and/or declining safety performance of operating plants. The PIs are intended to augment the SALP process and to provide for a more timely identification of declining performance. Consequently, the Pls are trended on a more frequent basis than SALP to detect symptoms of declining performance and to provide more objective input into SALP. Performance Indicators are intended to be one of several tools for use by senior NRC management in decision-making regarding plant-specific regulatory programs. The Pls for a given plant should be viewed as a set. They do not provide a valid basis for ranking individual nuclear power plants and should not be presented in such a way as to imply "problem facility" status for individual plants.

\subsection{The Current PI Program}

The PI Program is one aspect of the Commission's efforts to monitor the performance of commercial nuclear power plants in the United States. Under the direction of AEOD, the PI Program currently presents industry wide data on eight selected performance indicators for 111 operating commercial nuclear power plants. The PI data are extracted from Immediate Notifications submitted in accordance with 10 CFR 50.72, Licensee Event Reports (LERs) submitted in accordance with 10 CFR 73, and Monthly Operating Reports submitted in accordance with plant technical specifications. In addition, Significant Events are derived from NRC screening of operational events, and quarterly Collective Radiation Exposure data are obtained from the Institute of Nuclear Power Operations (INPO).

Performance Indicator Reports are published quarterly. Each report provides the following information for each plant for the most recent eight quarters:

a) Quarterly counts for scrams, SSAs, SEs, and SSFs;

b) Quarterly rates for FOR and EFO;

c) Quarterly values of Collective Radiation Exposure;

d) Six quarter (iong term) moving averages by quarter for each of the above PIs and each cause code;

e) Critical hours by quarter;

f) Short term self-trends for scrains, SSAs, SEs, SSFs, FOR, EFO, and each cause ccie; 
g) Long term deviations from industry averages for scrams, SSAs, Ses, SSFs, FOR, and EFO; and

h) One line descriptions of all scrams, SSAs, SES, and SSFs for the most recent four quarters.

In addition to the above plant-specific information, the industry six quarter moving average is displayed.

Appendix A contains detailed definitions of each $\mathrm{Pl}$; conventions used in the calculations; notes on the display methods; NRC Announcement 200, which provides guidance on the use of PIs; and representative PI data for one plant.

\subsection{Performance Indicator Report Enhancements}

In April of 1988, the NRC staff proposed the use of the causes and corrective actions associated with all reportable events as new indicators for the PI Program. In a Staff Requirements Memorandum in June of 1988, the Commission approved a six-month trial program to further evaluate this proposal. The trial program was completed and the NRC staff reported the iesults to the Commission in February of 1989. At this time, the NRC staff recommended the inclusion of cause code data in the PI Program and the use of corrective actions as supplemental information rather than as a separate indicator. The NRC staff also committed to develop appropriate displays for the cause code indicator. These displays were presented to the Commission in July of 1989. It was also recommended that cause codes be displayed in a manner similar to that used for other performance indicators except that the appropriate Nuclear Steam Supply System (NSSS) average would be used in place of the industry older plant average in the "Deviations from Older Plant Means" chart. The Commission approved the inclusion of cause code trends in the NRC quarterly Periormance Indicator Report. However, the Commission did not approve the display of cause code deviations. Rather, the Commission requested that the NRC staff assess the validity of comparing individual plants to their NSSS average in light of the variations in plant design within NSSS groups which could affect the comparability of LERs among licensees. Specifically, the NRC staff was asked to address how the sets of reportable events differ between older and newer plants due to complexity or number of technical specifications, between two, three, and four loop plants, etc., prior to the Commission's approving cause code deviations. A study was initiated at the Oak Ridge National Laboratory (ORNL) to determine appropriate "peer groups" for comparing reported event data among licensees.

The first use of peer groups in the PI Program began with the second quarter 1989 report, when SSFs and CRE began to be compared to the appropriate PWR or BWR average, rather than the industry average. This was done because the NRC staff recognized that, with a single train high pressure injection system, BWRs have more SSFs than PWPis, which have muitiple train high pressure injection systems. It was also recognized that BWRs generate more radiation exposure than PWRs. Therefore, for these two Indicators, PWRs and BWRs have been compared only to the appropriate group since that time. The ORNL study, however, was intended to encompass all reportable events in order to produce sultable peer groups for comparing cause codes derived from all LERs. This study and its results are described in detail in Section 2.

Early in the peer group study, it was recognized that cause code data are cyclic in nature, with a period approximating that between refueling outages. Further investigation of this behavior led to the conclusion that a plant's operating phase (startup, power operations, refueling, etc.) could have as much or more of an effect upon event reporting as differences between peer groups. This operating cycle phase effect had been noted previously. Automatic scrams, while critical cannot, by definition, occur during outages. Also, SSAs and SSFs were noted to occur somewhat more often during outages, when maintenance and surveillance activities are more prevalent. However, the effect of operating cycle phases was even more pronounced in the cause code data. Therefore, a study was initiated at the Idaho 
National Engineering Laboratory (INEL) to identify those phases of an operating cycle in which event reporting varies significantly. The methods and results of this study are presented in Section 3.

To incorporate the results of the peer group and the operating cycle phase studies into the PI Program, a joint effort in cooperation with the INEL and ORNL to develop new calculational and display techniques was undertaken. The goal of this task was to substantially increase both the quality and the quantity of the data in the PI Report without significantly increasing the size of the report. At the same time, it was important that the data be displayed in a manner that could be easily understood and readily interpreted. This program and its results are described in Section 4.

Assessment of the new methods was important in order to determine whether the increased complexity of the calculations, displays, and quality assurance processes can be justified by the improved understanding of plant performance. This effort is described in Section 5.

Conclusions and recommendations are presented in Section 6. 


\section{PEER GROUPS}

\subsection{Background}

In the Secretary's memorandum of August 10, 1989, on SECY-89-211, the Commission requested that the NRC staff assess the validity of comparing individual plants to their NSSS average in light of the variations in plant design within NSSS groups which could affect the comparability of LERs among licensees. In response to this request, a study was initiated at ORNL to determine appropriate peer groups for comparing reported event data among licensees. This section describes the development of peer groups to be used in the presentation of PI cause code clata derived from all LEF's.

\subsection{Methodology}

The NRC staff, assisted by the ORNL, identified more than 80 factors which could affect event reporting. These factors generally fell into the four broad categories of design, regulatory issues, organization, and plant operating mode (startup, operation, or shutdown). Upon looking m: each of these areas, the NRC quickly conciuded that a plant's operating mode could have as much or more effect upon event reporting as all of the other categories together. Therefore, this issue was addressed separately in a study at the INEL to identify those phases of plant operation in which event reporting varies significantly (see Section 3). The three categories of design, regulatory issues, and organization are discussed below.'

The NRC recognized the need to establish a minimum number of plants in any peer group to provide confidence in the validity of the group statistics. In addition, it was deemed important to solicit input frori others in the industry, particularly those who had already constructed plant groupings for other purposes. The results of both of these efforts are also described below. ${ }^{[2,3]}$

2.2.1 Design Characteristics - Plant design characteristics can impact licensee reporting. Many design issues were considered, such as
Nuclear Steam Supply System (NSSS) vendor; vintage, or product line; generating capacity; and de gn of many plant systems, particularly the protection, containment, emergency core cooling, and feedwater systems. These characteristics range from the very general (NSSS vendor) to the quite specific (number and type of feedwater pumps). Use of the NSSS vendor alone to form perer groups would result in four groups. The Commission specifically requested the NRC staff to consider more than these four. It was found that the use of very specific design characteristics would result in many peer groups with only a small number of plants in each group. To meet the limitations on minimum group size, the number of design features that could be incorporated would be small and would be limited to the molu general ones. The advantage of design features is that they tend to be stable over time, so that peer groups based on design features would not change often, if at all.

\subsubsection{Regulatory Issues - Regulatory} requirements and programs can have a significant impact upon licensee reporting. They include the type of technical specifications (standard or custom), licensing date, required backfit programs such as environmental qualification, mandated or voluntary (in response to NRC concerns) review programs, and other NRC programs such as Headquarters and regional inspections. Regulatory issues that are not plant specific, such as NRC programs, or that are the same for many plants, such as the type of technical specifications, could be used to construct peer groups that conform to the minimum size. However, most regulatory issues tend to change over time, which limits their usefulness in developing peer groups. Many of the plant specific issues, though, such as backfits arising out of the lessons learned from the Three Mile Island event, are a function of NSSS vendor or other aspects of plant design, and therefore, can be accommodated in peer groups based upon design considerations.

2.2.3 Organizational Issues - Issues associated with the organization that operates the 
plant, such as policies, programs, and training, are perhaps the most important factors affecting reporting. However, every plant has its own set of organizational issues, most of which are subject to change over time. More importantly, it is the effect of these issues that the NRC staff attempts to measure; consequently, it is not appropriate to include them when developing peer groups. For these reasons, it is impractical to construct peer groups based upon organizational factors.

2.2.4 Peer Group Size - The effect of peer group size was studied to determine the minimum size acceptable to provide statistically valid data for performing $\mathrm{PI}$ calculations. Those calculations include certain parameters for each peer group. It is important that these parameters accurately represent group performance. A method often used to quantify the accuracy of an estimated paran ieter is to place a confidence interval on the paraineter. A confidence interval is an interval whici: bounds the true value of the parameter for a certain percentage of the time over the long term. The more narrow the confidence interval, the more precisely the estimate represents the true value of the parameter. The confidence intervals were evaluated as a function of the number of plants in a peer group. The results of this evaluation determined the minimum number of plants in a group (see Appendix B).

\subsubsection{Input from Other Organizations - Input} from others was useful in defining the criteria to be used to establish peer groups, as well as in understanding the difficulties to be expected when comparing plants because of the diversity in design implementation. Appendix $\mathrm{C}$ provides a summary of those contacted and the input provided by each.

\subsection{Results}

From the peer group size study, it was determined that confidence intervals grow quite large with fewer than six plants in a group. Therefore, peer groups should have six or more plants. This was an important consideration when constructing peer groups. It was also determined that design characteristics are the most important factor to use in comparing reporting among plants. They provide stable groups which can be used to compare how different licensees, given similar plant designs, perform relative to each other. Certain regulatory issues were recognized to play an important role in reporting, principally, type of technical specifications, licensing date, and backfit programs. But these issues are closely related to a plant's licensing date relative to the event at Three Mile Island, Unit 2, or to NSSS vendor. In addition, there are several plants so unlike any others that they don't fit into any peer group, yet they must be accommodated. With these considerations in mind, and $w^{\prime \prime}$. review and comment by the Westinghouse ari. BWR Owners Groups, a set of nine peer groups based on NSSS vendor and vintage were constructed. The peer groups were modified slightly in consideration of certain regulatory issues (see Appendix D). This grouping incorporates the important effects of both plant design and regulatory concerns: NSSS vendor, generating capacity, product line, age, type of technical specifications, TMI backfit programs, and licensing date. While this set of peer groups was developed for the specific purpose of cc nparing cause codes among licensees, the NRC staff intends to use them for all PIs. For certain indicators, peer groups based upon other design or regulatory issues may be more appropriate. However, the increased complexity of using different sets of peer groups for some Pls cannot be justified. The NRC staff considers this set, based upon these design and regulatory issues, to be appropriate for comparing the overall performance of licensees operating similar plants in a similar regulatory environment. 


\section{OPERATING CYCLE}

A study was conducted to research the effects of the plant operating cycle on event reporting. The goal of this study was to identify phases in plant operations when the operating conditions change and as a result, the reportable event experience rate change. Based on the cyclic behavior of the cause code data observed by ORNL, during the peer group analyses, it was surmised that the number of reported events changes as plant activities change during a plant's operating cycle. This section describes the development of the operating cycle phases used in the presentation of the PI data.

\subsection{Phase Profile}

An operating cycle is considered to be plant operations from the completion of one refueling outage to the completion of the next refueling outage. This operating cycle was analyzed to identify the times during power plant operations when, due to changing plant conditions, the frequency of reportable evenis occurring was likely to change.

\subsubsection{Operational Profile Background - A} hypothetical operating cycle profile was constructed showing the periods in a plant operating cycle where plant operating status changes from operations to shutdown and vice versa. It was hypothesized that with the change in plant operating status, equipment and plant systems status also change. The change in status would result in a change in the number of reportable events. The hypothetical operating cycle profile is presented in Figure $1 .^{4}$ This profile shows 16 different operating conditions that a plant experiences, with each condition varying in duration from hours to months. Examples of such conditions are: preparation for startup, startup, operations to $25 \%$ reactor power, operations from $25-100 \%$ reactor power, operations at $100 \%$ reactor power, etc.

The performance indicator event data are maintained and identified as daily events. Since some of the hypothetical operating cycle phases are less than a day in duration, the event data would not support analyses of phases less than a day in length. To be consistent with the data, the phases were consolidated. The consolidated phase profile is presented in Figure 2. This figure presents the operating cycle as having five individual phases: Startup, Power Operations, Non-Refueling Outages, Pre-refueling, and Refueling Outages..$^{[4,5]}$

The frequency that the PI events occurred during each of the five phases was studied in detail using applicable statistical tests to verify that the phases were distinctly different. ${ }^{[5,6]}$ The event frequency for the five phases was found to be different as the plant transitions from phase to phase. As examples of the changes in reportable events frequencies from phase to phase, Figures 3 and 4 are previded. These figures present the event frequencies for the data from the third quarter 1989 through the second quarter 1992 . These figures provide bar charts showing the event rates for the Pls by phase.

3.1.2 Startup (I) - For the operational cycle profile, the Startup Phase is defined as follows.

The startup phase is the period of the operational cycle that begins as the plant leaves cold shutdown mode following a refueling outage and continues for 25 days. During the 25 day period, if the plant is shut down for four or more consecutive days the 25 day clock would stop and the 25 day count would resume at the completion of the outage (see the definition of the non-refueling outage phase below).

The startup phase was determined to be a distinct phase because, during the transition from cold silutdown to power operation, the plant performs activities unique to this period, such as physics testing. During the startup phase, plant conditions are changing, such as power level, radiation level, system temperatures and pressures, and operating limits. Typical activities 


\section{HYPOTHETICAL PHASE DIAGRAM \\ FOR OPERATIONAL CYCLE \\ Operational Cycle vs Plant Status}

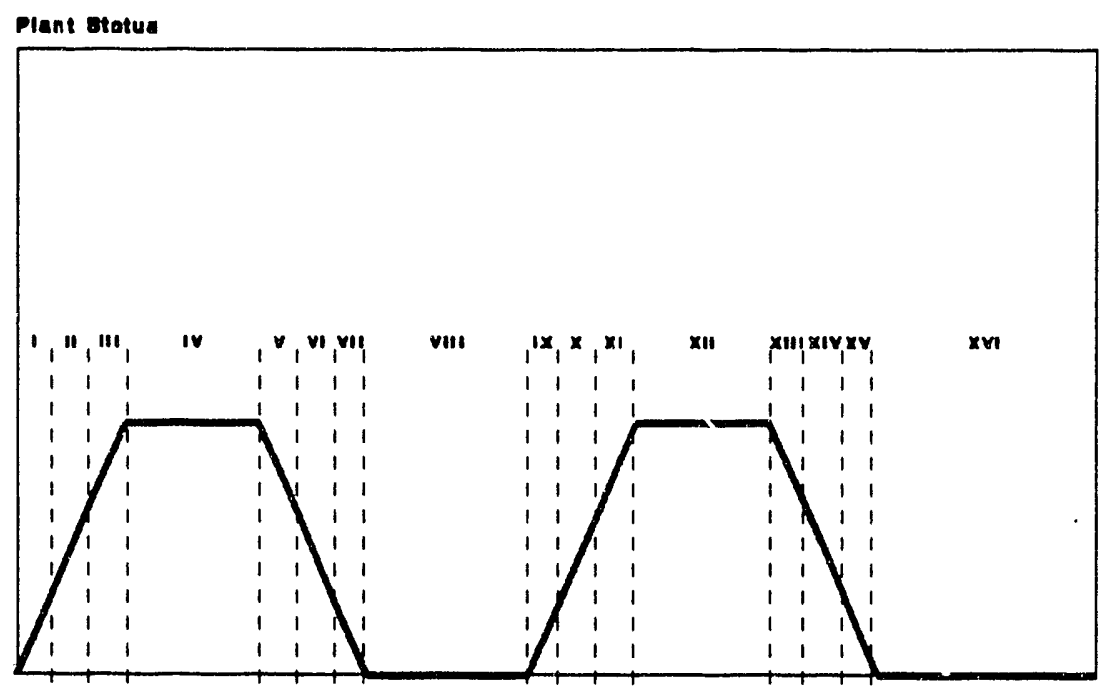

OPERATIONAL CYCLE

Figure 1. Hypothetical operational cycle phase diagram

\section{PHASE DIAGRAM FOR OPERATIONAL CYCLE}

Operational Cycle ve Plant Status

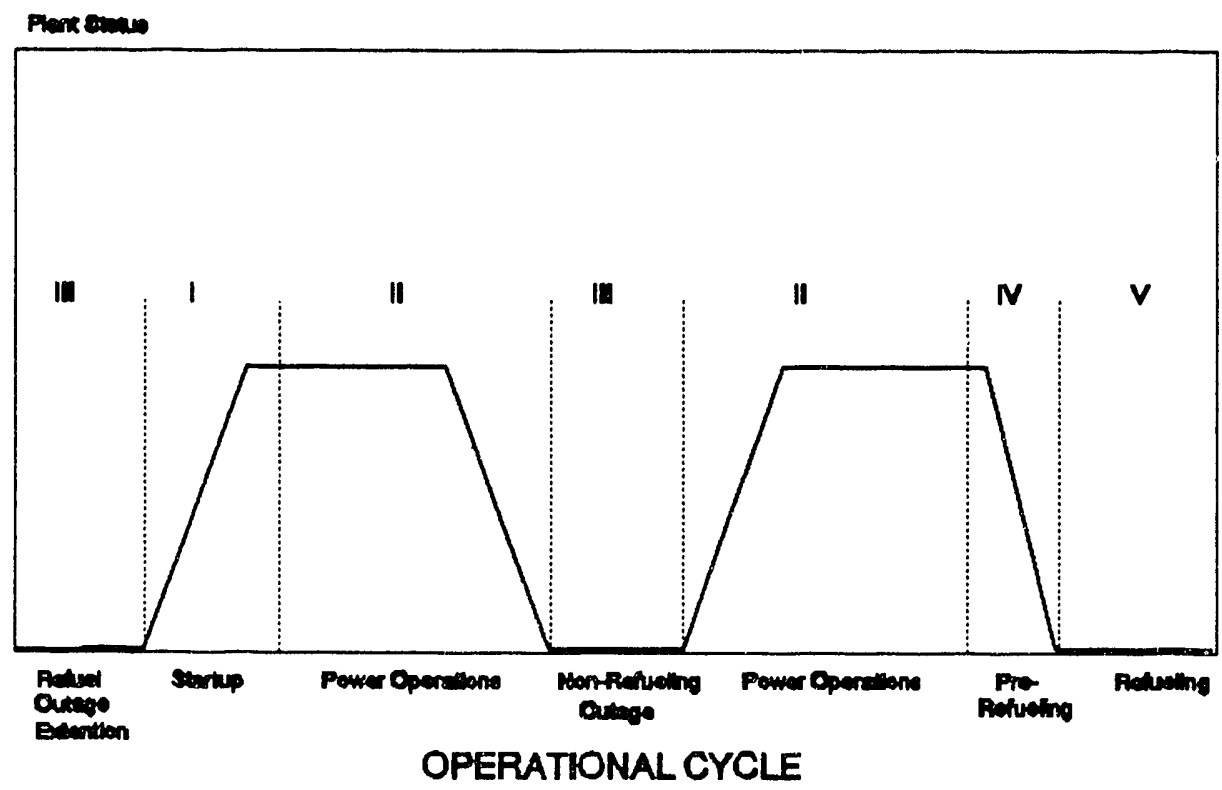

Figure 2. Phase diagram for operational cycle 


\section{Reporting Rates by Phase Inchatry Maan Rato}

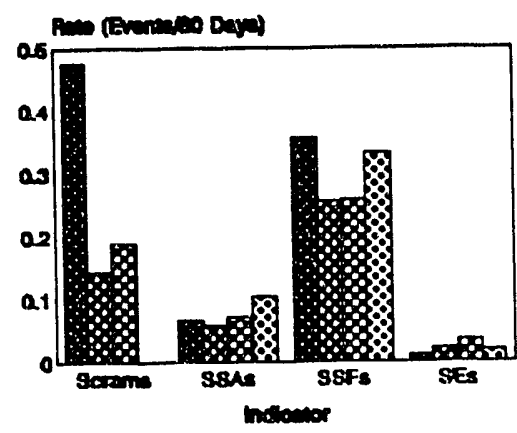

Figure 3. PI event rate.

performed during the startup phase include system allgnments for operations, postmaintenance testing, surveillance testing, and normal power operations.

In the definition provided above, the startup pt. $5:$ is limiled to the first 25 operating days following a refueling outage. This interval was determined to be the most optimum duration. The basis for the selection can be noted in the plot inflection points in Figure 5. The data presented in this plot is based on LER data for 1989 and 1990 . The most recent data shows the same inflection points but not as clearly. To determine the optimum time interval for the startup phase, it was decided that the points where the PI event experience frequencies changed would be used to identify the optimum time. It can be noted in the referenced figure that the majority of the reporting frequency inflection points occur between 15 and 35 days with a number of the inflection points occurring on 25 days. Based on inflection point observations, 25 days was selected for the description for the startup phase.

\section{Reporting Rates by Phase Induetry Moan Rate}
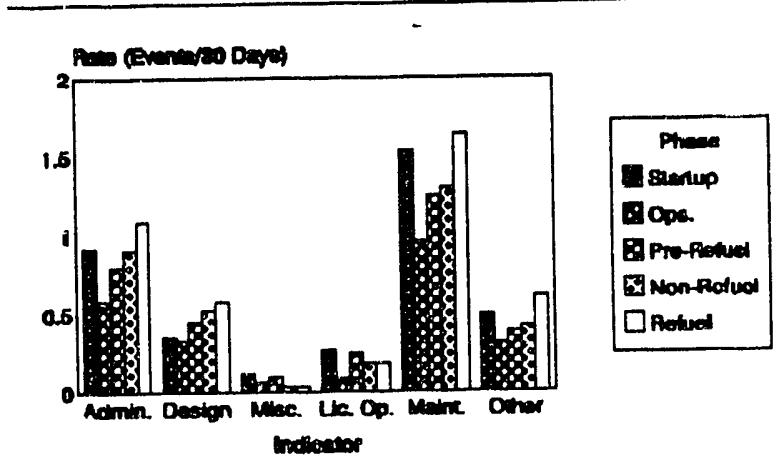

Figure 4. Cause Code PI rate.

\subsubsection{Power Operations (II) - For the} operational cycle profile, the Power Operations Phase is defined as follows.

The power operations phase is the period of the operating cycle that begins at the completion of the startup phase and continues to the beginning of the pre-refueling phase. Nonrefueling shutdowns of four or more consecutive shut down days are assigned to the non-refueling shutdown phase. (See the definition of the nonrefueling outage phase below.)

The power operations phase was determined to be distinct because the piant operating conditions are relatively steady, such as power level, radiation level, system temperatures and pressures, and operating limits. The operational goal is to generate the maximum electrical power output by maximizing the duration of the phase. However, the plant may conduct certain activities, such as surveillance testing and minor maintenance, which can impact plant operation. 


\section{Reportable Events for Startup Phase}
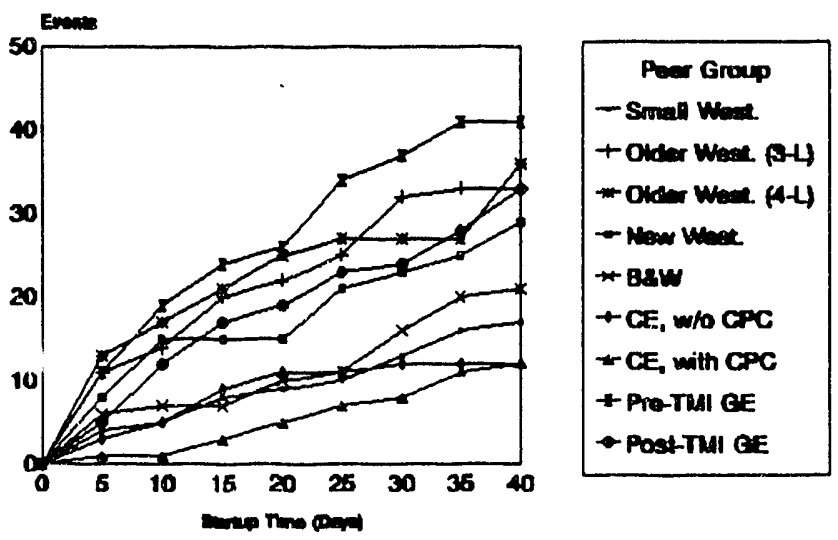

Figure 5. Illustration of reporting during startup.

3.1.4 Pre-refueling (IV) - The pre-refueling phase is defined as follows.

The pre-refueling phase is the period of the operational cycle that begins 25 days prior to entering a refueling outage and ends when the plant enters cold shutdown for refueling. Any shutdown periods of 4 or more consecutive days (a non-refueling outage) are not considered part of this phase. When a shutdown period meeting the nonrefueling outage definition is encountered the pre-refueling phase 25 day clock stops and then resumes when the outage is complete. The prerefueling phase was determined to be distinct because some plants may prepare for the upcoming refueling outage while still at power. The activities performed during this period may include: power coast down for fuel extension, surveillance testing,inspections, testing, maintenance, system alignments, and troubleshooting.

The selection of the interval used in the definition was evaluated using the same technique used for selecting the startup phase duration. An example of the event reporting information is presented in Figure 6 . In this figure, the events are counted by identifying the number of days that they occur prior to entering a refueling. Zero days is the day that refueling was entered, five days is five days before entering refueling, etc. The data presented - in this plot is based on LER data for 1989 and 1990. The most recent data shows the same inflection points but not as clearly.

It can be notec that the majority of the reporting frequency plot inflection points occur between 15 and 35 days with a number of the inflection points occurring on 25 days. Based on this observation and the desire to be consistent with the time frame selected for the startup phase, a 25 day duration was selected for the definition for the pre-refueling phase.

\subsubsection{Refueling (V) - The Refueling Phase is} defined as the following.

The refueling phase is the period of the operational cycle that begins when a plant shuts down and enters cold shutdown for a refueling outage and ends when the plant leaves cold shutdown following refueling. 


\section{Reportable Events for Pre-Refueling Phase}

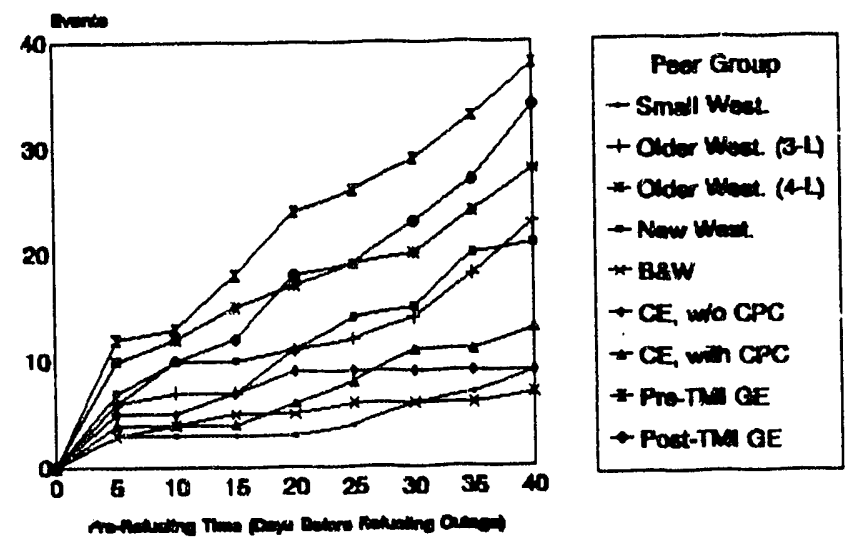

Figure 6. Illustration of reporting frequency during pre-refueling.

The refueling phase was determined to be distinct because the plant operating conditions are relatively steady: the reactor is shutdown and maintained in cold shutdown, system temperatures and pressures are reduced to permit personnel access, system maintenance, and refueling.

The operational goall is to complete the plant refueling and to bring the plant back to power operation as soon as possible. For this reason, it is desirable to minimize the number of activities that can extend the refueling phase. In addition, the shutdown time is used to perform other activities that could not "therwise be performed

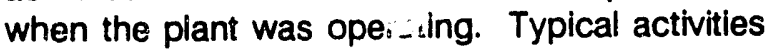
include: maintenance, surveillance testing, system and equipment modifications, post maintenance testing, and cold shutdown plant operations.

3.1.6 Non-refueling Outage (iil) - The nonrefueling outage is defined as the following.

The non-refueling outage phase is the aggregation of outages, other than refueling outages, during the startup, power operations, and pre-refueling phases where the plant is shut down for four or more consecutive days.
A non-refueling outage can occur during any phase, other than the refueling outage phase, i.e. startup, power operations, or pre-refueling. When non-refueling outages occur, the current phase is suspended until the outage is over. When the outage is complete the original phase would continue.

This restriction was implemented because when the plant is shutdown 3 days or less, the main goal in the plant is to return the plant to the previous phase as quickly as possible. Therefore, during the shutdown time, few activities are performed that could prohibit the plant returning to the previous phase. The events that occur during outages not meeting the non-refueling outage definition are assigned to the previous phase.

The non-refueling outage was determined to be distinct because plant conditions may be changing, as personnel attempt to restore the plant to its previous phase. Typical activities include trouble shooting, maintenance, post maintenance testing, and preparations to return to the previous phase of operation. The selection of which activities can be performed during the outage depends upon the plant conditions, such as radiation levels, system temperatures, operating limits and personnel access to areas of the plant. 


\section{LER Sensitivity to Outages \\ Pro-TMI BWR Plants}

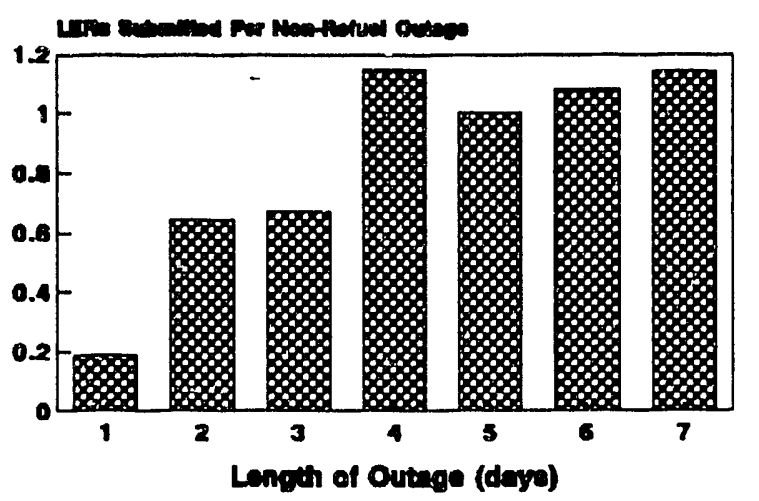

Figure 7. Illustration of the reporting frequency for outage duration.

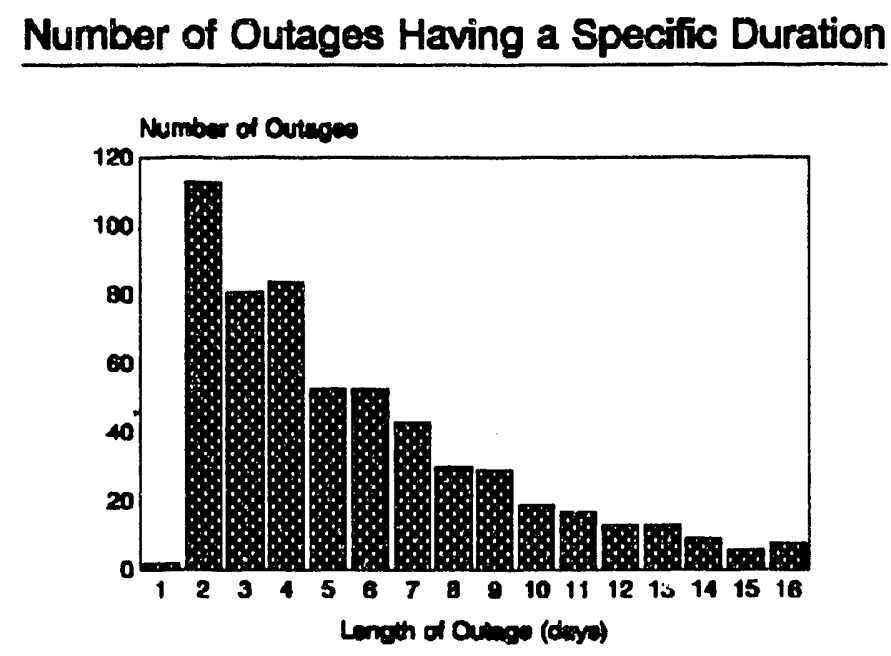

Figure 8. Illustration of the number of outages having a specific duration.

The minimum outage duration used in the nonrefueling outage phase definition was evaluated in detail. To identify the interval that should be used to differentiate the non-refueling outage phase from other phase periods, two criteria were selected: the number of LERs submitted and the number of outages having a specific duration. These criteria were selected because it was felt that they indicated that the operating status changed from an operating mode to a mode of performing activities different than those expected to expedite the return of the plant to the previous phase. Figure 7 and 8 provide examples of the information used to select the minimum duration of the non-refueling outage phase intervals.

It can be noted in Figure 7 that there is an inflection point in the LER reporting frequency at four days. It is felt that the number of LERs being submitted is a measure of the significance and number of activities being performed. This plot is 
based on 1988 and 1989 LER data, the most recent data show the same general inflection points. From Figure 8 , based on all outages from the third quarter 1985 through second quarter 1992, it can be noted that there is an inflection in the number of outages when the outages are greater than 4 days in duration. The inflection in the number of outages is considered to be indicative of when the plant operating philosophies change from power production to other activities. Based on these observations and conclusions, four days was selected for the duration of outages that would be included as non-refueling outages.

\subsection{Phase Type}

During the development of the peer groups and operational cycle methodology, it was concluded that the five operating cycle phases were valid; however, displaying trend and deviation information for this number of phases proved to produce complex data displays. To reduce the complexity, the phases were combined into two phase types: shutdown and operations. Using the phase type combinations, the phase dependent effects on the trend and deviation calculations could be captured and reduce data display complexity.

The Pl event frequency for each of the five phases was evaluated to determine if the phases could be combined and not lose the phase dependent effects. The individual phase event frequencies were found to be similar when the operations (power operations, startup, and pre-refueling phases) and shutdown (non-refueling and refueling outage phases) phases were compared with each other. There was one exception to this statement; the startup phase event frequency for some of the PI data was found to be different from any of the oiher phases. This will be discussed more in the next section. Based on the reporting frequency similarity, the phases were combined into two general phase types: operations and shutdown.

Using a hypothetical sequential plant operating history, the construction of the two subject phase types is illustrated in Figure 9.
Table 1 presents a listing of different reporting histories for each phase and phase type. This table was developed by counting the number of $\mathrm{PI}$ events and days in each phase from the start of the third quarter of 1989 through the second quarter 1992. A rate was calculated in PI events per day for each phase and multiplied by 30 . The numbers in the presentation are essentially a presentation of the average number of events in a thirty day period. From this table it can be noted that the reporting frequency for the phases in the operational and shutdown phase types are similar.

\subsubsection{Operations phase type - The operations phase type is defined as follows.}

The operations phase type is the period of the operational cycle that begins as the plant leaves cold shut down mode after a refueling outage. The phase type continues until the plant enters cold shutdown for the next refueling outage. Shutdown periods when the plant is shut down for four or more (per the non-refueling outage definition) are consecutive days not considered to be part of the operations phase type. The operations phase type is the aggregation of the operating intervals in the startup, power operations, and pre-refueling phases.

The startup phase is considered to be a subset of the operations phase type. As can be noted in Table 1, the event frequency for some of the indicators (scrams and maintenance cause code $\mathrm{PI}$ in particular) is different than the frequency for the other phases. However, even though the frequency for some indicators is different, the frequencies are similar enough that the events can be combined with the other indicators for the trends and deviations calculations. To address the difference in the reporting frequency, all events that occur during the startup phase are identified separately in the quarterly data presentations, discussed in Section 4. This step was taken so that the information is provided and consideration may be given to the fact that some events occurred during startup.

3.2.2 Shutdown phase type - The shutdown phase type is defined as follows. 


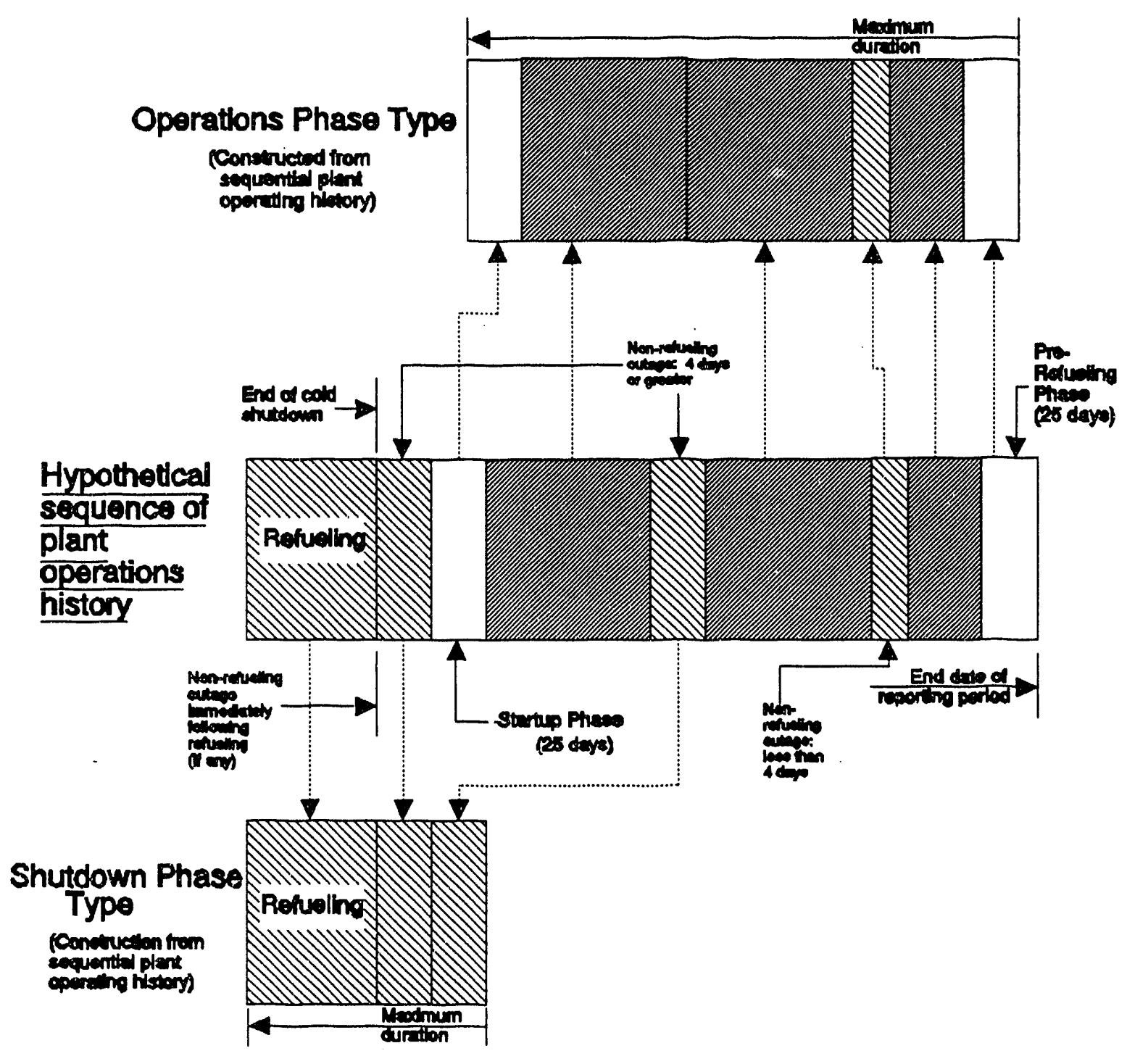

Figure 9. Illustration of phases and phase types. 


\begin{tabular}{||l|c|c|c|c|c||}
\hline \hline \multirow{2}{*}{$\begin{array}{l}\text { Table 1. Table of PI Event Phase Rates } \\
\text { Indicator }\end{array}$} & \multicolumn{3}{|c|}{ Operations Phase Type } & \multicolumn{2}{c|}{ Shutdown Phase Type } \\
\hline & \multicolumn{3}{|c|}{ Phases } & \multicolumn{2}{c||}{ Phases } \\
\cline { 2 - 7 } & Startup & Operations & Pre-Refueling & Non-Refueling & Refueling \\
\hline \hline Scram & 0.478 & 0.144 & 0.190 & NA & NA \\
\hline SSA & 0.067 & 0.060 & 0.074 & 0.105 & 0.168 \\
\hline SE & 0.012 & 0.023 & 0.037 & 0.020 & 0.047 \\
\hline SSF & 0.358 & 0.256 & 0.258 & 0.334 & 0.392 \\
\hline Admin. & 0.920 & 0.585 & 0.803 & 0.926 & 1.088 \\
\hline Lic. Op. & 0.269 & 0.086 & 0.245 & 0.187 & 0.184 \\
\hline Other Pers. & 0.490 & 0.318 & 0.392 & 0.420 & 0.608 \\
\hline Maint. & 1.535 & 0.964 & 1.245 & 1.305 & 1.638 \\
\hline Design & 0.352 & 0.330 & 0.454 & 0.525 & 0.575 \\
\hline Misc. & 0.125 & 0.067 & 0.098 & 0.034 & 0.038 \\
\hline
\end{tabular}

The shutdown phase type is the period of the operational cycle that begins when a plant shuts down and remains shutdown for four or more consecutive days and periods when the plant is in cold shut down for a refueling outage. The shutdown phase type is the aggregation of the refueling outage and non-refueling outage phase intervals during the plant's operating cycle. 


\section{CALCULATION AND DISPLAY METHODS}

To incorporate the nine peer groups and the two operating cycle phase types into the PI report, the NRC staff, in conjunction with the INEL, developed new calculational and display techniques. These techniques offer significant advantages over current PI methods, in addition to providing more information about plant performance. The new techniques are collectively termed the Operating Cycle Method (OCM). This section describes the OCM.

\subsection{Display Techniques}

The OCM includes new display techniques which provide additional information while maintaining the size of the PI report approximately the same. The additions are provided in the following sections.

4.1.1 Quarterly Data Display - The recommended quarterly, data presentations are illustrated in Figure 10 for a typical plant using the second quarter 1992 data. The significant changes from the current $\mathrm{PI}$ Program are summarized in Table 2 and are described in more detail below.

- The plant's peer group name is providied at the top of the display.

- The plant event count data are presented for the most recent 12 quarters.

- The operational plant status is illustrated at the top of the display. The operations phase type periods are displayed as the high parts on the line and the shutdown phase type periods are displayed as the low parts of the status line. To clarify the different shutdown phase type periods, the refueling outages are annotated with an ' $R$ '. Only the shutdown periods that meet the definition of a nonrefueling or refueling outage phases are indicated on the plot. This presentation is provided as a substitute for the critical hours. Load reductions or low power operations are not displayed.
- The PI event counts illustrated in the display are presented using a shaded vertical bar to indicate the plant status for the event date assigned. The shading illustrates the event counts occurring in the operations and shutdown phase types and the startup phase. It should be noted that the events are assigned to the phase type based on the event coding rules for the PI program. In a majority of the PIs, the events are reported on the day that the event occurred; however, some Pl events may be reported on the day that the event was discovered. This includes a large number of safety system failures and significant events. Reporting on the day that the event occurred identifies the day when the condition had the most effect on plant safety. Reporting the event on the day that condition was discovered may not identify the date that the plant safety was most affected. The NRC staff is evaluating this issue and considering alternate means for displaying the safety significance of such events.

- The forced outage rate (FOR), equipment forced outages per 1000 critical hours (EFO), and collective radiation exposure (CRE) are not presented in a phase or phase type presentation. These indicators are rates or averages for the quarter and as such, the data are not reported or maintained in a manner that enables a phase assignment or presentation. The vertical bar shading for the FOR, EFO, and CRE are different than the shades for the phase dependent PIs.

- The counts for each cause code category are presented. The count value bars are shaded to illustrate the number of events that occurred during the operations and shutdown phase types with the startup phase also displayed.

- Trend lines are calculated by using a linear regression model.

- The plant, peer, and industry trend lines are presented for the most recent 12 quarters. 


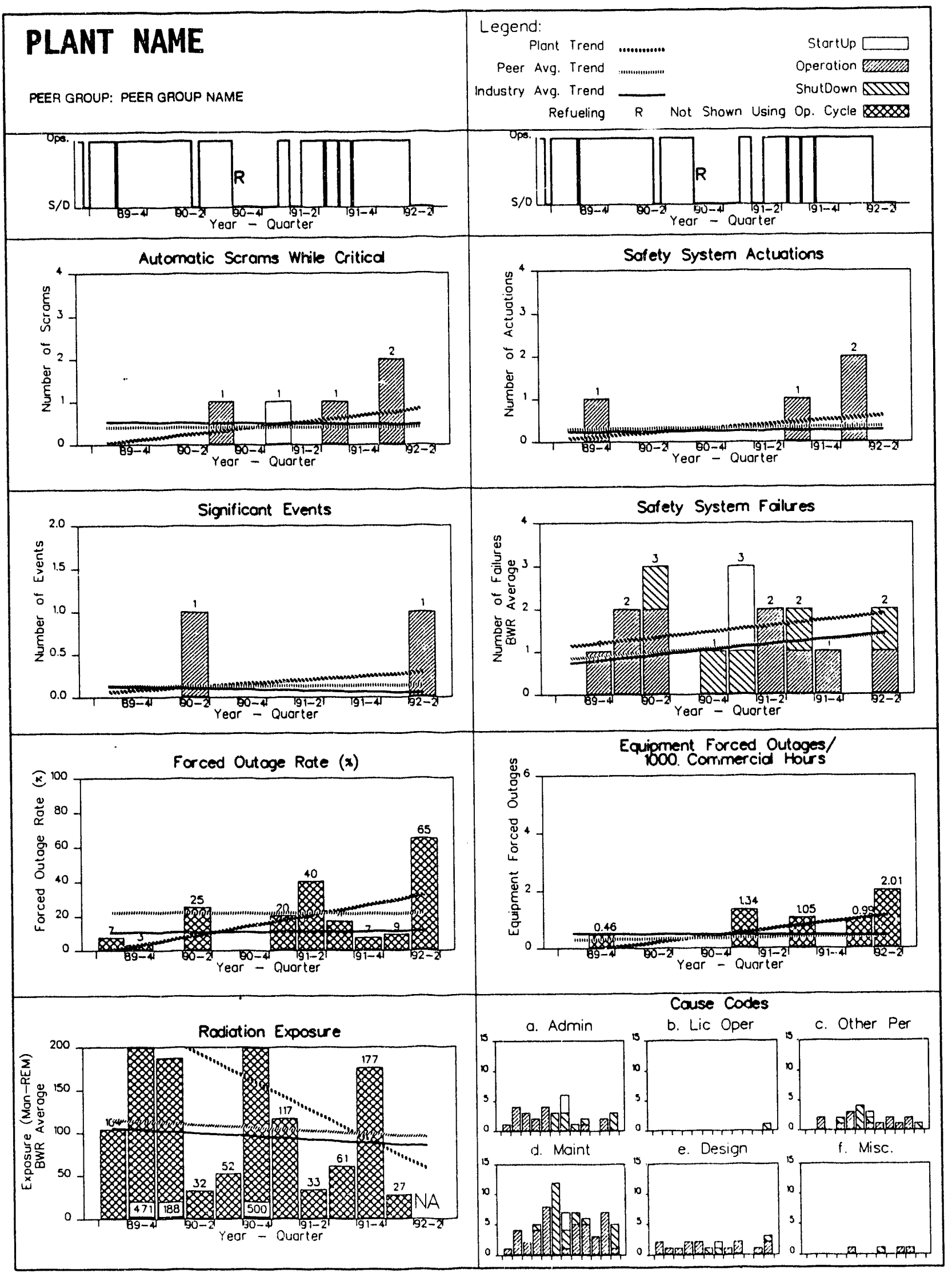

Figure 10. Illustration of OCM plant specific Pls. 


\begin{tabular}{|l|l||}
\hline \multicolumn{1}{|c||}{ OCM Program } & \multicolumn{1}{|c||}{ Summary of changes in OCM quarterly presentations of PI data. } \\
\hline \hline \multicolumn{1}{|c||}{ OCMrrent PI Program } \\
\hline $\begin{array}{l}\text { All data are presented for each of the } 12 \text { quarters } \\
\text { prior to the end date of the reporting period. }\end{array}$ & $\begin{array}{l}\text { All data are presented for each of the } 8 \\
\text { quarters prior to the end date of the reporting } \\
\text { period. }\end{array}$ \\
\hline $\begin{array}{l}\text { Plant trends are shown for all Pls except cause } \\
\text { codes. Trends are calculated as linear regression } \\
\text { fits to the counts or rates for each quarter. Trends } \\
\text { are calculated for each plant based on the quarterly } \\
\text { counts or rates, without regard to the operating } \\
\text { phase or phase type. }\end{array}$ & $\begin{array}{l}\text { Plant trends are calculated as } 6 \text { quarter } \\
\text { moving averages. }\end{array}$ \\
\hline $\begin{array}{l}\text { Industry trends are calculated as linear regression } \\
\text { fits to the industry average counts or rates for each } \\
\text { quarter. For SSF and CRE, trends are calculated } \\
\text { for BWR and PWR average counts. Peer trends are } \\
\text { calculated for each peer group based on the } \\
\text { average quarterly counts or rates, without regard to } \\
\text { the operating phase or phase type. }\end{array}$ & $\begin{array}{l}\text { Industry trends are calculated as six quarter } \\
\text { are calculated for BWR and PWR average } \\
\text { counts. Peer trends are new enhancements. }\end{array}$ \\
\hline $\begin{array}{l}\text { PIs reported as counts (Scrams, SSAs, SEs, SSFs } \\
\text { and cause codes) have the counts differentiated by } \\
\text { phase type or the startup phase. }\end{array}$ & New enhancement. \\
\hline $\begin{array}{l}\text { A timeline of each plant's operational history is } \\
\text { provided. }\end{array}$ & $\begin{array}{l}\text { The critical hours are plotted as an } \\
\text { operational history profile. }\end{array}$ \\
\hline
\end{tabular}

The trend lines are developed without consideration for the of plant operating status. That is, three years data for a specific PI are pooled regardless of the operational cycle phases. This approach was used because when the data for relatively long time intervals are combined, the phase dependent effects are smoothed out. The smoothing effects are caused by having a balance of events occurring between both operations and shutdown phase type periods.

- Industry trend lines are not provided for SSF and CRE. The SSF and CRE performance indicator trend lines are based on the data for all plants of a reactor type (i.e., PWR or $B W R$ ). The trend lines are different for these two indicators because in previous analyses it was noted that the number of SSF reportable events and CRE quarterly averages for the two reactor types are significantly different. To allow an accurate comparison of these two indicators, the trend lines are calculated by reactor type only.

- No trend lines are provided for the cause code PI because with the plots being small, a trend line in each box causes the display to be too complex and unreadable.

4.1.2 Trends and Deviations Display - The trend and deviation data presentations are illustrated in Figure 11 for a typical plant. The significant changes from the current PI Program are summarized in Table 3 and described in more detail below.

- The plant's peer group name is printed at the top of the display.

- The operations phase type self-trend presentation provides an indication of recent plant performance considering the plant's 


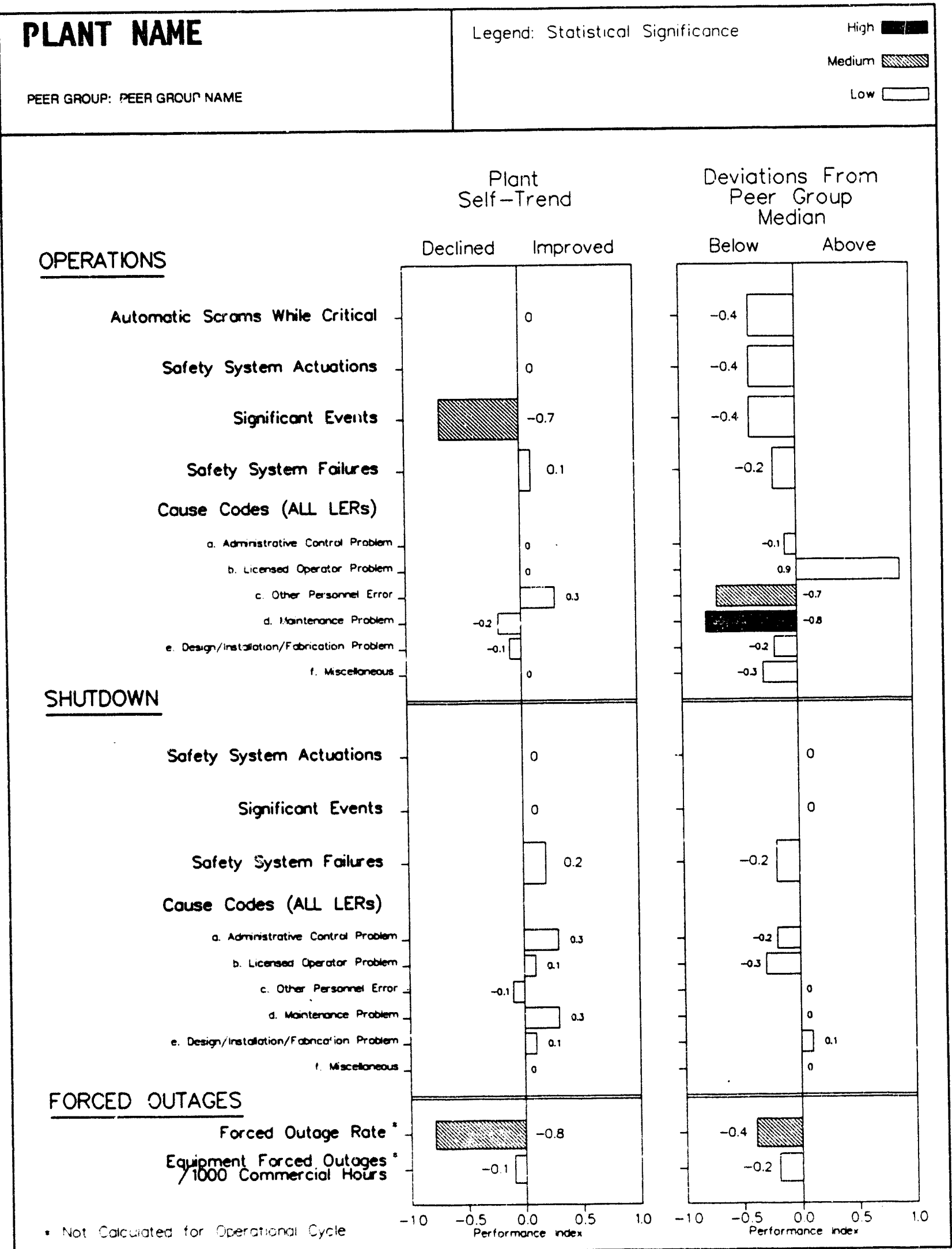

Figure 11. Tlustration of OCM plant specific self-trend and deviation data. 


\begin{tabular}{||l|l||}
\hline \multicolumn{1}{|c|}{$\begin{array}{c}\text { Table 3. } \\
\text { Summary of significant changes in OCM for reporting plant PI self-trends and } \\
\text { OCM Program }\end{array}$} & \multicolumn{1}{|c|}{ Current PI Program } \\
\hline \multicolumn{1}{|c|}{ OChe peer group. }
\end{tabular}

own data. The magnitude of the display presents a normalized slope of a linear regression line drawn between 30 day counts for the most recent 270 operating phase type days or the most recent 12 calendar months, whichever is shorter in duration.

- The shutdown self-trend illustrates the plant's short term shutdown phase type self-trend for each indicator. The presentation is a normalized slope of the linear regression line drawn between 10 day counts for the most recent 90 shutdown phase type days or 18 calendar months, whichever is shorter in duration. It should be noted that a shutdown phase type trend display is developed for all indicators except the EFO, FOR, and scram. The FFO and FOR indicators are discussed below. By definition, the scrams can not occur during shutdown and therefore a selftrend is not calculated.

- The operations phase type deviation presentation provides a long term comparison of the plant's performance indicator deviation from its peer group. The presentation is a normalized difference between the plant and peer group counts for the most recent 540 operating phase days or 36 calendar months, whichever is shorter in duration.

- The shutdown phase type deviation is an illustration of a plant's long term deviation from its peer group. The presentation is a normalized difference between the plant and peer group counts for the most recent 180 
shutdown phase type days or 36 calendar months, whichever is shorter in duration. It should be noted that a shutdown phase type deviation display is developed for all indicators except the EFO, FOR, and scram. The EFO and FOR indicators are discussed buiuw. The scram shutdown phase type deviation is not provided as stated in the shutdown phase type self-trend discussion above.

- The forced outage trend presentation at the bottom of the example page is an illustration of the short term self-trend for the plant's FOR and EFO performance indicators. The FOR performance indicator self-trend presentation is a normalized slope of a linear regression line drawn through 30 day rates for the most recent 270 generator on-line and forced outage days or the most recent 12 calendar months, whichever is shorter in duration. The EFO performance indicator presentation is the normalized slope of a linear regression line drawn between the 30 day equipment force outage counts for the most recent 270 operating phase type days or the most recent 12 calendar months, whichever is shorter in duration.

- The forced outage rate deviation illustration is a long term deviation of the plant's FOR and EFO performance indicators from its peer group. For the FOR performance indicator, the presentation is a normalized difference between the plant and peer group FOR rates for the most recent 540 generator on-line and forced outage days or 36 calendar months, whichever is shorter in duration. For the EFO performance indicator, the presentation is a normalized difference between the plant and peer group equipment forced outage counts for the most recent 540 operating phase days or 36 calendar months, whichever is shorter in duration.

- A statistical significance test is applied to each trend and deviation value illustrated in the display. The displays are shaded depending on the statistical significance of each trend and deviation value. The statistical significance rating is assigned based on the slope for the trends or difference for the deviation, the number of events, the time in the phase, the data distribution, and accepted statistical testing methods.

4.1.3 Supporting Data Displays - In addition to the presentations discussed above, a number of presentations provided in Volumes I and II of the PI report have been enhanced using the OCM system and calculation methods. The significant changes from the current $\mathrm{PI}$ Program are summarized in Table 4 and subsequently described in more detail below.

- The industry averacie display presented in the executive summary has been revised. The display has been expanded to include 12 quarters of data. This enhancement is consistent with the presentations in other portions of the report. In addition, a linear regression trend line has been placed on the display. The trend line is based on the 12 quarters of industry average number of event counts also presented in the display. For this presentation the effects of the phase impact has not been considered. The linear regression trend lines are not differentiated by operational phase or phase type. That is, the three years worth of data for a specific PI are pooled (regardless of operational phase). This approach was used because when the data for a large number of plants and relatively long time intervals are combined, the phase dependent effects are smoothed out. The smoothing effects are caused by having a balance of events occurring between both operations and shutdown phase type periods.

- Peer group trend displays, showing the peer group average numbers of events and linear regression trend lines for each PI during operations and shutdown phase types, have been added to the executive summary.

The peer group average is a normalized pooled average. The calculations are normalized to remove the effects of having fewer days in one phase type in one quarter versus having more in another. In addition, 
Table 4. Summary of significant changes in OCM for reporting plant supporting $\mathrm{PI}$ data.

\begin{tabular}{||l|l||}
\hline \multicolumn{1}{|c|}{ OCM Program } & \multicolumn{1}{|c|}{ Current PI Program } \\
\hline $\begin{array}{l}\text { The industry average display has been expanded } \\
\text { to present } 12 \text { quarters of data. A linear } \\
\text { regression line has been added to show industry } \\
\text { trends. }\end{array}$ & $\begin{array}{l}\text { Industry average display provided for } 8 \\
\text { quarters. A 6-quarter moving average trend } \\
\text { line provided. Also provided is a 6-quarter } \\
\text { moving average for the critical hours. }\end{array}$ \\
\hline $\begin{array}{l}\text { Peer group summary displays have been added } \\
\text { to the executive summary. The displays provide } \\
\text { peer group average number of events for each } \\
\text { quarter by phase type and for each indicator. }\end{array}$ & New enhancement. \\
\hline $\begin{array}{l}\text { The one line descriptions displays have been } \\
\text { compressed to make them more compact. }\end{array}$ & $\begin{array}{l}\text { The one line descriptions are provided in an } \\
\text { expanded display. }\end{array}$ \\
\hline $\begin{array}{l}\text { The plant data tables have been modiited to } \\
\text { include printouts of event counts by phase. The } \\
\text { data presentation has been expanded to provide } \\
\text { the data for the most recent } 12 \text { quarters. }\end{array}$ & $\begin{array}{l}\text { The plant data tables provide the data for the } \\
\text { most recent } 8 \text { quarters. }\end{array}$ \\
\hline $\begin{array}{l}\text { The dates for the calculations have been added } \\
\text { to the plant data tables. }\end{array}$ & $\begin{array}{l}\text { The time frame for the calculations are } \\
\text { provided in the introduction to the report. }\end{array}$ \\
\hline $\begin{array}{l}\text { A peer group summary table has been added to } \\
\text { show the median PI event values. }\end{array}$ & New enhancement. \\
\hline
\end{tabular}

linear regression trend lines are provided for the two reactor types and industry average. Operations and shutdown phase type displays are provided for all Pls except that a shutdown phase type display is not provided for the scram PI because scrams are not applicable during shutdowns and a phase type breakdown is not provided for the EFO and FOR performance indicators. The EFO and FOR indicators based on quarterly rates and therefore can not be separated by a phase type.

- The format for the one line event descriptions has been modified slightly to make the presentation more compact. The one line descriptions have been moved to Volume I.

- Plant data tables are provided in Volume II. These tables provide printouts of the counts for each performance indicator. The counts are provided by phase for the most recent 12 calendar quarters.

- Two date printouts are provided in the tables for each plant. The first is a printout of the boundary dates for each phase. This printout is provided so that the assignment of the phase counts can be reproduced. The second date printout provides a listing of the dates used in the Volume I trends and deviation calculations. Dates are provided for the operations and shutdown phase type trend and deviation calculations. These specific dates are used in all PI trend and deviation calculations except for the FOR PI. The boundary dates for the FOR calculations are listed separately because the boundary days are not based on a phase type evaluation.

- A peer group summary is provided in Volume II. This summary lists the median 
number of events for each PI for each of the phase types. The listing provides the median for all PIs except the FOR and EFO indicators.

\subsection{Calculational Techniques}

The OCM uses calculational techniques selected to indicate each plant's self-trends and deviations from its peer group median, and peer group and industry trends. The OCM also calculates the statistical significance of each self-trend and deviation in the Trends and Deviations display. Each trend and deviation bar is shaded to indicate the statistical significance.

\subsubsection{Plant, Peer Group, and Industry Trend} Presentations - In the executive summary and the quarterly data presentations section, a trend line is presented for the 12 quarters of data in the display. Selecting a trend presentation was based on the following criteria.

- The trend line needed to be based on accepted computational methods.

- The method for calculating trends needed to be applicable to incomplete data sets because the method will be used for other applications in developing the PI report.

- The method for calculating trends needed to be flexible enough that the calculation could be preformed for variable periods of time because the method will be used for other applications in developing the $\mathrm{PI}$ report.

A linear regression model was selected as the model to meet these criteria. The linear regression model selected to perform this calculation is implemented using a least squares approximation. The equation for the calculation is as follows.

$$
\text { Slope }=\frac{n\left(\sum x y\right)-\left(\sum x\right)\left(\sum y\right)}{n\left(\sum x^{2}\right)-\left(\sum x\right)^{2}}
$$

where:

$$
\begin{aligned}
& n=\quad \text { The number of data } \\
& (y)_{0}=\frac{\left(\Sigma x^{2}\right)(\Sigma y)-(\Sigma x y)(\Sigma x)}{n\left(\Sigma_{x^{2}}\right)-(\Sigma x)^{2}}
\end{aligned}
$$

where:

$$
\begin{array}{ll}
n= & \text { The number of data } \\
\text { points in the calculations } \\
\text { (12 for } 12 \text { quarters of } \\
\text { calculations). }
\end{array}
$$

When these two calculations are used, the equation being fit to the line is the following.

$$
Y=(\text { slope })(X)+(y)_{0}
$$

$$
x=
$$

The quarter for the point on the line being calculated (the quarter will be between 1 and 12 with 1 being the oldest quarter and 12 being the most recent quarter). 


$$
\begin{array}{ll}
Y= & \begin{array}{l}
\text { The value on the line for the } \\
\text { quarter being calculated }
\end{array} \\
(y)_{0}= & \begin{array}{l}
\text { The }(y) \text { calculated in the } \\
\text { equation above. }
\end{array} \\
\text { Slope }= & \begin{array}{l}
\text { The Slope calculated in the } \\
\text { equation above. }
\end{array}
\end{array}
$$

During the selection of the trending model, many models were considered. The linear regression model was selected because it is one of the most frequently used statistical methods for identifying trends in data. In addition, a linear regression model has attributes that can be readily used to determine the severity and direction of the trend (the slope of the trend line). The use of the slope becomes important in the discussion of the plant self-trend calculations in the next section.

4.2.2 Plant Self-Trend - For each PI, the plant self-trend information, shown on the left side of Figure 11, represents recent plant performance based on the plant's own data. As can be noted in the figure, there are three self-trend display areas separated by the operating cycle phase type; operations and shutdown, and an area for forced outages. Based on an evaluation of the operating cycle phase type data, it was concluded that the data are normally distributed. It should be noted that the forced outage data were also reviewed, and though not strictly normally distributed, the data are distributed such that the model is applicable. For the modeling technique to be valid, it is necessary for the model be valid for the given data distribution. With the PI data distribution and a desire to keep the calculation methods consistent with the other calculations performed for the PI report, a linear regression model was selected.

The slope of the linear regression model is the attribute that is indicative of the direction and magnitude of a trend. Since, it is desired that the self-trend presented in the display show the trend direction and magnitude, the plant self-trend is computed by calculating the slope of the linear regression line fit to the plant's PI counts.

To use the linear regression model, the time interval is assumed to be constant with the event count parameter being analyzed. Since the selftrend computations are based on calculation by phase type, the phase type time is separated into equal time intervals. Figure 12 provides an example of the phase type time separation for the plant self-trend calculations.

With the selection of the computational method, the time intervals for the calculation were considered. There were two time intervals that had to be identified: the total length of time over which the calculation was to be performed and the time segment lengths for the calculations. The number of days that each plant spent in shutdown and in operations was reviewed using operational data through the end of 1991. Table 5 summarizes the results.

The compliment to the contents of Table 5 is the operational time. If the operational time is considered, the median operational time in 12 months is approximately 300 days. To ensure that the majority of the plants would have complete data sets the interval was decreased 30 days to 270 operational days in the most recent 12 months. The specific reasons that 270 days was selected is as follows:

- The majority of the plants would have complete data sets.

- The data can be divided evenly for trend calculations.

- The 270 days approximates 3 quarters for a plant that has continuous operation. Three quarters of operation was considered to be indicative of most recent plant operations and indicative of current performance trends.

- Generally, plants appear to be operational approximately two thirds of the time. This equates to about 270 days in one year.

Also based on Table 5, the time interval selected for the shutdown phase type trend calculations was 90 shutdown phase type days in the most recent 18 months. This interval was selected for the following reasons: 


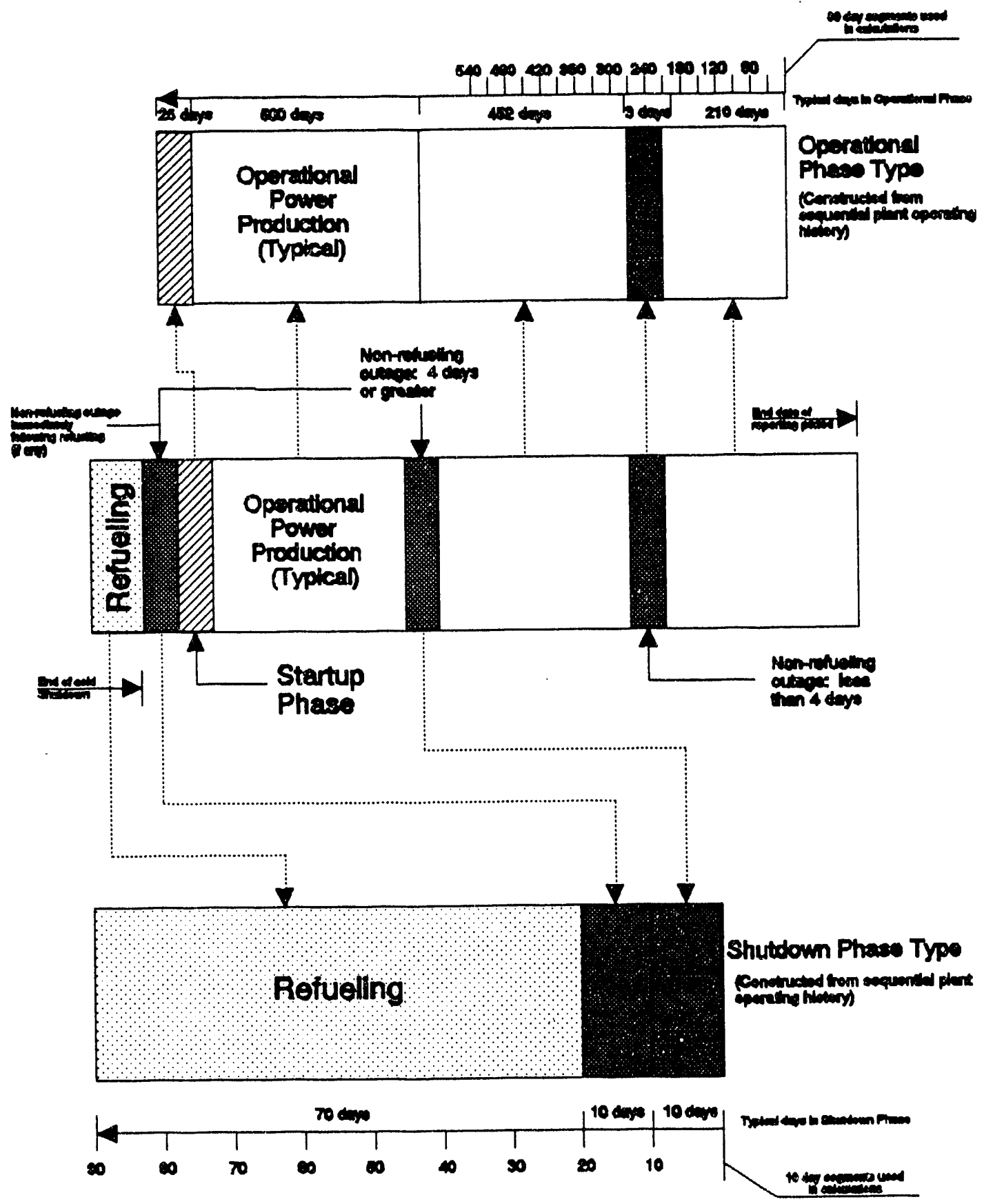

Figure 12. Illustration of phase type time partitioning 


\begin{tabular}{||l|c|c|c|c||}
\hline \hline \multicolumn{3}{||l||}{ Table 5. Number of days in shutdown for the most recent 3 year period. } \\
\hline \hline $\begin{array}{l}\text { Number of Days } \\
\text { in Shutdown }\end{array}$ & $\begin{array}{l}\text { Over Most Recent } \\
12 \text { Months }\end{array}$ & $\begin{array}{l}\text { Over Most Recent } \\
18 \text { Months }\end{array}$ & $\begin{array}{l}\text { Over Most Recent } \\
24 \text { Months }\end{array}$ & $\begin{array}{l}\text { Over Most } \\
\text { Recent 36 } \\
\text { Months }\end{array}$ \\
\hline Maximum & 180 & 353 & $>360$ & $>360$ \\
\hline Minimum & 0 & 12 & 12 & 12 \\
\hline Median & 62 & 91 & 139 & 207 \\
\hline
\end{tabular}

- The data can be divided evenly for trend calculations.

- A large number of plants have at least 90 shutdown days in an 18 month period.

- The 90 days approximates one quarter of shutdown condition. One quarter of shutdown was considered to be indicative of most recent plant shutdown operations and indicative of plant performance.

- The 90 days within 18 months approximate the number of shutdown days that are expected in one complete fuel cycle.

The intervals for the EFO and FOR calculations were selected to be the same intervals as used for the operations phase type trend calculations for the following reasons.

- Selecting the same time intervals maintains the indicator calculations consistent from one indicator to the next.

- The EFO and FOR trend calculations are similar to the operations phase type calculations. The EFO PI calculation is similar to the operations phase type calculations because it is normalized using operational hours. The FOR PI calculation is similar because the majority of the time used in the FOR calculations is operations phase type time.

Once the intervals for the calculations had been identified, the next step was to identify the interval for each segment. After evaluating the time segment lengths in detail, it was found that if few segments were used, i.e. the number of days in each segment is large, the trend could change erratically from one data analysis to the next. That is, the trend could change from an improving to declining trend from one analysis to the next with as few as one or two events. This was considered to be too sensitive. Therefore, the number of segments had to be large enough in duration to preclude this phenomena. On the other end of the spectrum, if the intervals were too small, nearly all of the segments would have zero or one event count and therefore have small trend changes even if the total number of events were high. This was considered to be too insensitive. A compromise time segment length was selected: 30 days per time segment for the operations phase type and 10 days per time segment for the shutdown phase type. Using the intervals for the calculations, these time frames resulted in nine segments for both the operations and shutdown plant self-trend calculations.

Establishing the intervals for the calculations provided the majority of the boundaries for the calculations, however it was noted that two additional restrictions were necessary so that the calculations could be adequately controlled. The first was that it was necessary to specify actions to be taken should a plant not have 270 days of operational phase type time or 90 days of shutdown phase type time within the report evaluation period. Based on an evaluation of the data, it was found that even if the desired number of days is not available, a trend calculation can be performed. The trend calculation, even though based on an incomplete data set, still provides important information. However, if the number of phase type days is too small, the trend could be misleading. For example if a plant had only a 
small number of shutdown days, a few or no events would be considered to be representative of the plant's entire trend if not accounted for in the calculation technique. To prevent misleading trends values from being shown, a minimum time required in the phase type was implemented: 90 operations days for the operations phase type and 30 shutdown days for the shutdown phase type. These minimum number of days were selected because they ensure that at least one third of the maximum time is available; which was considered to be sufficient time to ensure that the trend value would be realistic.

The final restriction placed on the calculations was a calendar time restriction, i.e. the maximum time back that would be used to look for the desired number of operational or shutdown days. During some of the earlier development, there were few restrictions placed on the data used; the only restriction was the maximum number of days for the calculations. Because of this practice, often the trend and deviation calculations were performed using $\mathrm{PI}$ data that was greater than seven years old. Using data as old as seven years was not considered to be appropriate because the plant operations and management had changed enough over that period of time that the data may no longer represent current plant performance. To ensure that the data are representative of current plant performance, calendar time restrictions were placed on the data: 12 calendar months for the operations phase type and 18 calendar months for the shutdown phase type. The calendar restrictions were selected based on a majority of the plants having the maximum time available for the calculations. The specific decisions on the calendar times was made based on the data presented in Table 5.

Since some $\mathrm{Pl}$ events occur more frequently than others, the slopes for all indicators can not be displayed in one presentation without being normalized because they will be significantly different. T display the slopes for all indicators can in one presentation, methods for normalizing and scaling were considered.

The factors used for normalizing and scaling the slope calculations were analyzed with the following criteria in mind:
- Identify factors that provide a valid representation of the trend.

- Permit the trends for all indicators to be presented on a single plot.

- The scaling factors are to be based on the data being presented.

- The factors are not to affect the ordering of plant performance from one indicator to the next.

- The factors affect neither the sign nor the among-plant ordering of these trend values.

Two pieces of information are needed to scale the trend performance measures. The first is the range of such measures for each performance indicator. The second is the desired range for the performance indicator report plotting scale. The range of measures for each performance indicator is observed from the data across plant units. The desired range for the plotting scale has been arbitrarily selected to be from minus one to plus one.

The potential scaling factors were reviewed with the goal of ranging the slope values between minus one to plus one. Based on the review, it was determined that one of the most defensible scaling factors was to normalize using the maximum value of the values being normalized. That is, each positive value may $t$. divided by the maximum of the values across the industry. Similarly, negative values would be scaled by dividing by the minimum value across the industry. This procedure scales all the performance measures to lie strictly within the desired range.

However, this causes an undesired influence by the outliers. If outliers exist among the numerator values, the scaling factors that bring such values in line with the desired plotting positions may be so large that the resulting scaled performance measures for the other plants are quite small. Because of this potential effect of outliers, modifications of the above procedure are used for the performance indicator data. To minimize the impact of the outliers, the scaling factors were selected to be the 2nd and 98th percentile of the 
values instead of the minimum and maximum. To further minimize the impact, instead of scaling the maximum and minimum to lie between minus one and plus one, each set of values are scaled to lie between -0.9 and 0.9 . This choice ensures that most of the trend performance measures will lie in the desired interval without a few outliers compressing the plotted values.

The specific details of the trend scaling factor calculations are as follows. For each performance indicator and phase type, the trend data for all plants form a population with a range of numerator measures of plant performance. The denominators are computed as follows:

Denominator $=98$ th percentile for numerator

or

Denominator $=\underline{2 n d}$ percentile for numerator

$$
(-0.9)
$$

Equation (a) is used for positive numerators and Equation (b) is used for negative numerators.

The percentiles are computed as follows. Define $n$ as the number of performance indicator numerators in a population, with $d_{(1)}, d_{(2)}, \ldots, d_{(1)}$, $\ldots, d_{(n)}$ as the ordered values of the numerator slope or rate differences (from minimum to maximum). . Corresponding to these values, consider the sequence $\{1 / n, 2 / n, \ldots, i / n, \ldots, n / n\}$. Define $p$ as the fraction corresponding to the percentile being sought $(2 / 100$ for the second percentile and $98 / 100$ for the 98th). If $p$ (e.g., 0.02 ) is less than $1 / n$, the minimum sample value is used as the second percentile and all negative rate differences are scaled in the interval from -0.9 to 0 . If one of the values in the $\{i / n\}$ sequence equals $p$, and $p$ is less than one, the corresponding $d_{(i)}$ and the next value $\left(d_{(1+1)}\right)$ are averaged to obtain the desired percentile. Otherwise, the greater of the two $d$ values whose sequence values most closely bracket $p$ is the desired percentile.

Once the slope ranges have been identified, it is necessary to scale the majority of the slope values to lie within the display. If the slopes are scaled to lie within the plus one to minus one scale, a large number would be pegged off or to the plot boundary. To scale the values to within the boundaries of the display, the normalized slopes are multiplied by .9 .

The final equation for the plant self-trend calculation is as follows.

$$
\text { PI Data Display }=\frac{(-b)}{|\eta|}
$$

where:

$$
b=\text { Slope, }
$$

A plant's performance may be improving $(b<0)$, unchanged $(b=$ $0)$ or degrading $(b>0)$. In addition, the minus sign is applied to the displayed $b$ so that positive values of the data display will indicate improving plant performance.

$\eta=$ Scaling factor to normalize plant variations.

For a hypothetical PI case, the plant self-trend PI data displays would be normalized as:

$$
\begin{aligned}
& \text { if } b>0 \\
& \text { Display }=-b_{A} * \eta_{28} ; \eta_{28}=\frac{0.9}{(b)_{28}}
\end{aligned}
$$

Where $\eta_{2 \%}=$ the 2 percentile value of all calculated plant trend slopes for a given PI.

\subsubsection{Plant Deviations from Peer Group} Median - The display on the right side of Figure 11 , represents the long term plant performance when the plant data is compared to the peer group data. As in the plant self-trend display, the deviation display is separated into three areas with the display separated by the two phase types and forced outage section. Based on an evaluation of the operating cycle phase data, it appears that when the data is considered over a long period of time, the data are binomially 
distributed within a phase type. Also, as in the self-trend development, the forced outage data does not necessarily meet this distribution, but the distribution is similar enough that the computational methods are still applicable. The modeling techniques selected for performing the comparison of the plant to the peer group is to calculate the difference between the plant and the peer group rate from the plant rate and normalizing the difference. This method was selected based on the data distribution.

The rate calculations are performed by counting the number of phase type PI events for each indicator and calculation time frame. Then the number of phase type days for the same time frame are counted. The number of phase type PI events is divided by the number of phase type days. The results of this division become the plant rate for the particular indicator. This process is repeated for each phase type.

Using the phase type rates for each plant and all plants in a peer group, the median for the peer group is calculated. The median is used for comparison to the plant rate.

Three types of peer group comparison values were considered: mean, average, and median. During the considerations, the goal was to identify a comparison value that is stable and not highly influenced by outliers. The median was selected as the most defensible for the following reasons.

- Average values are less influenced by outliers as the sample size increases; however, no peer group has more than 25 plants and some have as few as eight. This sample size does not provide enough stability in the data if average values are used.

- Mean values can be significantly influenced by one data point. Therefore, a change in one outlier can have an impact on the mean value. To use a mean value for comparison would require that the outliers be removed from the mean calculations. Since the sample size is small for some performance indicators, identifying and removing outliers is not simple or accurate. If an outlier system is used, it is possible that plants that are not outliers would be removed because of the small sample sizes. This practice would not provide enough stability in the calculations or reduce the influence of outliers.

After the calculation methods were established, the time interval to be used in the deviation calculations was considered. The goal of the deviation calculation is to provide an indication of performance over a longer time period than the plant self-trend calculation. The operations phase type self-trend calculation time frame was selected to be 270 days; to be consistent with the trend calculation, the operations phase type deviation calculation time frame was selected to be twice the trend time frame or 540 days. As can be seen in Table 5 (if the compliment of shutdown days are used as operational phase type time), selecting this interval provides a data set with the majority of the plants to having the necessary interval of operational phase type time available. The time interval selected for the shutdown phase type deviation calculation was 180 shutdown days, twice the self-trend interval.

Once the length of time intervais were selected, it was necessary to specify actions to be taken should a plant not have $\mathbf{5 4 0}$ days of operational phase type time or 180 days of shutdown phase type time. As in the trend calculation evaluation, it was found that even if the desired number of days could not be attained, a deviation calculation can be performed to provide performance information. As in the self-trend calculation, a minimum time in phase was implemented to prevent misleading deviation values: 90 operations days for the operations phase type and 30 shutdown days for the shutdown. These minimum number of days were selected to be consistent with the self-trend calculation time limits.

As in the trend calculations, a calendar time restriction was imposed on the deviation data calculations. The restrictions prevent using data that are too old to be representative of current plant performance. The calendar restrictions placed on the deviation data calculations are: 36 calendar months for the operations phase and shutdown phase type. The calendar restrictions were selected based on a majority of the plants 
having the maximum time available for the calculations. The specific decisions on the calendar times were based on the data presented in Table 5.

The deviation calculation scaling factors are identified as described for the trend calculations in Section 4.2.3 except that the scaling factors are calculated based on the slopes across the industry, the scaling factors are calculated based on the difference between the peer group and the plant rates. Just as in the trend calculations, the rate differences are used across the industry to identify the scaling factors. Using this method, the resulting scaling factors do not disturb the ordering of plant performance, the basic plant performance assessments, or the sign nor the among-plant ordering of these values.

The equations for calculating the plant deviation from peer group medians are as follows.

$$
\begin{gathered}
\text { PI Data Display }=\left(\frac{\Delta_{e}}{|\boldsymbol{k}|}\right) \\
\Delta_{e}=\varepsilon-\omega
\end{gathered}
$$

where:

$\epsilon=$ Average number of events over the duration of the phase type, for example: total counts during a phase/number of phase days.

$\omega=$ Peer group median of $\epsilon$.

$\kappa=$ Scaling factor to normalize plant variations.

$\omega$ is necessary so that the displayed PI data reflects a deviation from the plant's peer group "average" performance. $\omega$ is the median of $\epsilon_{\mathrm{s}}$ for the peer group and is equal to: a) the middle ranked $\epsilon$ in peer groups having an odd number of plants, b) the average of the middle ranked $\epsilon_{\mathrm{s}}$ peer groups having an even number of plants. For example in a peer group consisting of 9 plants ( 1 through 9 ) ordered for increasing $\epsilon$, then $\omega=\epsilon_{5}$ or the 5 th ordered $\epsilon$. If there were 10 plants in the peer group, then $\omega=\left(\epsilon_{5}+\epsilon_{6}\right) / 2$.

The need for $\kappa$ arises from the desire to have the peer group related $\mathrm{PI}$ data for each plant scaled to the same basis. In selecting this scaling factor to attain a common (normalized) basis, it was concluded that the best basis was that of the total plant 2nd and 98th percentiles of $\Delta_{\epsilon}$ similar to the scheme used to scale the plant self-trend slope. The 2nd percentile is used for the $\Delta_{\epsilon}$ values below the peer group median and the 98th percentile $\Delta_{\epsilon}$ is used for values above the peer group median.

For hypothetical PI cases, it may be considered that the deviation of a plant's performance from its peer group would be normalized as:

If $\Delta_{\epsilon}$ is below the peer group median,

$$
\text { Display }=\left(\Delta_{A} * k\right) ; \quad k=\frac{0.9}{\Delta_{28}}
$$

If $\Delta_{\boldsymbol{\epsilon}}$ is above the peer group median,

$$
\text { Display }=\left(\Delta_{B} * k\right) ; \quad \boldsymbol{K}=\frac{0.9}{\Delta_{988}}
$$

4.2.4 Statistical Significance - For the OCM $\mathrm{PI}$ report, there are 42 trend and deviation calculations performed for each plant. In the past, there has not been a method for identifying which of these trend or deviation measures are statistically significant. The OCM methodology includes provisions for evaluating the trend and deviation data to determine the statistical significance of each value.

To determine the statistical significance of the trend and deviation data the significance is established considering the following criteria: 
- The trend and deviation calculation algorithms,

- The distribution of events across time and plants,

- The number of events that occurred,

- The length of time over which the events were experienced, and

- A statistical significance test based on accepted statistical method.s.

The basis for the plant self-trend significance tests is the idea that "normal" plants have events occurring randomly. So for the plant self-trend significance assessments, events were simulated to occur randomly across a time interval. For a given number of events occurring and a given time interval, ten thousand simulations of randomly distributing the events were done. Using the random data distributions, the trend (slope) for each simulation was calculated. The ten thousand trends yielded a distribution characteristic of "normal" conditions. When determining a significance of a plant's specific trend value, the trend value is compared to the distribution considering the slope value, number of events, and time interval. When the plant's slope is compared to the simulated distribution, its value determines the significance of the trend by considering the frequency with which the randomly simulated slopes occurred. Slope values on the extremes of the distribution are considered significant and unusual.

For the deviation from the peer group median evaluation, a plant's particular count is compared with a reference distribution to determine its significance. For the deviation analysis, the number of event counts for each plant are expected to follow a binomial distribution. Since a binomial distribution is a well known standard distribution, the significance of a plant's value is directly accessed. The count value is compared to the distribution and assigned significance based on the frequency of occurrence.

Once the significance comparison tables for the trend and deviation calculations were completed, the significance values were bound using threshold values to give ranges of values for which the trend and deviation values would be considered to be of high, medlum, or low significance. The high, medium, and low significance ratings were used to assign the shading used in the trend and deviation displays. The use of the shading can be seen in Figure 11. Table 6 presents the threshold values, banded significance levels, and shading assignments.

The significance level of a PI value indicates how unusual the value is compared to an expected value. Small significance levels indicate that the observed value is unusual. The larger the significance level, the less unusual the observed value. Since the significance comparison tables become the standard for bar shading, only a fixed set of significance levels were used in the PI program. The significance levels used were chosen to cover a wide range to allow an evaluation and comparison of $\mathrm{PI}$ values at a broad resolution. The values chosen also correspond to those more commonly used in statistical evaluations. 


\begin{tabular}{||l|l|l||}
\hline \multicolumn{2}{|c|}{ Table 6. Summary of threshold values used for assigning statistical significance. } \\
\hline \multicolumn{1}{|c|}{ Threshold Value } & \multicolumn{1}{|c|}{ Significance } & Shading \\
\hline$<=0.025$ & High & Black \\
\hline$<=0.200$ & Medium & Gray \\
\hline$>0.200$ & Low & White \\
\hline $\begin{array}{l}\text { When the probability of a trend or deviation is small, the trend or } \\
\text { deviation value is rare under random conditions and therefore more } \\
\text { significant. }\end{array}$
\end{tabular}




\section{PEER GROUP AND OCM ASSESSMENT}

The peer group and OCM methods for presenting the performance indicators have berin developed and the methods assessed. Tho assessment of these systems is discusse; in the following sections.

\subsection{Peer Group Assessment}

it has been noted that plants with certain Nuclear Steam Supply System (NSSS) vendors have different numbers of reportable events than others. It has also been noted that some plants within a single NSSS vendor group may have a higher number of reportable events than the other plants designed by the same vendor. Because of the disparity in the number of reportable events between plants, different combinations of plant groupings were evaluated to determine the commonality between plants that could result in similar numbers and types of reportable events. The results of the evaluation were docuriented in an ORNL report. ${ }^{3}$

As discussed in Section 2, nine peer groups were developed. The nine peer groups are identified in Table 7. Also included in the table is a listing of the number of plants in each peer group.

5.1.1 Similarities in the Reporting Patterns of Peer Groups - The peer groups were formed based on design-related information, and statistical requirements for minimum peer group size. The similarity of the event reporting patterns of the plants, which comprise the groups, was not considered, as this is the data the peer groups were intended to help evaluate. However, an analysis was conducted to see if similarities exist in the reporting patterns of the plamts within each peer group.

The analysis was conducted by comparing the reporting patterns from the nine peer groups with data from ten randomly generated peer groups. The data for each of the proposed peer groups were compared to data for each of the other proposed peer groups, and the data for each of the randomly generated groups were compared to the data for each of the other randomly generated peer groups. This resulted in 81 comparisons between the various groups. In addition, the individual plant data within each group was compared to determine the similarities between the reporting patterns of plants within each peer group.

The results of the analysis showed that the reporting patterns for the randomly generated groups were not significantly different from each other. The analysis also indicated that strong similarities in the reporting patterns of the plants within each group do not exist. The analysis of the data for the proposed peer groups showed higher significance levels between the groups, indicating greater differences between the reporting patterns for the groups. In addition, the data indicated strnnger similarities in the reporting patterns for the plants within each of the proposed peer groups than between plants in the random groups.

These results are co.sistent with engineering judgement; that plants of simiiar sesign will have more similart. as in their resporting patterns than andomly selected groupings of plants. However, the groups were not formed on the basis of the similarities or differences in their reporting patterns; therifore, the valtdity of the groups is not dependent uscon differences observed in PI data.

5.1.2 Añaiysis Methodology for Evaluation of Peer Group Reporting Patterns - Two concerns regarding the composition of the peer groups were voiced i'uring early reviews. The first concern was that some peer groups could have a relatively small $r$ umber of plants. The issue was that with a small number of plants in a peer group, it may not be possible to get the desired confidence levels for statistical analyses.

The second concern was that the performance of a peer group might be dominated by units operated by the same utility, whether at single or multiple sites. For example a peer group of the B\&W plants could be dominated by the three Oconee units. The CESSAR CE peer group could be dominated by the three Palo Verde units. The older peer group of older Westinghouse three 


\begin{tabular}{||l|c||c|c||}
\hline \hline \multicolumn{1}{||c|}{ Table 7. Peer groups used for the OCM deviation analysis. } & $\begin{array}{c}\text { No. of } \\
\text { Plants }\end{array}$ \\
\hline Small Westinghouse & $\begin{array}{c}\text { No. of } \\
\text { Plants }\end{array}$ & Peer Group Designator & 23 \\
\hline 3-loop Westinghouse & 9 & GE - Pre-TMI 2, 3 \& 4 & 14 \\
\hline 4-loop Westinghouse & 10 & GE - Post-TMI 5 \& 6 & 8 \\
\hline New 3- and 4-loop Westinghouse & 24 & CE - With CPC* & 7 \\
\hline B\&W & 9 & & \\
\hline$*$ CPC $=$ Core Protection Calculator; & Total number of plants = 111 & \\
\hline
\end{tabular}

toop plants could be dominated by the Surry and North Ânna units.

The two concerns were addressed by examining PI data compiled during 1988 and 1989. Two years of data were chosen to help ensure sufficie: : cuata for the study and to attempt to minimize effects associated with the cyclic nature of PI data, which typically oscillates with a one to two yzar period based upon plants' fuel cycles. The seven? I's used in this evaluation are shown in Table 8. The cause code PI was broken down inco six. individual cause codes that are also shown in the taible.

An analysis of variance (A,VOVA) of the PI data by peer group was performed. The results of the analysis were that relationships could be established between the peer groups and the indicators that typically had the highest frequencies (e.g., cause codes for administrative control problems, maintenance errors, other personnel errors, and the safety system failure indicator; although the relationships were not highly correlated.

Relationships could not be established between the peer groups and the indicators that typically had sparse data (e.g., safety system actuations, significant events, forced outage rate, equipment forced outages per 1000 commercial critical hours, and the design error cause code).
The results of the ANOVA evaluations are presented below.

Westinghouse

plants

Differences between PI frequencies for the old twoloop peer group and the new three and four-loop peer group were apparent for several of the indicators. These groups generally appeared distinct from each another. The event frequencies for the peer groups of the older three-loop plants and the older four-loop plants were typically between the old two-loop peer group and the new three and fourloop peer group. The peer groups for the older threeloop plants and the older four-loop plants could not be statistically distinguished either from the peer group of older two-loop plants or from the peer group of newer three-loop and four-loop plants.

CE plants The event frequencies for the pre-CESSAR CE plant peer group were always less than those for the CESSAR CE plant peer group; however, 


\begin{tabular}{|c|c|c|}
\hline 1. & & Automatic scram while critical \\
\hline 2 & & Safety system actuation \\
\hline 3. & & Safety system failure \\
\hline 4 & & Sionificant event \\
\hline 5. & & Equipment forced outages per 1000 critical hours \\
\hline 6. & & Forced outage rate \\
\hline 7 & & Cause codes \\
\hline & ســ ( & Administrative control problem \\
\hline & . & Desian fabrication installation or construction error \\
\hline & ســــ (a & Miscellaneous \\
\hline & $d$ & Licensed operator error \\
\hline & ــ & Other personnel error \\
\hline & $f$ & Maintenance problem \\
\hline
\end{tabular}

not at statistically significant confidence levels. The preCESSAR CE plant group did appear quite similar to the Westinghouse two-loop plant peer group.

B\&W plants The event frequencies for the B\&W plant peer group were relatively low compared to certain peer groups for several Pls (e.g., other personnel errors, maintenance errors, random equipment failures, and safety system actuations) and were among the highest for several other indicators (design errors, administrative control problems, safety system fallues, and significant events), aithough not at statistically significant confidence levels. For some PIs, the B\&W group appeared similar to some groups. For other PIs, they appeared similar to others. No generalities could be drawn.

GE plants The event frequencies for the two GE plant peer groups were relatively similar to each other.
5.1.3 Summary of ANOVA Evaluations - In summary, the results of the ANOVA evaluations generally agreed with intuition. The plant peer groups consisting of older plants typically had lower data frequencies than the peer groups for newer plants. The Westinghouse two-loop plant peer group and the new Westinghouse three-loop and four-toop plant peer groups were statistically different from each other. The two CE plant peer groups were also different from each other, although not at statistically significant levels.

The PI data, as expected, do not reflect the design differences among the plants; this may be due to regulatory, utility management, and fuel cycle effects not quantified in this evaluation factors that the peer groups were intended to help evaluate.

Although not recommended, combinations of the groups may be considered. These combinations, however, are not without potential problems. These problems may hinder acceptance of the peer groups for other reasons.

\subsubsection{Potential Problems with Combining} Peer Groups - Problems associated with sparse data (common for many of the PIs) are frequently dealt with by combining data where possible. This is a valid technique when the individual 
elements are similar. The technique is not valid if the individual elements are not similar. Biased groups can result from combinations based upon dissimilar elements even if the frequencies and rates for the groups are similar.

It may be difficult to address concerns that could occur if the peer groups and associated reporting data are perceived to be biased. Biased peer group reporting rates and frequencies could result if individual groups are combined. A number of industry problems have been specific to certain plant design types. Post-accident water level measurement, bleed and feed, owners' groups initiated inspections or reviews, and containment integrity issues are examples of problems specific to certain plant design types. All of these issues can significantly affect the reporting patterns, and hence, the Pls for a peer group. Caveats or cautions about comparing the performance of an individual plant with peer group PI data perceived as biased may preclude meaningful observations or conclusions.

5.1.5 Peer Group Size - The peer group population size was studied to determine the minimum size acceptable for providing statistically valid data for performing PI peer group calculations. As presented in Appendix $B$, the confidence interval was evaluated for the PI data and when the number of plants in a peer group was fewer than six, the confidence interval was wide and divergent. Peer groups with six or more plants tended to have relatively equal confidence intervals. Figure 13 provides an example of how the confidence interval changed with the number of plants. The top plot shows the log of the factor and emphasizes the differences in the multiplication factor as the number of plants in the peer group changes. The bottom plot shows the linear plot of the factor and emphasizes how the factor converges across the confidence intervals as the number of plants increase. Figure 13 illustrates how each peer group should have $\epsilon$, or more plants.

\subsubsection{Conclusions of Peer Group} Assessment - The evaluation of different peer groups considered numerous aspects of each plant. Examples of general criteria considered are: plant age, vintage, and reporting practices. In addition to the general criteria, specific technical differences were considered: NSSS vendors, thermal output, number of coolant loops, containment design, emergency core cooling systems, and control and protection system technology. A number of specific items involving the age of the plant were also considered. Examples of specific age factors are: number of years of commercial operation, year ordered, date of construction permit, date of operating license, year of intended operation, and date of initial criticality. Besides the general and technical criteria, one statistical requirement was evaluated: the optimum size for a peer group. During the evaluation, it was noted that each peer group had to be large enough to insure statistically adequate comparisons but sized to contain only plants with similar design and operational features.

To demonstrate that the peer group structure provides adequate breakdown of the plants, Figure 14 is provided. As can be noted in this figure, based on events from the third quarter 1989 through the second quarter 1992, the reporting frequency for the different peer groups are notably different.

Based on technical justifications considering the factors identified above, the 111 commercial nuclear power plants were grouped into nine peer groups. A listing of the plants within each peer group is provide in Appendix D.

\subsection{Assessment of the Effects of Operating Cycles}

The goals of the assessment of the operating cycle methods was directed towards demonstrating that the methods are necessary and the presentations provide valid information. These two goals are addressed more in the following sections.

5.2.1 Observation of Cyclic Behavior of Cause Code Data - As part of the development of cause codes in 1989, an effort was undertaken to develop a cause code presentation format that would be sensitive to changing performance trends. This format was based upon cumulative plots of cause code data on a daily basis. During the review of the cumulative plots, attention was 


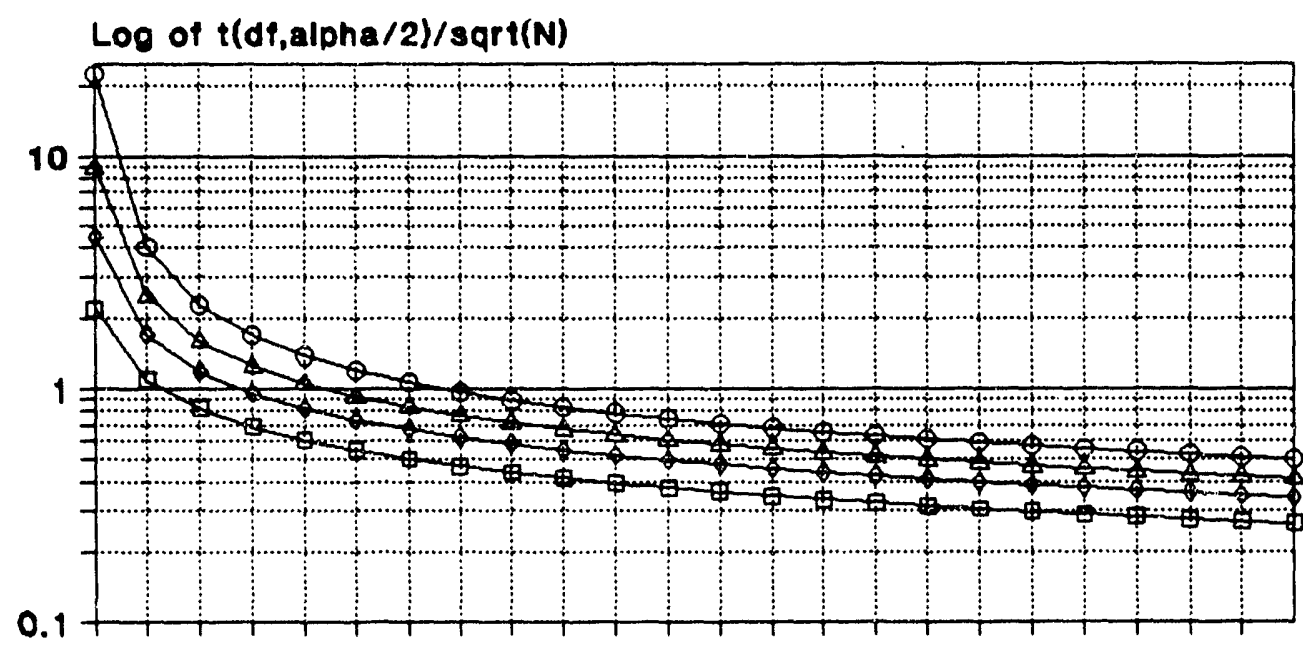

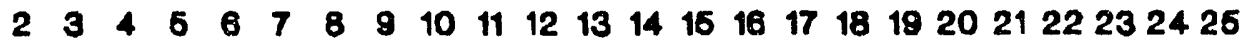
Number of Plants in a Peer Group

Ð 80\% Level $\rightarrow$ 90\% Level $\triangle$ 96\% Level $-98 \%$ Level

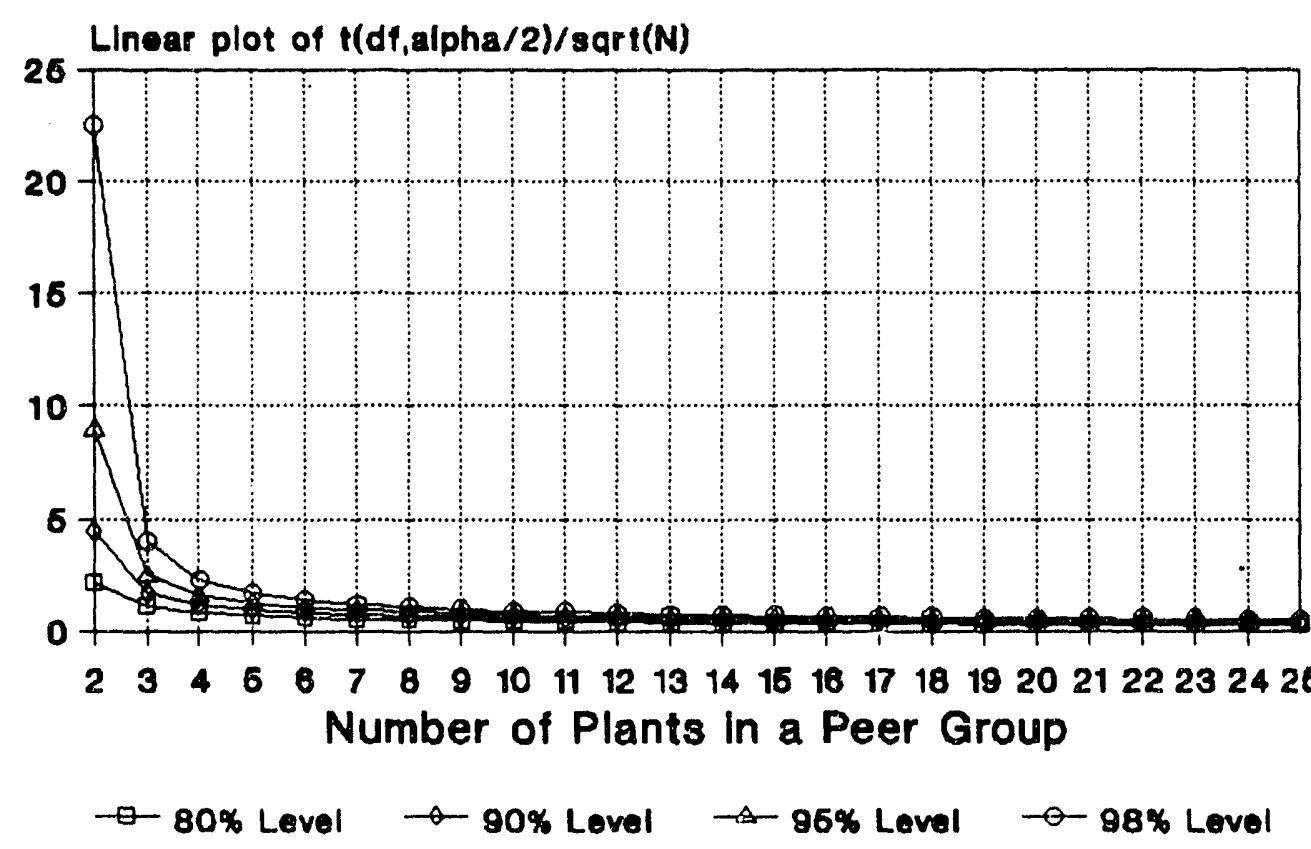

Figure 13. Multiplying factors of the standard deviation for confidence intervals. 


\section{PEER SCRAM AVERAGE TREND}

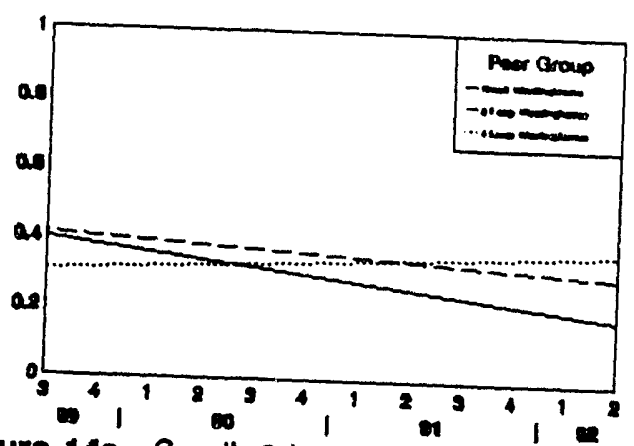

Figure 14a. Small, 3-Loop, and 4-Loop Westinghouse scram averages

\section{PEER SCRAM AVERAGE TREND}

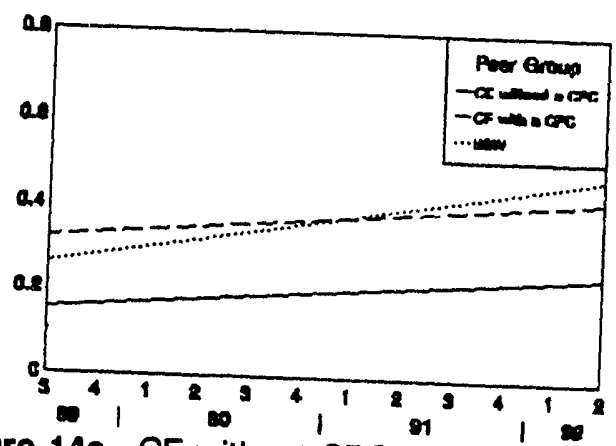

Figure 14c. CE without $C P C, C E$ with $C P C$ and $B \& W$ peer scram averages

\section{PEER SSA AVERAGE TREND}

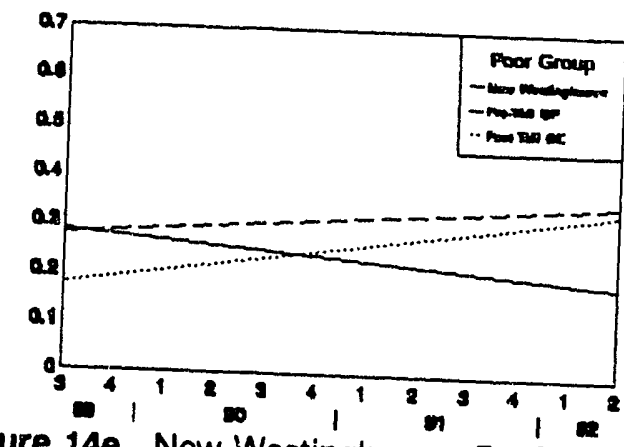

Figure 14e. New Westinghouse, Pre-TMI GE, and Post-TMI peer SSA averages
PEER SCRAM AVERAGE TREND

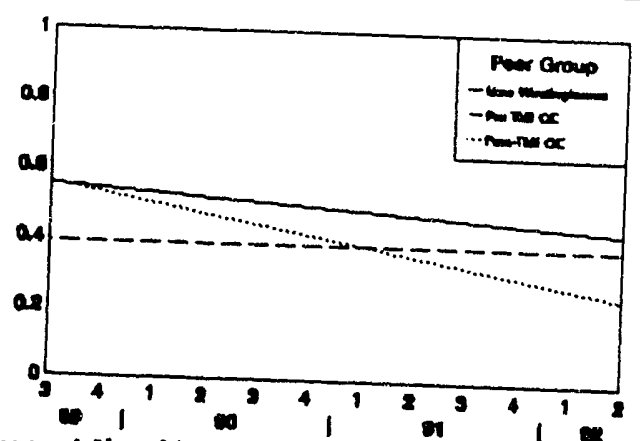

Figure 14b. New Westinghouse, Pre-TMI GE Post-TMI GE peer average scrams

\section{PEER SSA AVERAGE TREND}

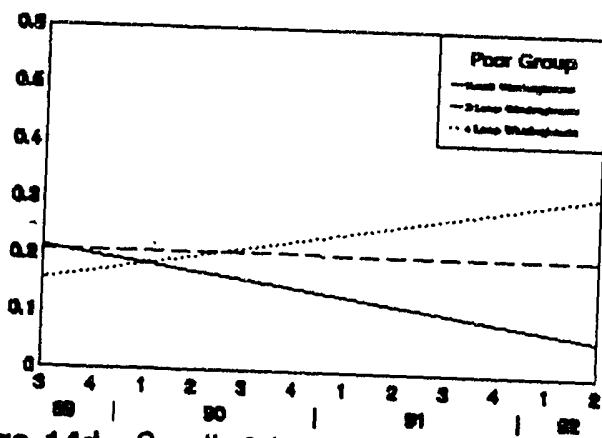

Figure 14d. Small, 3-Loop, 4-Loop Westinghouse peer average SSAs

\section{PEER SSA AVERAGE TREND}

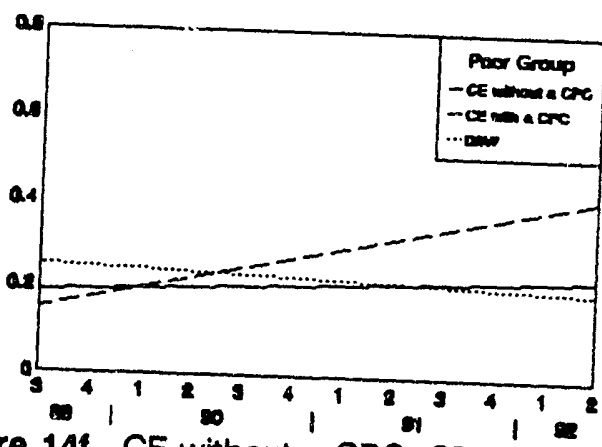

Figure 14f. CE without a CPC, CE with a $C P C$ and $B \& W$ peer SSA average

Figure 14. Illustration of peer group trends for the scram and SSA indicators. 


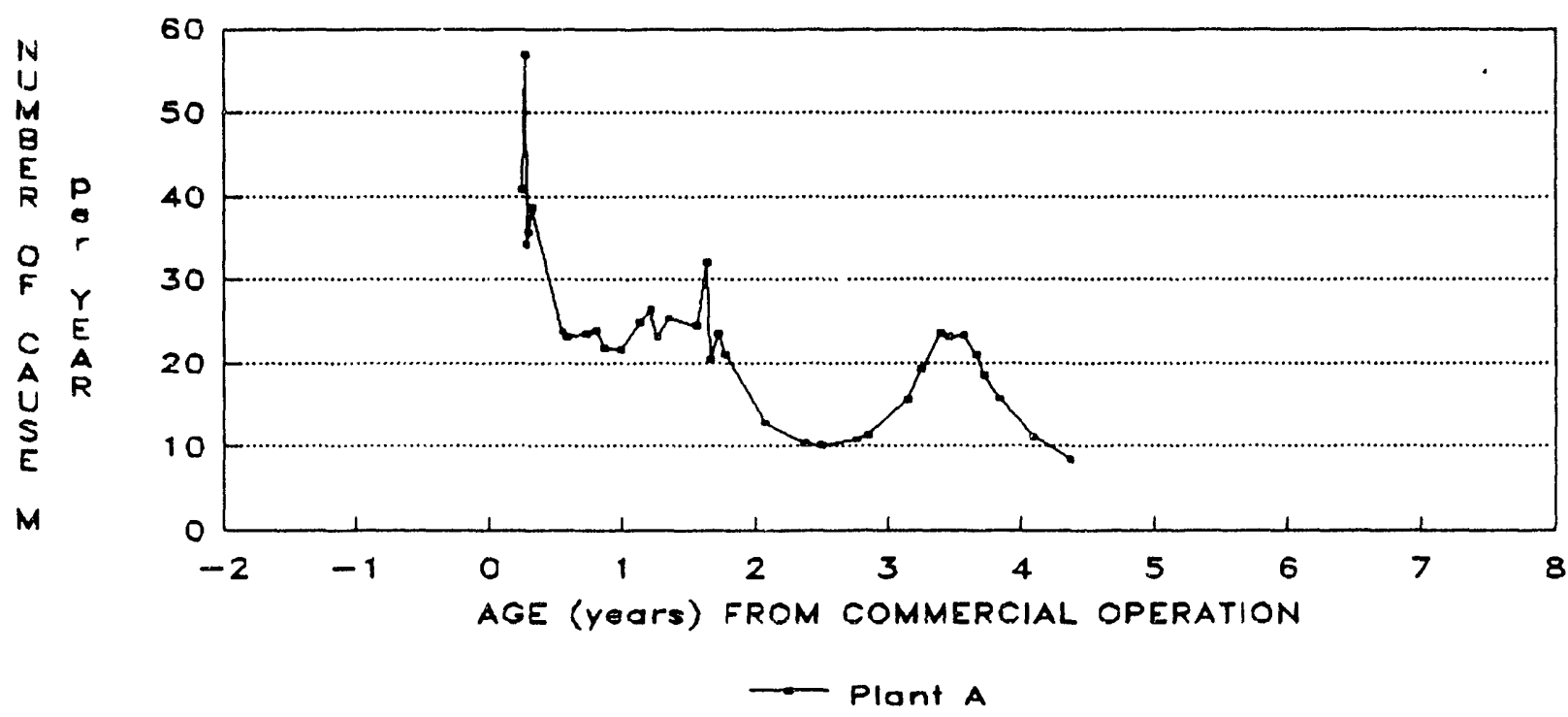

Figure 15. Plant A Maintenance Error Cause Code Generation Rate vs Plant Age

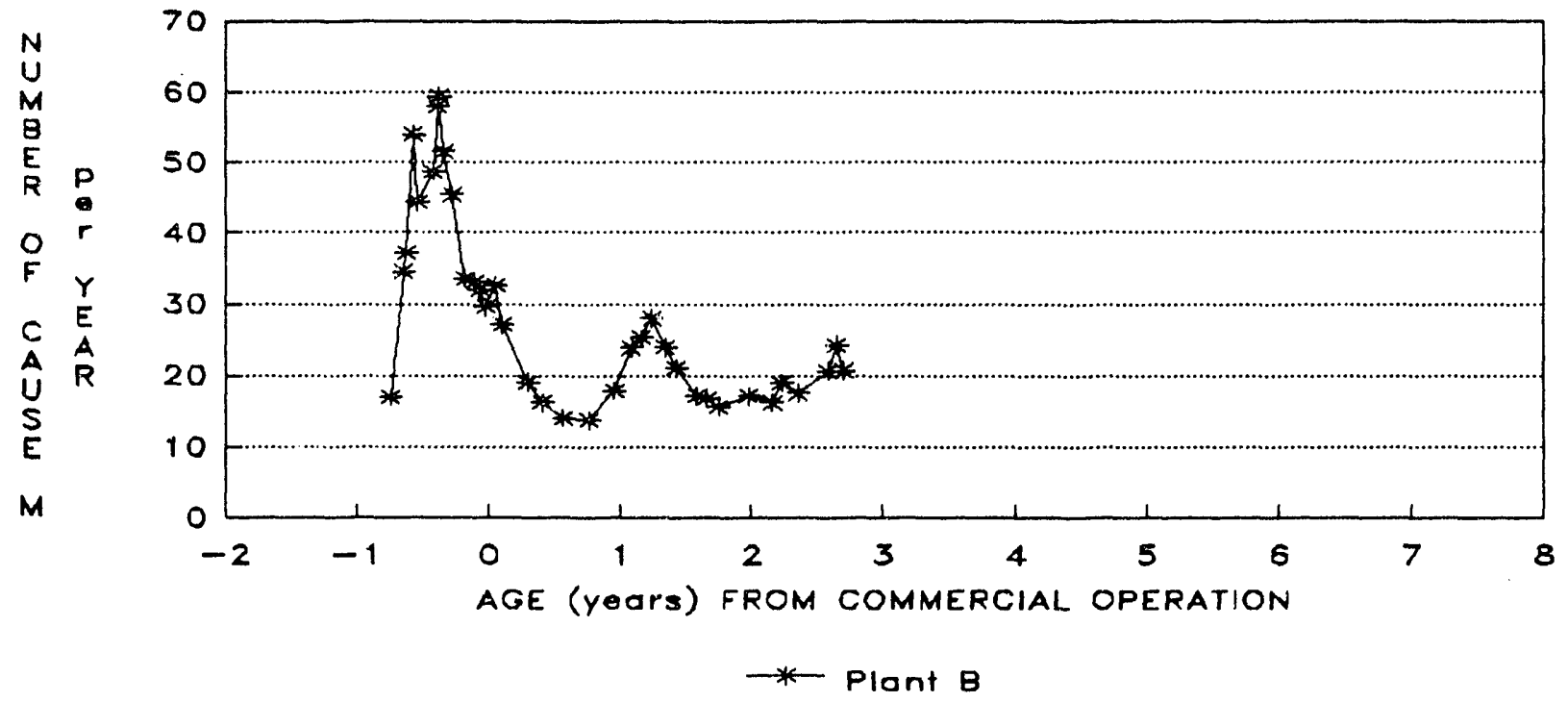

Figure 16. Plant B Maintenance Error Cause Code Generation Rate vs Plant Age 


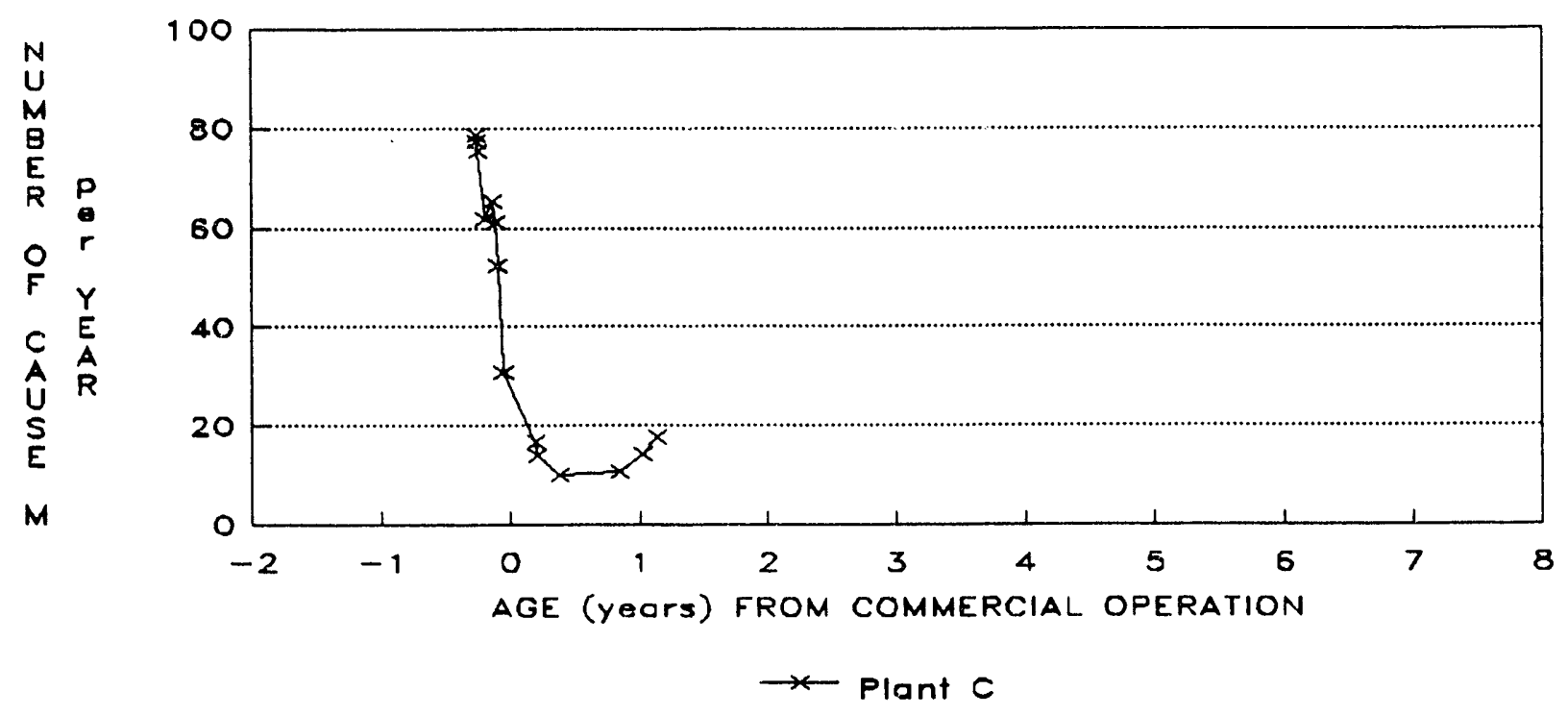

Figure 17. Plant $C$ Maintenance Error Cause Code Generation Rate vs Plant Age

focused on sharp changes in the slopes of the curves, which represent differences in the rates atwhich events occurred. A significant number of cause codes clustered in a relatively short time results in a discernible change in slope. Interest in the slope lead to the development of a display format especially sensitive to changes in the slope of the cumulative curves. Figures 15,16 , and 17, based on 1988 and 1989 data, show plots of the cause code rate (or slope of the cumulative cause code data line) for three relatively new plants. Each of these figures share two interesting features. First, a higher rate of cause code generation is apparent near the plant age of zero. This higher rate appears to trend downward as the plant age increases. Second, the data are of a cyclic nature. There appear to be peaks and valleys in the data with a period of about 1.5 years; this interval is frequently associated with plant refueling intervals.

Intuitively, higher rates of maintenance error cause codes are expected during refueling periods when maintenance activity is high; therefore, the potential for maintenance-related errors is greater. This possibility was exarnined by identifying refueling outages or other outages on additional graphs showing the rate of maintenance error cause code generation as a function of plant age.
Figures 18,19 , and 20 provide the maintenance error cause code rates for representative older plants. These figures illustrate the relationship between outages (especially, refueling outages) and the maintenance error cause code. In addition, Figure 19 illustrates a sharp peak at about 7.2 years for Plant $E$. The plant experienced three non-refueling outages of about 4 months total duration during this time. A high rate of maintenance error cause codes accompanied these outages.

Analogous to the maintenance error cause code, rates for other cause codes can also vary according to the operating cycle. For example, licensed operator errors can be relatively high during startup when demands on operators are high. The cause code for administrattve control problems frequently identifies procedure problems. These problems can be higher during periods when maintenance activities and surveillance testing are high, such as during refueling outages or startups. Personnel errors may be high during these periods for the same reasons.

5.2.2 Implications of Cyclic Behavior of Cause Code Data - The cyclic nature of the cause code data is an important factor in presenting data by plant peer groups, especially 


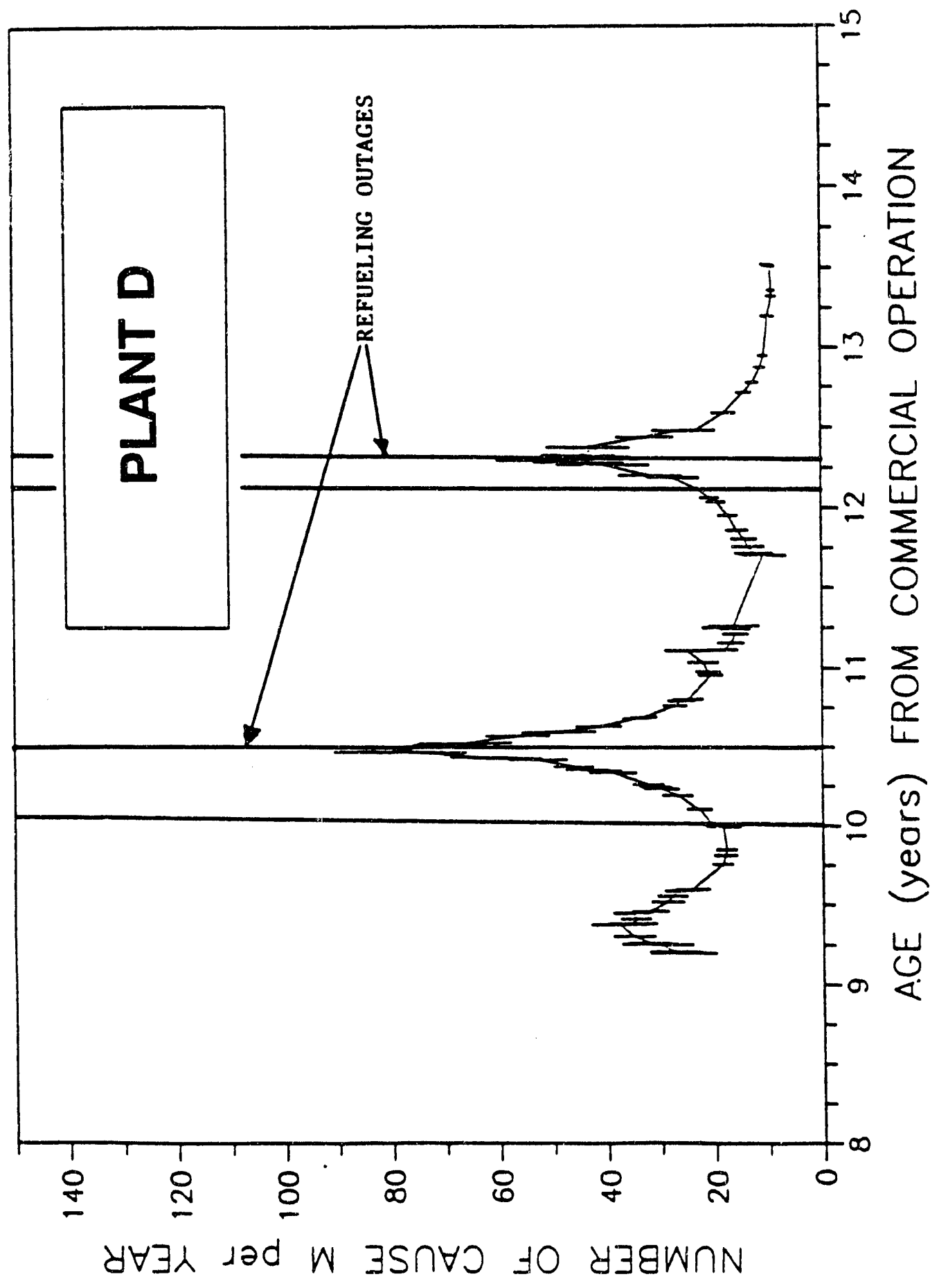

Figure 18. Maintenance error cause code generation rate vs plant age for plant $D$. 


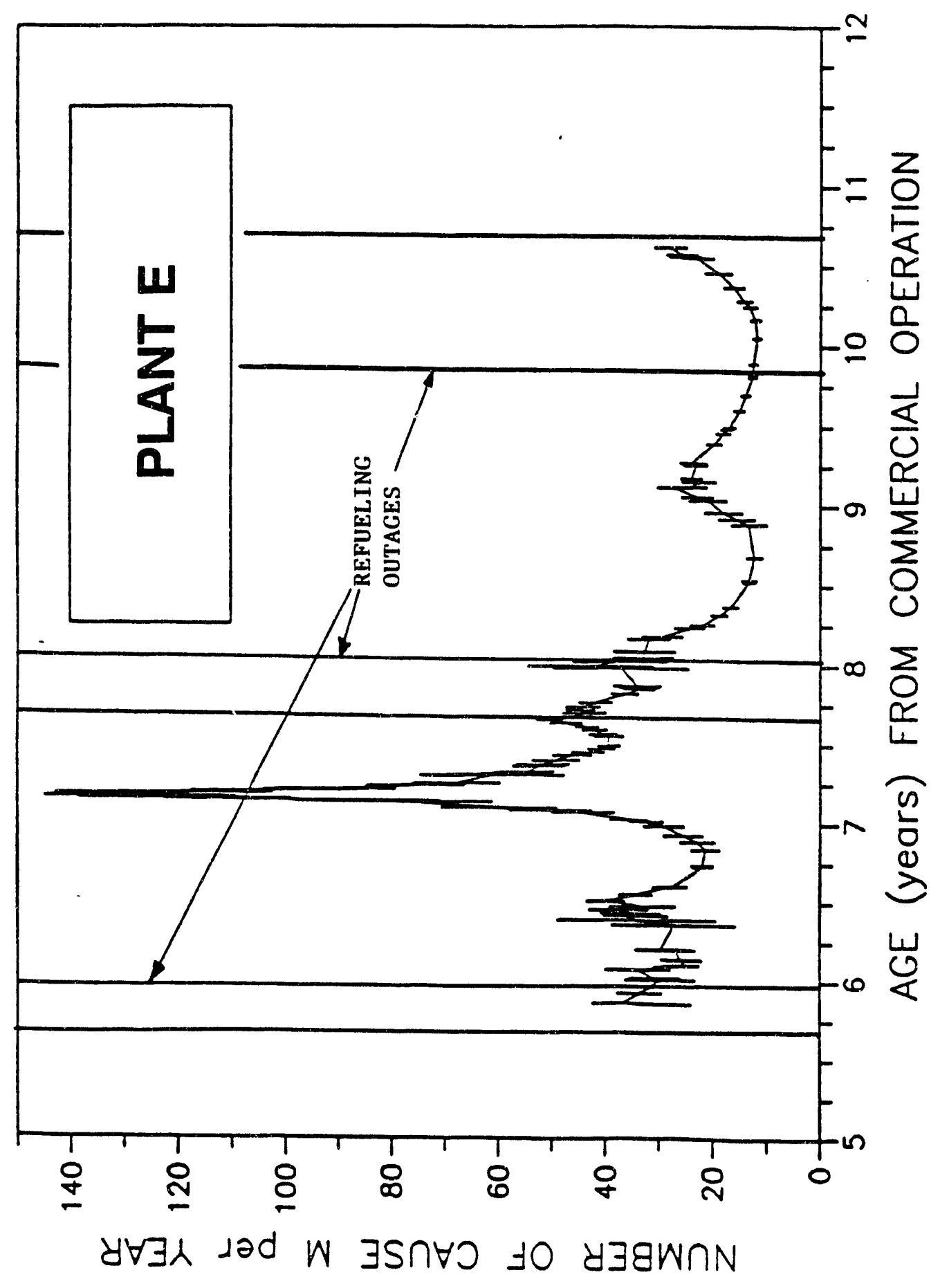

Figure 19. Maintenance error cause code generation rate vs plant age for plant $E$. 


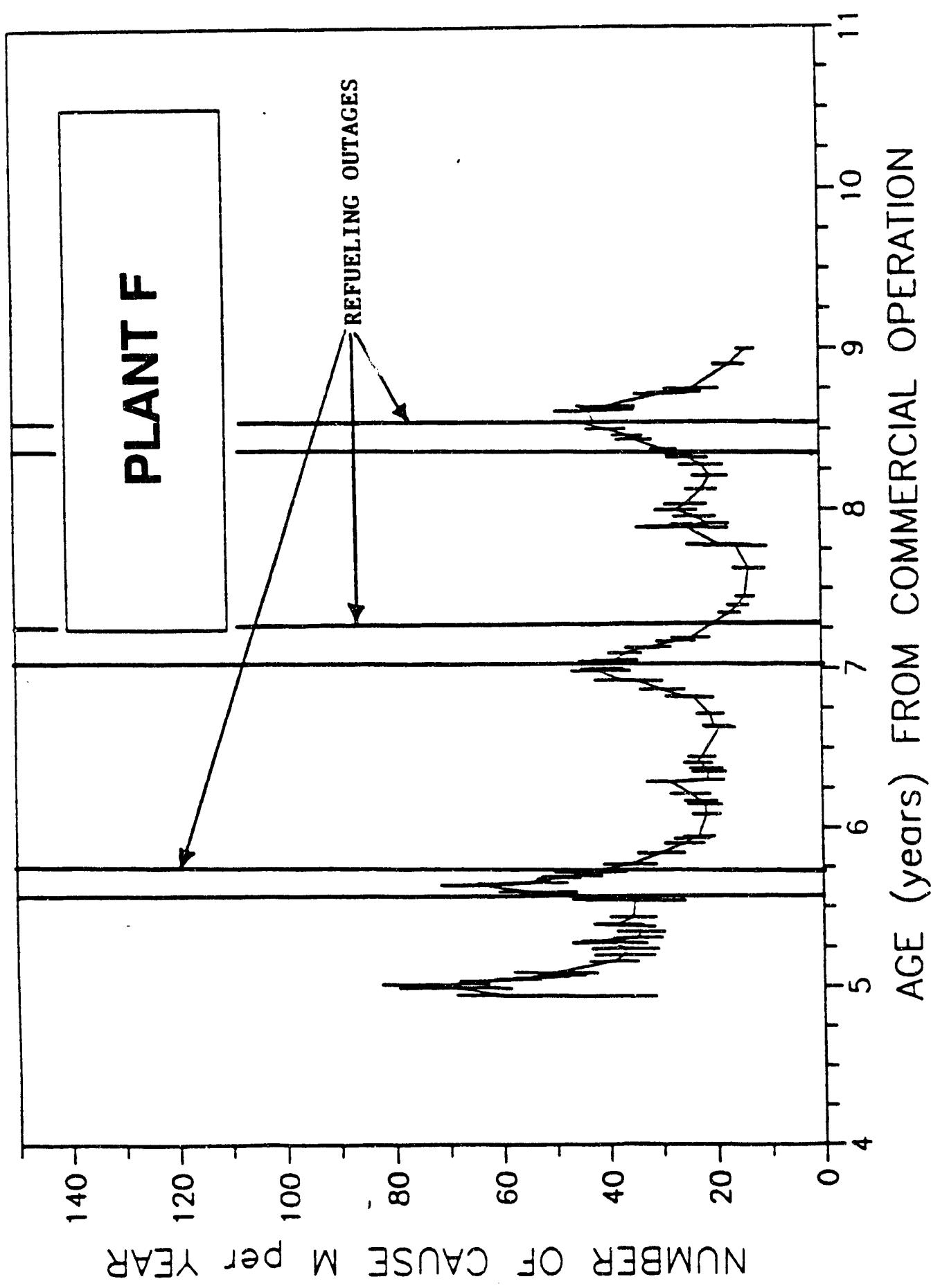

Figure 20. Maintenance error cause code generation rate vs plant age for plant $F$. 
in deciding whether the performance of one plant is within expected bounds for the peer group. Data in Figures 15, 16, and 17 show slopes that vary by factors of 4 to 8 over the course of several cycles.

Without an understanding of the cyclic behavior, plant performance trends can be misinterpreted. First, recent plant performance trends can be interpreted as declining (or improving) even tho Igh the behavior is consistent with the plant's operating conditions. For example, a plant in a refueling outage might have a higher maintenance error rate than it did in the several quarters of operation just prior to the refueling outage. This plant would show declining performance with the current presentation of PI data. The plant's actual performance may have improved, however, compared to its previous refueling outage when similar types of activities associated with refueling were performed.

Second, the plant's performance can be considered to be atypical of the rest of the peer group when, in fact, its performance is normal for the plant's operating conditions. For example, the plant of interest may have just completed a refueling outage typified by a higher maintenance error rate than the previous quarters of operation. The other plants in the peer group may have been in operating modes other than in refueling, which typically have lower maintenance error rates. In this case, performance of the plant would be viewed as declining compared to the rest of the peer group.

Third, actual plant performance relative to itself or to its peer group can be evaluated with greater precision because the variability due to the operational cycle phases can be accounted for directly.

These observations were important for the introduction of peer groups. The potential for misinterpreting $\mathrm{PI}$ data still would exist once the peer groups were implemented. Thus, to draw more meaningful conclusions from the PI data, it was necessary to develop and assess presentation of $\mathrm{PI}$ data based on an operational cycle approach.
5.2.3 Qualitative Assessment of the Operational Cycle Calculation Methodology - A assessment of the OCM was performed to determine if its use improved the qualitative selection of outlier plants. This analysis consisted of 1) selecting outlier plants from the secondquarter $1992 \mathrm{PI}$ reports using the current and OCM displays and 2) comparing the list of outliers with the list of plants of greater concern from the Spring 1992 Senior Management Screening Meeting.

Outliers were selected from the current method by visually integrating the negative values for the plant self-trends and the industry deviations and ignoring the positive values. If the integrated value exceeded a threshold value then the plant was identified as an outlier. The reasoning behind this criterion is that good performance in one area does not necessarily offset poor performance in another area. Values that are not statistically significant are eliminated.

In a similar manner, outliers were selected from the OCM method by visually integrating the medium and highly statistically significant negative Pls. It was hypothesized that changes in the probability bands which correspond to medium and high levels of statistical significance would affect the number of outliers selected since the number of statistically significant ironds and deviations will increase as the prubajulity bands are widened. To determine the effect of changes in the probability bands assigned to the levels of statistical significance, the selection process described above was applied to three sets of OCM displays, each with probability bands assigned to the medium and high levels of statistical significance. The results indicated that as the probability bands were widened for the medium and/or high levels of statistical significance, the number of plants of greater concern which were identified as outliers increased. However, the total number of outlier plants selected also increased. Therefore, appropriate probability bands were determined by balancing the number of plants of greater concern identified with the total number of outliers selected.

The Senior Management Screening Meeting list of plants of greater concern is only broken down to 


\begin{tabular}{||l|c|c|c|c|c|}
\hline Table 9. Correlation between plants of greater concern and outliers from both methods. \\
\hline Method & $\begin{array}{c}\text { Number of } \\
\text { Plants of } \\
\text { Greater } \\
\text { Concern }\end{array}$ & $\begin{array}{c}\text { Number of } \\
\text { Plants of } \\
\text { Greater } \\
\text { Concern } \\
\text { Identified as } \\
\text { Outliers }\end{array}$ & $\begin{array}{c}\text { Percentage of } \\
\text { Plants of } \\
\text { Greater } \\
\text { Concern } \\
\text { Identified as } \\
\text { Outliers }\end{array}$ & $\begin{array}{c}\text { Total Number } \\
\text { of Outliers } \\
\text { Identified }\end{array}$ & $\begin{array}{c}\text { Percentage of } \\
\text { Total Outliers } \\
\text { that Are } \\
\text { Plants of } \\
\text { Greater } \\
\text { Concern }\end{array}$ \\
\hline Current & 22 & 13 & 59 & 24 & 54 \\
\hline OCM & 22 & 12 & 55 & 32 & 38 \\
\hline Note: 10 plants were selected by both methods, 7 plants were missed by both methods. \\
\hline
\end{tabular}

\begin{tabular}{|l|c|c|c|c|c||}
\hline \multicolumn{2}{||c|}{ Table 10. Correlation between plant sites of greater concern and outlier sites from both methods. } \\
\hline Method & $\begin{array}{c}\text { Number of } \\
\text { Sites of } \\
\text { Greater } \\
\text { Concern }\end{array}$ & $\begin{array}{c}\text { Number of } \\
\text { Sites of } \\
\text { Greater } \\
\text { Concern } \\
\text { Identified as } \\
\text { Outliers }\end{array}$ & $\begin{array}{c}\text { Percentage of } \\
\text { Sites of } \\
\text { Greater } \\
\text { Concern } \\
\text { Identified as } \\
\text { Outliers }\end{array}$ & $\begin{array}{c}\text { Total Number } \\
\text { of Outlier } \\
\text { Sites } \\
\text { Identified }\end{array}$ & $\begin{array}{c}\text { Percentage of } \\
\text { Total Outlier } \\
\text { Sites that } \\
\text { Are Sites of } \\
\text { Greater } \\
\text { Concern }\end{array}$ \\
\hline Current & 12 & 8 & 67 & 19 & 63 \\
\hline OCM & 12 & 7 & 58 & 29 & 41 \\
\hline Note: 7 sites were selected by both methods, 2 plants were missed by both methods. \\
\hline
\end{tabular}

the site level. The outliers were selected from the PI data at a plant level. As a result of this difference in the available data, two comparisons were made, one at the plant level and one at the site level.

In the first comparison, the list of plart sites of greater concern was assembled. From this list, a list of the individual plants at these sites was developed. This list of plants was compared to the list of outliers identified through the PI data using the current and OCM displays. The results of this analysis are shown in Table 9.

In the second comparison, the list of plant sites of greater concern was assembled. This list of sites was compared to the list of outliers identified through the PI data. If one or more plants were identified as an outlier at a site, then the method was successful at flagging the site. The results of this analysis are shown in Table 10.

From these comparisons, the following conclusions can be drawn:

- The two methods are equally effective at identifying plants and sites of greater concern.

- A number of plants and sites were not selected as outliers with either method. This indicates that not all the plants at a particular site were of greater concern or that the 
concerns at these plants are not reflected in the input data utilized by the PI program.

In summary, outlier plants were selected using both the current and the OCM displays. Various probability bands were assigned to the two levels of statistica! significance for the OCM and an appropriate level selected. The list of outlier plants from both methods were compared to the list of plants (or sites) of greater concern. The results indicated that the two methods are equally effective at identifying plants and sites of greater concern. However, the OCM does a better job of identifying the areas where the poor performance is manifesting itself due to the additional information displayed.

\subsubsection{Statistical Significance Test} Assessment - The statistical significance test identifies the plant self-trend and deviation values that are not the result of random events. As an example of the process used to identify the trend significance levels, Figure 21 is provided. In this figure, the slope values for a PI trend are shown on the X-Axis. The distribution of the slope values comes from a simulation with a fixed number of events and a fixed number of intervals. A plant's single slope value is fit to the function and assigned the significance level associated with the distribution. The width of each bar in the plot indicates the range of the slopes that would be assigned a significance level. The magnitude of each bar indicates the scaled relative frequency that the slopes within this bar are expected to occur. A figure similar to Figure 21 plot could be developed for each combination of numbers of events and intervals that could be encountered in the slope calculations. Table 11 provides a listing of the information shown in Figure 21 and the shade assigned to each significance level.

The plot showing the process for the deviation calculation would be similar to the Figure 21 trend plot, except it would be based on the difference in rates between the peer group and plant instead of slopes.

The performance indicator data used in the second quarter $1992 \mathrm{PI}$ report was analyzed to determine if the significance levels were being assigned at a appropriate frequency. Table 12 presents a listing of the total of the number each of the significance values from the second quarter 1992 Operational Cycle PI report. If the number of assigned cases for each significance value is considered, it appears that a reasonable number of each has been assigned.

\subsection{Pilot Program}

The peer group and OCM methods for presenting the performance indicator data has been used to develop three draft Operating Cycle PI reports. Following the publication of each report, each report was reviewed and commented on by the NRC PI Interoffice Task Group (ITG). The draft reports were discussed in detail during meetings on September 12, 1991, May 27, 1992, and August 26, 1992. Following each of the meetings, the comments were summarized and distributed to all Task Group members. ${ }^{[7.8 .9]}$ Following the distribution of the comments, the peer group and OCM systems were modified in accordance with the comments. The following paragraphs summarize the comments from the NRC Interoffice Task Group and the actions taken to address them.

\subsubsection{September 12, 1991 ITG Meeting - On} September 12, 1991, a meeting was held to discuss the operational cycle methods for presenting the performance indicators. The meeting was attended by staff from the NRC Regions, NRC AEOD, NRC NRR, and NRC AEOD contractors. The general conclusions of the meeting were the following:

1. As shown in the Operational Cycle report, significant improvements in the presentation of the PIs could be realized by addressing the difference in the indicators during various phases of a plant's operating cycle.

2. Modifications in the method are necessary to obtain the most benefit. The following modifications were identified.

- The method needs to be sensitive to trends over a six-month interval to 


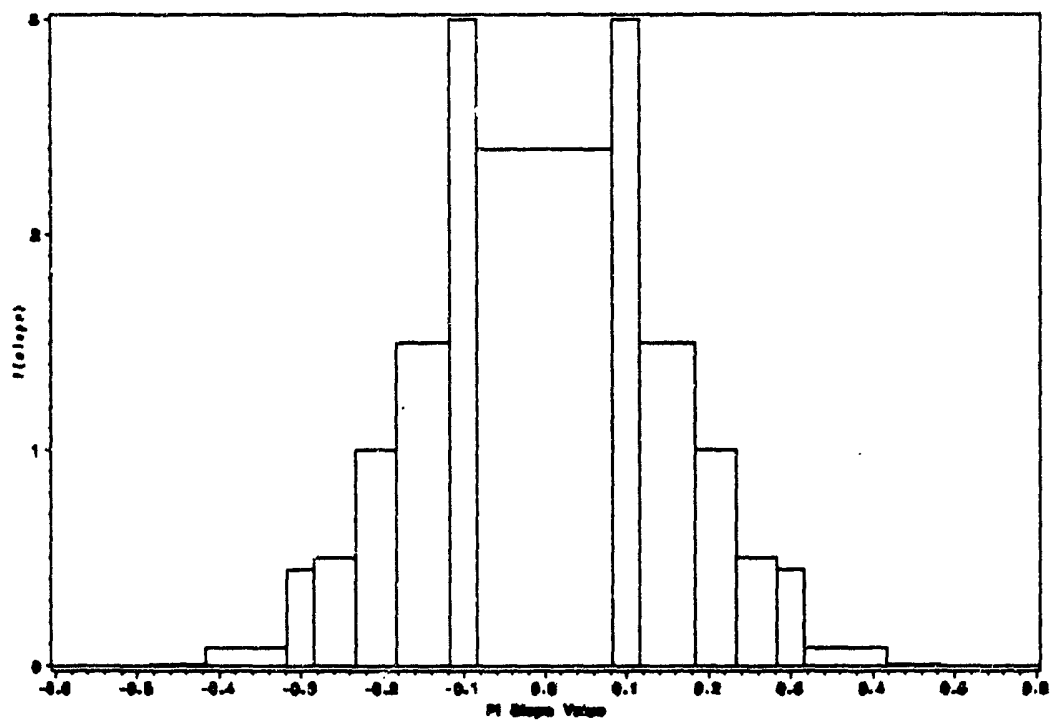

Figure 21. Illustration of PI trend significance

\begin{tabular}{|c|c|c|c|}
\hline Significance & Slope Bar Start & Slope Bar End & Shade Assignment \\
\hline 0.0001 and Less & -0.60000 & -0.48333 & Black \\
\hline 0.0010 & -0.48333 & -0.41667 & Black \\
\hline 0.0100 & -0.41667 & -0.31667 & Black \\
\hline 0.0250 & -0.31667 & -0.28333 & Black \\
\hline 0.0500 & -0.28333 & -0.23333 & Gray \\
\hline 0.1000 & -0.23333 & -0.18333 & Gray \\
\hline 0.2000 & -0.18333 & -0.11667 & Gray \\
\hline 0.3000 & -0.11667 & -0.08333 & White \\
\hline $\begin{array}{c}0.3000 \text { and } \\
\text { Greater }\end{array}$ & -0.83333 & 0.00000 & White \\
\hline $\begin{array}{c}0.3000 \text { and } \\
\text { Greater }\end{array}$ & 0.00000 & 0.08333 & White \\
\hline 0.3000 & 0.08333 & 0.11667 & White \\
\hline 0.2000 & 0.11667 & 0.18333 & Gray \\
\hline 0.1000 & 0.18333 & 0.23333 & Gray \\
\hline 0.0500 & 0.23333 & 0.28333 & Gray \\
\hline 0.0250 & 0.28333 & 0.31667 & Black \\
\hline 0.0100 & 0.31667 & 0.41667 & Black \\
\hline 0.0010 & 0.41667 & 0.48333 & Black \\
\hline 0.0001 or Less & 0.48333 & 0.60000 & Black \\
\hline
\end{tabular}




\begin{tabular}{|c|c|c|c|c|c|c|c|c|}
\hline \multirow{2}{*}{$\begin{array}{l}\text { Sig. } \\
\text { Levels }\end{array}$} & \multicolumn{4}{|c|}{ Operations Phase Type Trends } & \multicolumn{4}{|c|}{ Shutdown Phase Type Trends } \\
\hline & $\begin{array}{c}\text { Slope } \\
<0\end{array}$ & $\begin{array}{l}\text { Slope } \\
=0\end{array}$ & $\begin{array}{c}\text { Slope } \\
>0\end{array}$ & Total & $\begin{array}{c}\text { Slope } \\
<0\end{array}$ & $\begin{array}{l}\text { Slope } \\
=0\end{array}$ & $\begin{array}{c}\text { Slope } \\
>0\end{array}$ & Total \\
\hline 0.0001 & 0 & 0 & 0 & 0 & 0 & 0 & 0 & 0 \\
\hline 0.0010 & 3 & 0 & 0 & 3 & 1 & 0 & 0 & 1 \\
\hline 0.0100 & 7 & 0 & 5 & 12 & 5 & 0 & 2 & 7 \\
\hline 0.0250 & 11 & 0 & 5 & 16 & 5 & 0 & 3 & 8 \\
\hline 0.0500 & 20 & 0 & 13 & 33 & 10 & 0 & 12 & 22 \\
\hline 0.1000 & 77 & 1 & 46 & 124 & 30 & 2 & 32 & 64 \\
\hline 0.2000 & 68 & 14 & 80 & 162 & 30 & 6 & 60 & 96 \\
\hline 0.3000 & 37 & 0 & 117 & 154 & 30 & 1 & 63 & 94 \\
\hline$>0.30$ & 5 & 417 & 262 & 684 & 9 & 586 & 163 & 758 \\
\hline \multirow[t]{3}{*}{ Blank } & & & & 33 & & & & 171 \\
\hline & \multicolumn{4}{|c|}{ Operations Phase Type Deviations } & \multicolumn{4}{|c|}{ Shutdown Phase Type Deviations } \\
\hline & $\begin{array}{l}\text { Diff. } \\
<0\end{array}$ & $\begin{array}{l}\text { Diff. } \\
=0\end{array}$ & $\begin{array}{l}\text { Diff. } \\
>0\end{array}$ & Total & $\begin{array}{l}\text { Diff. } \\
<0\end{array}$ & $\begin{array}{l}\text { Diff. } \\
=0\end{array}$ & $\begin{array}{l}\text { Diff. } \\
>0\end{array}$ & Total \\
\hline 0.0001 & 12 & 0 & 1 & 13 & 3 & 0 & 0 & 3 \\
\hline 0.0010 & 6 & 0 & 1 & 7 & 3 & 0 & 0 & 3 \\
\hline 0.0100 & 28 & 0 & 25 & 53 & 9 & 0 & 2 & 11 \\
\hline 0.0250 & 28 & 0 & 20 & 48 & 10 & 0 & 3 & 13 \\
\hline 0.0500 & 29 & 0 & 40 & 69 & 14 & 2 & 3 & 19 \\
\hline 0.1000 & 43 & 0 & 42 & 85 & 24 & 0 & 13 & 37 \\
\hline 0.2000 & 72 & 0 & 99 & 171 & 35 & 0 & 35 & 70 \\
\hline 0.3000 & 90 & 10 & 78 & 178 & 63 & 4 & 42 & 109 \\
\hline$>0.30$ & 162 & 303 & 110 & 575 & 145 & 508 & 172 & 825 \\
\hline Blank' & & & & 22 & & & & 131 \\
\hline
\end{tabular}


closely relate to the frequency of the Senior Management Meetings.

- The method should indicate the magnitude and significance of plant trend and deviation values without being too complex to understand.

- The data display required modification to more clearly illustrate operating cycle phases on the quarterly graphs, additional quarters of information must be added to the quarterly data display, and the trend and deviations graphs required modification to illustrate the magnitude and significance of each value and distinguish the trend and deviation values between shutdown and operation times.

The peer group and operational cycle methods were modified to address each of these items. Table 13 summarizes the modifications.

5.3.2 May 27, 1992 ITG Meeting - On May 27, 1992, a meeting was held to discuss the operational cycle methods modifications resulting from the previous meeting. The meeting was attended by staff from the NRC Regions, NRC AEOD, NRC NRR, and NRC AEOD contractors. The general conclusions of the meeting were the following:

1. The proposed modifications are robust and present significant amounts of useful information. The use of peer groups and operating cycles, along with incorporating the statistical significance tests add significantly to enable a clear evaluation of plant performance.

2. Additional modifications in the method are necessary to obtain the most benefit. Examples of the changes identified are the following.

- A singular, calendar-based, time frame for the trend and deviation calculations needed to be added. The total times used were to encompass only data displayed on the quarterly data page (i.e., three years maximum).
- Change the significance levels designations to LOW, MEDIUM, and HIGH.

- Plant trend lines were to be added to the quarterly data summary figures.

- The name of the EQUIPMENT Cause Code was to be changed to MISCELLANEOUS.

- The Equipment Forced Outage and Forced Outage Rate indicators trend and deviation calculation methods were different than the methods for the OCM. Comparable methods needed to be developed for these indicators.

- Modifications to the report text and displays were necessary to simplify the presentation.

- Methods were needed to present peer group versus industry trends.

- Explore modifications of the display to decrease the number of trend or deviation displays that overrange the display scale.

The operational cycle method was modified to address each of these items. Table 14 summarizes the modifications.

5.3.3 August 26, 1992 ITG Meeting - On August 26, 1992, a follow on meeting was held to discuss revisions to the operational cycle methods for presenting the performance indicators. The meeting was attended by staff from the NRC Regions, NRC AEOD, NRC NRR, and NRC AEOD contractors. The general conclusions of the meeting were the following:

1. The changes from the present PI report are so significant that those people not involved with the development are finding it difficult to use and interpret the OCM revised performance indicators. AEOD should provide training to regional personnel on the use of the OCM data. 


\begin{tabular}{|c|c|c|}
\hline Item & Modifications & Enhancement \\
\hline 1 and 3 & $\begin{array}{l}\text { The time intervals for the calculations were modifled to be } \\
\text { commensurate with the interval between Senlor Management } \\
\text { Meetings. }\end{array}$ & $\begin{array}{l}\text { The Intervals selected provide the trend and } \\
\text { devlation data considering the t/me since the last } \\
\text { Senlor Management Meeting. }\end{array}$ \\
\hline 2 and 3 & $\begin{array}{l}\text { The significance level for the trend and devlation values is determined. } \\
\text { The signiflcance level is used to shade the trend and deviation values. }\end{array}$ & $\begin{array}{l}\text { This provides a visual presentation of the } \\
\text { slgniflcance level. }\end{array}$ \\
\hline 2 and 3 & $\begin{array}{l}\text { The length of the bars on the rlght page is proportional to the } \\
\text { magnitude of the trend and deviation value. }\end{array}$ & $\begin{array}{l}\text { This visually depicts the magnitude of the trend and } \\
\text { deviation values. }\end{array}$ \\
\hline 3 & $\begin{array}{l}\text { A timellne showing the periods of time that each plant was operating } \\
\text { or shutdown. }\end{array}$ & $\begin{array}{l}\text { This addition replace the critical hour presentation, } \\
\text { used previously. }\end{array}$ \\
\hline 3 & $\begin{array}{l}\text { The number of quarters displayed on the left page display (quarterly } \\
\text { data presentation) was increased. }\end{array}$ & $\begin{array}{l}\text { To increase the number of quarters displayed and } \\
\text { the long term trend information. }\end{array}$ \\
\hline 3 & $\begin{array}{l}\text { The event counts for each quarter are counted considering the } \\
\text { operating phase. The phase counts are on the quarterly display by } \\
\text { shown by shading the stacked bars by phase. }\end{array}$ & $\begin{array}{l}\text { This addition adds more display for the operational } \\
\text { cycle impact. }\end{array}$ \\
\hline 3 & $\begin{array}{l}\text { The cause code counts of events was added to display Instead of the } \\
\text { current slx-quarter moving average. }\end{array}$ & $\begin{array}{l}\text { To make the dlsplay more sensitive to the cause } \\
\text { codes. }\end{array}$ \\
\hline 3 & $\begin{array}{l}\text { The right page presentation was modifled to include measures of } \\
\text { operations and shutdown performance. }\end{array}$ & $\begin{array}{l}\text { This additlon adds more display for the operational } \\
\text { cycle impact. }\end{array}$ \\
\hline
\end{tabular}

\begin{tabular}{|c|c|c|}
\hline Item & Modifications & Enhancement \\
\hline 1 & $\begin{array}{l}\text { Time frames were estabilshed for the trend and deviation calculations. } \\
\text { The number of days used in the calculations were established, both a } \\
\text { maximum and a minimum. Calendar restrictions were Implemented. }\end{array}$ & $\begin{array}{l}\text { This addition ensures that the data used for the } \\
\text { trend and deviation calculations is shown on the left } \\
\text { page. }\end{array}$ \\
\hline 2 & $\begin{array}{l}\text { The description of the significance levels was changed to LOW, } \\
\text { MEDIUM, and HIGH. }\end{array}$ & $\begin{array}{l}\text { These labels more clearly clefine the ranges of the } \\
\text { slgnifficance test. }\end{array}$ \\
\hline 3 & Plant trend lines were added to the quarterly data presentation. & $\begin{array}{l}\text { This addition presents more data so the peer group } \\
\text { can be compared to the plant data. }\end{array}$ \\
\hline 4 & $\begin{array}{l}\text { The EQUIPMENT cause code was changed to MISCELLANEOUS cause } \\
\text { code. }\end{array}$ & $\begin{array}{l}\text { This change more clearly describes the } \\
\text { MISCELLANEOUS cause code. }\end{array}$ \\
\hline 5 & $\begin{array}{l}\text { The EFO and FOR trend and deviation calculation methods were } \\
\text { developed and are simllar to the methods for the other Indicators. }\end{array}$ & $\begin{array}{l}\text { This allows all performance indicators trend and } \\
\text { deviation calculations be performed using the same } \\
\text { methodology. }\end{array}$ \\
\hline 6 & $\begin{array}{l}\text { The PI report text and displays need to be simpllfled to make them } \\
\text { more understandable. }\end{array}$ & $\begin{array}{l}\text { The text and displays were modified with simpliclty } \\
\text { in mind. }\end{array}$ \\
\hline 7 & $\begin{array}{l}\text { Peer group and industry display methods have been developed and are } \\
\text { used in the presentations in the executive summary. }\end{array}$ & This allows an industry to peer group comparison. \\
\hline 8 & $\begin{array}{l}\text { Methods for decreasing the number of trend and deviation fingers that } \\
\text { are pegged were considered. }\end{array}$ & $\begin{array}{l}\text { The calculation methods were not changed, but } \\
\text { methods were identifled to reduce the number if the } \\
\text { changes are deemed necessary. }\end{array}$ \\
\hline
\end{tabular}


2. Further modifications in the method are necessary to improve the information interpretation. Examples of the changes identified are the following.

- It would be helpful to provide a peer group trend line on the quarterly data display.

- The cause code event description should be provided in the "Event Descriptions" presented in the back of Volume 1 of the OCM PI report.

- The scales on some of the quarterly data displays need to be changed to make the trend lines more legible.

- There was some items on the quarterly data presentations that were not explained. There was some duplication of outages and phase types in Volume 2 data tables.

- One of the major improvements associated with the new methods is the incorporation of significance levels in the "Trends and Deviations" display. This modification should help identify poorer performing plants and those areas where this poorer performance is manifesting itself. Do the presently selected significance level break points adequately identify important trends? Are they flagging too few areas as significant performance changes and, thereby overlooking plants that should be evaluated more closely.
3. There was one issue discussed during the ITG meeting that was not resolved. This issue will be considered and resolved at a future date. The issue is presented below.

- Many safety system failures are discovered conditions that have existed for a period of time. How do these failures get assigned to different operational phases? For example, during a surveillance test while the plant was shut down, a condition was discovered that would have made a safety system inoperable but that safety system was needed only during power operations.

The operational cycle method was modified to address each of the resolved items. The resolution of the open issue has not been completed. Table 15 summarizes the modifications.

5.3.4 Summary of Pilot Program - The pilot program consisted of 1) the development of draft reports using the peer group and OCM methods for the display of performance indicator data, and 2) the review of these draft reports by the NRC PI Interoffice Task Group (ITG). The three reviews conducted by the ITG resulted in numerous modifications and improvements in the display and calculational methods utilized. Of the 20 comments made by the ITG, 19 have been successfully addressed, while one issue remains unresolved. 


\begin{tabular}{|c|c|c|}
\hline Item & Modifications & Enhancement \\
\hline 1 & $\begin{array}{l}\text { AEOD has presented the } P 1 \text { program at several regional resident } \\
\text { inspector conferences. If the modiflcations are approved by the } \\
\text { Commission, additional presentations will be made at the soonest } \\
\text { avallable opportunity. }\end{array}$ & $\begin{array}{l}\text { The training will allow a more detailed understanding } \\
\text { of the information in the } O C M \text { PI data presentation. }\end{array}$ \\
\hline 2 & $\begin{array}{l}\text { An average peer group trend line was incorporated into the quarterly } \\
\text { data displays for each indicator. }\end{array}$ & $\begin{array}{l}\text { This addition provides more information so that the } \\
\text { plant trends can be more clearly understood. }\end{array}$ \\
\hline 2 & 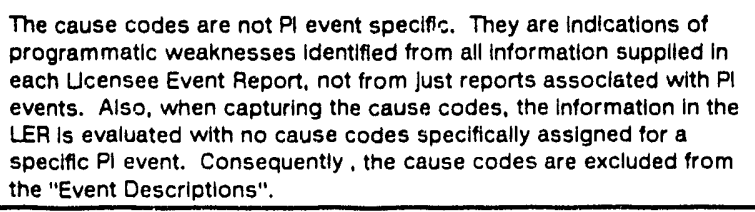 & There was no enhancement made for this request. \\
\hline 2 & $\begin{array}{l}\text { The scales on the quarterly data presentations were reviewed and } \\
\text { modiflcations made in the scales where a change would enhance the } \\
\text { display. }\end{array}$ & $\begin{array}{l}\text { By changing the display scales, the trend lines can } \\
\text { be more clearly seen and evaluated. }\end{array}$ \\
\hline 2 & $\begin{array}{l}\text { The report was revlewed and changes made where the information } \\
\text { was not available. }\end{array}$ & $\begin{array}{l}\text { Providing the missing information will allow a more } \\
\text { clear understanding of the display and data. }\end{array}$ \\
\hline 2 & $\begin{array}{l}\text { Changes in the significance test break points for assigning the display } \\
\text { shades. }\end{array}$ & The break polnts have been selected. \\
\hline 3 & $\begin{array}{l}\text { The treatment of pre-existing conditions and their assignment has not } \\
\text { been resolved. }\end{array}$ & Not resolved. \\
\hline
\end{tabular}




\subsection{CONClusions}

The results of the development, assessment, and trial use of the operational cycle methodology for analyzing and presenting the performance indicators are summarized below. Each conclusion is described, together with the pertinent finding and references to the appropriate section of the report. The appendices contain material to support these findings and conclusions.

1. The operational cycle methodology (OCM) has been developed and the methods evaluated for analyzing and presenting the performance indicators.

- The peer groups identified for use in calculating deviations were assessed, using applicable statistical analysis techniques, as an effective peer group breakdown for comparing the operational performance of operating commercial nuclear power plants. (See Sections 2 and 5.1)

- Separating the plant operating cycle into five operating phases (startup, power operations, pre-refueling, refueling outages, and non-refueling outages) and combining these phases into phase types, (operations and shutdowns), enables a comparative evaluation of plant performance during the two major operational phase types. (See Sections 3.1 and 3.2)

- The phase and phase type structure for partitioning event data has been determined to be an effective method for preparing data for calculating trend and deviation values. The phase type calculations adjustments to account for the effects of different operating conditions within the plant has been found to be indicative of short and long term plant performance. For example, if the plants in the peer group were in varying operational phases, then the maintenance error rate may have significant variability due to different error rates for each phase. Evaluations can be performed more consistently by aligning the phases and then comparing a plant's performance to the remainder of the peer group for the same phases. (Sections 3.2 and 4.2)

- The OCM self-trend calculation method consists fitting a linear regression line to event counts for periods of time spent in each phase type. The slope of the linear regression is normalized using a scaling factor to present the short term trend of plant performance. (See Section 4.2)

- The OCM deviation from the peer group calculation method consists of subtracting the peer group event median rate from the plant rate. The difference is normalized using a scaling factor to present the long term plant performance trend. (See Section 4.2)

- A statistical significance test for the trend and deviation values was developed and utllized to enhance the identification of areas of possible poor or declining performance. The significance test accounts for the way the data are distributed, the way the trend and deviation calculations are performed, the number of events that have occurred, the length of time over which the events occurred, and employs accepted statistical significance testing methods. (See Sections 4.2.4 and 5.2.4)

2. The OCM adjustments to the performance indicators are ready for implementation.

- The method for identifying outages and PI events have been established and utilized in a pilot program for evaluation and comparison with the current PI report. (See Section 5.3)

- The OCM calculation programs have been developed and implemented in 
software programs. The software has been used to produce three parallel PI reports for evaluation by the NRC staff. (Section 5.3)

3. The Peer Group structure and OCM adjustments to the PI program have been reviewed by the NRC PI Interoffice Task Group and found to substantially enhance the program. The comments received based on the Task Group review have been incorporated into the processes. Future enhancements will be incorporated as they are identified and as the OCM reports continue to be evaluated. 


\section{REFERENCES}

1. Oak Ridge National Laboratory, Letter Report 2 for Development of Plant Peer Groups, Martin Marietta Energy Systems, Inc. (February 1990).

2. Oak Ridge National Laboratory, Development of Commercial Nuciear Plant Peer Groups for Presentation of Performance Indicator Data, ORNL/NOAC-261, Martin Marietta Energy Systems, Inc. (May 1990).

3. Oak Ridge National Laboratory, Development and Evaluation of Proposed Modifications to the Nuclear Regulatory Commission's Performance Indicator Program, ORNL/NOAC-265, Martin Marietta Energy Systems, Inc. (July 1991).

4. H. M. Stromberg, J. H. Bryce, C. D. Gentillon and C. Kido, Operational Cycle Effects on the Performance Indicators, EGG-EAST-9107, EG\&G Idaho, Inc. (June 1990).

5. H. M. Stromberg, J. H. Bryce, C. D. Gentillon and C. Kido, Operational Cycle Adjustments to the Periormance Indicators, EGG-EAST-9445, EG\&G Idaho, Inc. (February 1991).

6. H. M. Stromberg and C. D. Gentillon, Further Development of Operational Cycle Trend and Deviation Measures for the Performance Indicators, EG\&G Idaho, Inc. (January 1992).

7. D. E. Hickman, Chief Performance Indicator Section Trends and Patterns Branch Office for Analysis and Evaluation of Operational Data, memorandum on Performance Indicator Interoffice Task Group Review of Operating Cycle Methodology, dated December 4, 1991.

8. D. E. Hickman, Chief Performance Indicator Section Trends and Patterns Branch Office for Analysis and Evaluation of Operational Data, memorandum on Summary of PI Interoffice Task Group Meeting - May 27, 1992, dated June 23, 1992.

9. D. E. Hickman, Chief Performance Indicator Section Trends and Patterns Branch Office for Analysis and Evaluation of Operational Data, memorandum on Summary of PI Interoffice Task Group Meeting - August 26, 1992, dated September 11, 1992. 


\section{APPENDIX A \\ Performance Indicator Program}

\section{A.1 Overview}

The PI Program is one aspect of the NRC's efforts to monitor the performance of licensees who operate commercial nuclear power plants in the United States. Under the direction of AEOD, the program currently monitors industry wide data on carefully selected PIs (Section A.2). The data are collected and processed on a regular schedule using validated computational methods (Section A.3). In conjunction with collection and analysis, the data are reported on a regular schedule in a standard format (Section A.4). In response to AEOD's emphasis on continually improving methods, the program has been evolutionary in its development and application. The NRC Senior Management has provided guidelines for the use of the PIs (Section A.5)

\section{A.2 Performance Indicators}

The PI Program is a single, coordinated effort that provides selected industry trends and patterns through eight specific PIs as described below. Unless noted otherwise the primary data sources for the PIs are 10 CFR 50.73 Licensee Event Reports (LERs), 1OCFR 50.72 Immediate Notification reports, and Monthly Operating Reports.

A.2.1 Automatic Scrams While Critical (Scrams) - This indicator monitors the number of unplanned automatic scrams that occur while the reactor is critical. Typical sources for the scrams include unplanned transients, equipment failures, spurious signals, human error, etc.

A.2.2 Safety System Actuations (SSA) - Safety system actuations are manual or automatic actuations of the logic or equipment of either certain Emiergency Core Cooling Systems (ECCS) or, in response to an actual low voltage or a vital bus, the Emergency $A C$ Power System. In determining which events should be counted by this indicator, the following conventions are used:

1. Only actuations of the High Pressure Injection (HPI) System, Low Pressure Injection (LPI) System, or Safety Injection Tanks are counted for pressurized water reactors (PWRs). For boiling water reactors (BWRs), only actuations of the High Pressure Coolant Injection (HPCI) System, Low Pressure Coolant Injection (LPCI) System, High Pressure Core Spray (HPCS) System, or Low Pressure Core Spray (LPCS) System are counted. Actuations of the Reactor Core Isolation Cooling (RCIC) System are not counted.

2. Actuations of Emergency $A C$ Power Systems are counted only if they were in response to an actual low voltage condition on a vital bus.

3. Logic actuations of any of the equipment associated with the specific ECCS or Emergency AC Power System are considered necessary and sufficient to constitute a data count. For example, if only a valve in a system is commanded to move to its emergency operational position, this is counted as an actuation. A pump does not have to be commanded to go to its emergency mode of operation and fluid does not need to be injected for an occurrence to be counted.

4. Only one ECCS actuation is counted in any one occurrence, even if multiple 
ECCS systems actuate during the occurrence. For example, actuation of both the High Pressure Injection and the Low Pressure Injection Systems at a PWR during the same occurrence counts as only a single ECCS actuation.

5. Only one emergency diesel generator (EDG) actuation is counted in any occurrence, even if multiple EDGs actuate during the occurrence. For example, actuation of all four EDGs at a unit counts as only a single actuation for that occurrence.

6. Occurrences involving actuations of both an EDG on a dead bus and an ECCS are given two counts, one for the EDG actuation and one for the ECCS actuation.

7. At multi-unit sites that share equipment (e.g., a swing EDG or shared buses), actuations are counted and assigned to the unit at which the actuation signal or loss of power originated. If the signal source cannot be associated with one unit, the actuation is assigned to both units.

A.2.3 Significant Events (SE) - Significant events are those events identified by NRC-NRR staff through detailed screening and evaluation of operating experience. The screening process includes the daily review and discussion of all reported operating reactor events, as well as other operational data such as special tests or construction activities. An event identified from the screening process as a significant event candidate is further evaluated to determine if any actual or potential threat to the health and safety of the public was involved. Specific examples of the type of criteria are summarized as follows:

1. Degradation of important safety equipment. Events considered under this category include situations that had the potential to reduce or actually reduced the operational capability of equipment. One example is the identification of a common cause failure mechanism, which could cause redundant components or multiple independent components to fail in response to a test or actual demand signal. This category does not include such items as a missed surveiliance test, if the equipment was subsequently tested and determined to be operable.

2. Unexpected plant response to a transient. Events considered under this category include situations in which changes in reactor parameters represent unanticipated reductions in margins of safety. For example, a rapid plant cooldown following a reactor trip that is exacerbated by a balance-of-plant malfunction or an undesirable system interaction. This category does not include minor differences in predicted and observed conditions that can be reasonably explained by instrument errors or modeling techniques and simplifying assumptions.

3. Degradation of fuel integrity, primary coolant pressure boundary, important associated structures. Events considered under this category include those of similar character to those identified in item 1 above, related to nuclear fuel, reactor coolant system containment, or important plant structures.

4. Scram with complication. Events considered under this category are scrams that occurred while the affected reactor was critical, followed by an equipment failure, malfunction, or personnel error. The failure, malfunction, or error generally does not include those that led to or directly caused the scram. Failures that both cause the scram and reduce the capability of the mitigating system (e.g., electric power, instrument 
air, other auxiliary support functions, or deficient procedures) are counted. In addition to the situations described in items 1 through 4 above, other broad categories considered for significant events include:

5. Unplanned release of radioactivity. Events considered under this category include unplanned releases of radioactivity that had the potential to exceed or actually exceeded the limits of the Technical specifications or Regulations.

6. Operation outside the limits of the Technical Specifications. Events considered under this category include occurrences when plant operation was conducted inconsistent with the license requirements. This category applies to risk significant deviations and most likely does not include incidents involving missed surveillances, small errors in setpoints, or other administratively inoperable conditions.

7. Other. Events considered under this category include a serias of events or recurring incidents that alone are not significant but when considered collectively represent ineffective corrective actions or a deficiency in plant hardware or administrative programs.

A.2.4 Safety System Failures (SSF) - Safety system failures are any events or conditions that could prevent the fulfillment of the safety function of structures or systems. If a system consists of multiple redundant subsystems or trains, failure of all trains constitutes a safety system failure. Failure of one of two or more trains is not counted as a safety system failure. The following is a list of the major safety systems, subsystems, and components monitored for this indicator:

Accident Monitoring Instrumentation
Auxiliary (and Emergency) Feedwater
Combustible Gas Control
Component Cooling Hater System
Contaiment and Contaiment Isolation
Containment Coolant Systems
Control Room Emergency Ventilation
Emergency Core Cooling Systems
Engineered Safety Features Instrumentation
Essential Compressed Air Systems
Essential or Emergency Service Water
Fire Detection and Suppression Systems
Isolation Condenser

Accident Monitoring Instrumentation (and Emergency) Feedwater Component Cooling Hater System Contaiment and Containment Isolation Emergency Core Cooling Systems Essential Compressed Air Systems Fire Detection and Suppression Systens

A.2.5 Forced Outage Rate (FOR) initiated no later than the end of the weekend following the discovery of an off-normal condition. Based on the data provided in the monthly operating reports, the forced outage rate for a period of time is the number of forced outage hours divided by the sum of unit service hours (i.e., generator on-line hours) and forced outage hours for the time period under consideration.

\section{A.2.6 Equipment Forced Outages per 1000 Commercial Critical Hours (EF0) -} This indicator is the number of forced outages caused by equipment failures per 1000 critical hours of commercial reactor operation. It is the inverse of the mean time (average number of thousand critical hours) between forced outages caused by equipment failures. The inverse number was adopted to facilitate calculation and display. The source of these data are the same as for the forced outage rate. 
A.2.7 Collective Radiation Exposure - This indicator is the total radiation dose accumulated by unit personnel per calendar quarter. With the exception of the Indian Point and Millstone sites, unit values at multi-unit sites are obtained by dividing the station total by the number of units contributing to the exposure. The Indian Point and Millstone sites report individual unit values. The radiation exposure data are obtained from the Institute of Nuclear Power Operations (INPO). Because of the reporting techniques employed in gathering the data, these data lag the other performance indicator data by one quarter.

A.2.8 Cause Codes - Cause codes are intended to identify possible deficiencies in six programmatic categories. The cause cod ; data are developed using the NRC's Sequence Coding and Search System (SCSS) database. Any event can have any or all of the cause codes assigned to it, but only one of each type can be assigned to any one event. This database is developed from all LERs, not just those associated with specific events monitored by the other PIs. The LER reviews for, and assignment of, the cause codes are performed by Oak Ridge National Laboratory (ORNL). The programmatic categories and their definitions are:

1. Administrative Control Problems - Management and supervisory deficiencies that affect plant programs or activities are included in this category. This category covers the implementation of the functional disciplines necessary to operate a nuclear power facility. Examples of the functional disciplines are operations, maintenance, licensing, design, health physics, etc. Examples of administrative control problems include poor planning, breakdown or lack of adequate management or supervisory control, inadequate interdepartmental coordination, poor communication between supervisors and staff or among departments, deficiencies resulting in weak or incorrect operating, surveillance or testing procedures, and departures from program requirements. The administrative control problems category is used if there is evidence that a particular problem is recurring and effective corrective action has not been taken.

2. Licensed Operator Errors - This programmatic cause category captures errors of omission or commission by licensed reactor operators during plant activities. Tr se errors may have initiated events or may be committed during the course of an event. Licensed operator errors typically occur due to carelessness, lack of experience or training, fatigue, stress, attitude, or poor work habits. Improper supervision is al so included whenever the event is the result of improper instructions given by a licensed operator, such as an operations supervisor or control room shift supervisor. Not included in this category are administrative control problems, such as incorrect procedures or inadequate planning activities, which caused an operator to take inappropriate actions.

3. Other Personnel Errors - This programmatic cause category captures errors of omission or commission committed by non-licensed personnel involved in plant activities. Personnel included in this category are plant staff (technicians, maintenance workers, equipment operators) and contract personnel. Not included in this category are administrative control problems, such as incorrect procedures or inadequate planning activities, which caused personnel to take inappropriate actions. This cause category is used in conjunction with the Maintenance Problems category when an 
event is the result of a personnel error involved with a maintenance activity.

4. Maintenance Problems - The intent of the maintenance problems cause category is to capture the full range of problems which can be attributed to programmatic deficiencies in the maintenance functional organization. Activities included in this category are maintenance, testing, surveillance, calibration, and radiation protection. The deficiencies noted within this category lead to inadequate or improper upkeep and repair of plant equipment and systems or inadequate programs to monitor equipment and plant performance necessary to prevent hardware failures.

This is the broadest of all categories and is intended to identify areas where improved plant performance is possible through a program which includes such things as increased attention to detail, more frequently performed surveillances, or the use of better trained personnel. The Maintenance Problems Cause category is used to track the performance of plant management's capability to repair failed equipment and to preclude equipment failures through improved preventative maintenance programs. Additionally, as an indication of potential maintenance problems, hardware failures which cannot be readily attributed to any preventable cause are also included in this category.

Maintenance related errors are often coupled with other cause categories such as Other Personnel Errors or Administrative Control Problems. The Maintenance Problems category is used in conjunction with other categories when an error occurs while a maintenance, surveillance, or test activity is in progress, whether the error was the result of a deficient procedure or a personnel error.

5. Design/Construction/Installation/Fabrication Problems - This category covers a full range of programmatic deficiencies in the areas of design, construction, installation, and fabrication. It is used in conjunction with other cause categories to capture all contributors to the event. One exception to the use of these categories is that the nature of an error in the design process implies a personnel error, it is not necessary to also include one of the personnel error categories for the design error. This cause category may be used in conjunction with other cause categories such as administrative control problems.

6. Equipment Failures (Electronic Piece-Part or Environmental-Related Failures) - This category is used for spurious or one-time failures of electronic piece-parts and failures due to meteorological conditions such as lightning, ice, high winds, etc. Electronic components which are included in this category are circuit cards, rectifiers, fuses, capacitors, diodes, resistors, transducers, amplifiers, and computation modules.

This category does not include failures that can be attributed to ouner problems, such as maintenance problems or design/construction/installation/fabrication problems. Additionally, failures of mechanical equipment for which a cause can not be identified are included in the maintenance problems category. 


\section{A.3 Data Collection, Processing and Analysis}

A.3.1 Schedule - Data collection is continuous as the LERs and other data sources are generated and distributed. Analysis is performed quarterly on a calendar year basis, with each analysis session occurring shortly after all data become available for a specific quarter, normally in the following quarter. The one exception is that of the radiation exposure PI provided by INPO. These data $1 \mathrm{ag}$ the other PIs by one quarter.

A.3.2 Data Collection - To facilitate timely analysis, PI data (counts and rates) are entered into a mix of personal computer (PC) and mainframe databases and spreadsheets as the reports are received. Because of certain logistics, the resporsibility to produce and maintain these databases is shared by INEL (Scrams, SSAs, SSFs, FOR, and EFOS), NRC-NRR (SEs), INPO (Collective Radiation Exposure) and ORNL (Cause Codes).

A.3.3 Analysis - In the initial phase of the analysis, the collected data is transmitted to the INEL where it is sorted and quality assured. This is followed by analysis to provide the following for each plant for the current and previous seven quarters:

a) Total counts by quarter for each of the scram, SSA, SE, SSF, and cause code PIs, and

b) Quarterly rates for each of the FOR, EFO, and radiation exposure PIs.

All PIs, except cause codes, are sorted and analyzed to provide:

c) Each plant's six quarter moving average by quarter,

d) Composite six quarter moving average of the older plants by quarter, and

e) Composite eight quarter average of the newer plants.

The PC based analysis software, developed at AEOD and INEL, contains MODULA programs that are used to produce graphical output to present an integrated picture of the plant's operating history. Examples of the output are overlays of each plant's quarterly critical hours with scrams, SSAs, and radiation exposure rates. Items c) and d) are used for further trend and deviation analysis that will be described shortly. Items d) and e) originated early in the development of the PI Program, a time when a significant number of the total reactor population were plants with less than one calendar year of operation after receiving their full power license. Because of the time required to reach mature plant operations it was considered prudent to differentiate the older from the newer reactors. The need for this differentiation has decreased as newer plants have matured.

The second stage of data processing and analysis is directed towards determining short term trends in plant performance and long term deviation from industry average performance. The trend and deviation analysis values are based on event count differences divided by a normalizing factor.

A plant's short term performance trend, measured in standard deviations, is calculated by subtracting its average event count for the most recent two quarters from that of the most recent six quarters and then dividing by the 
standard deviation of the event counts for the most recent six quarters. Trends are calculated for all PIs except radiation exposure.

A plant's long term deviation from the industry average performance, measured in standard deviations, is calculated by subtracting the plant's average event count from the industry average event count (adjusted for new and outlier plants), for the most recent six quarters, and then dividing by the standard deviation of the industry's average event counts for the most recent six quarters (adjusted for new and outlier plants). Deviations are calculated for all PIs except for radiation exposure and cause codes.

\section{A.4 Reporting and Documentation of PIs}

All PI data are reported quarterly to the Commission and NRC senior managers (see Reference Al for a typical quarterly report). These reports are placed in the Public Document Room following dissemination to NRC Management and the Commission. The quarterly reports contain the type of analysis data described in Section A.3 for each plant not in long term shutdown (Part I). Additional details relating to the raw data collected for analysis is provided in Part II of each quarterly report. Specific plant data and the industry average data are reported quarterly to the respective 1 icensee managers and NRC Resident Inspectors.

While it is not possible to show all of the data contained in a quarterly report in this paper, Figures $A 1$ and $A 2$ illustrate the heart of the published information for a typical plant. Figure Al provides individual charts of the quarterly data trends for each of the PIs. Based on six-quarter moving averages, these charts display long term plant trends for each indicator. Except for the cause codes, these charts also display the industry six-quarter moving average to provide a comparative performance level. The six-quarter moving average is computed with industry mean values except for the safety system failures and collective radiation exposure being computed separately for boiling water reactors and pressurized water reactors. Additionally, distinctions in the industry average calculations are made based on plant age. For older plants, the industry averages are the older plant mean values; newer plants include both the newer plant and the older plant mean values. In addition, for the cause codes, individual bars displaying the actual quarterly indicator data values are not included. To present a picture of the plant's recent operating history, the plant's critical hours are included for automatic scrams while critical, safety. system actuations, and collective radiation exposure.

Figure A2 contains two charts that provide plant profiles of the trends and deviations from corresponding performance indicator values. The "Short Term Trends" chart displays the number of standard deviations by which the plant's moving average for the most recent two-quarter period varies from the plant's moving average for the most recent six-quarter period. This information is provided for all of the PIs except collective radiation exposure. The "Deviation From 01der Plant Means" chart displays the number of standard deviations by which the plant's moving average for the most recent six-quarter period varies from the industry's six-quarter moving average. Newer plant figures also contain a "Deviation From Newer Plant Means" chart that displays 
Figure ( )a

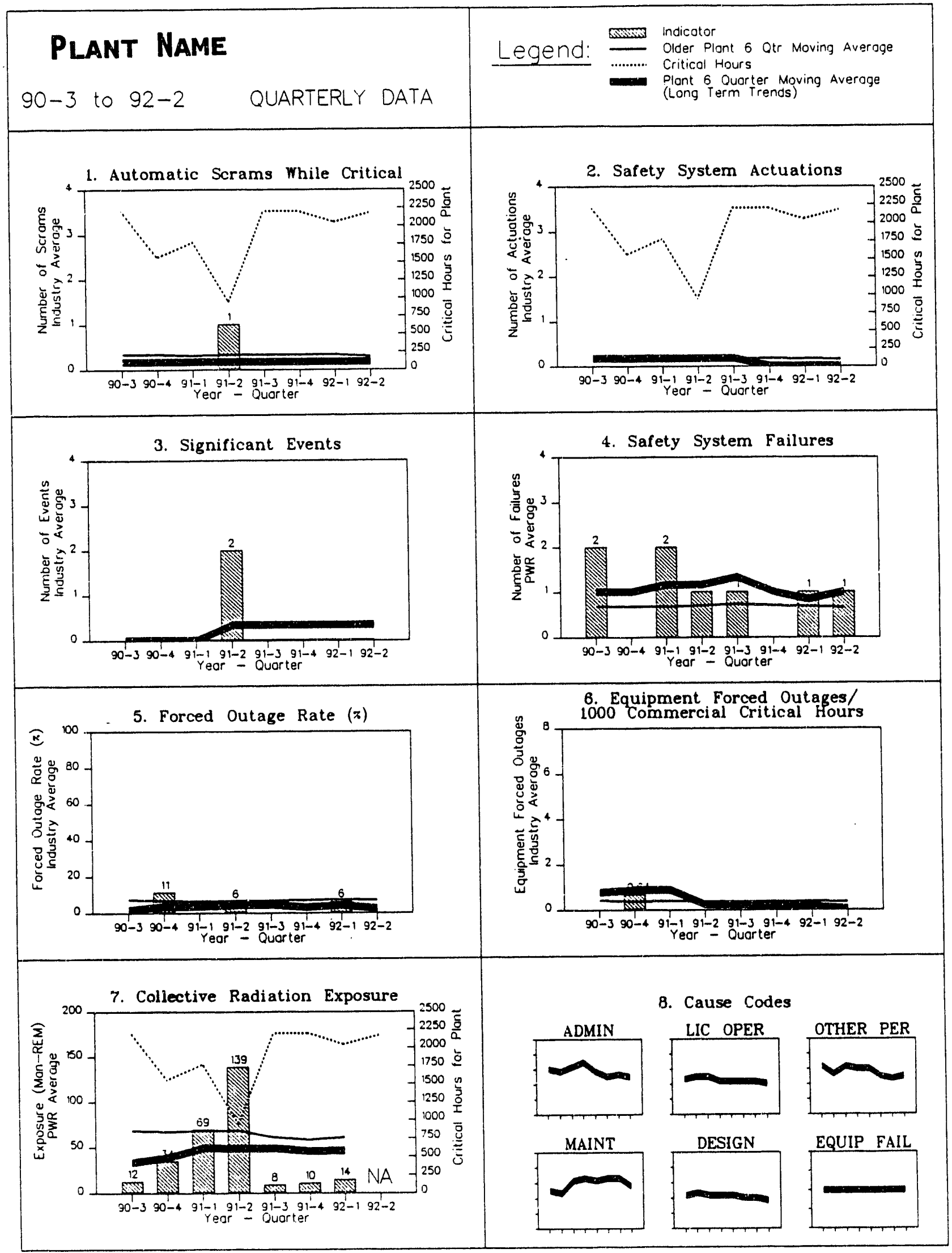

Figure A1. Illustration of plant specific PIs. 
Figure ( )b

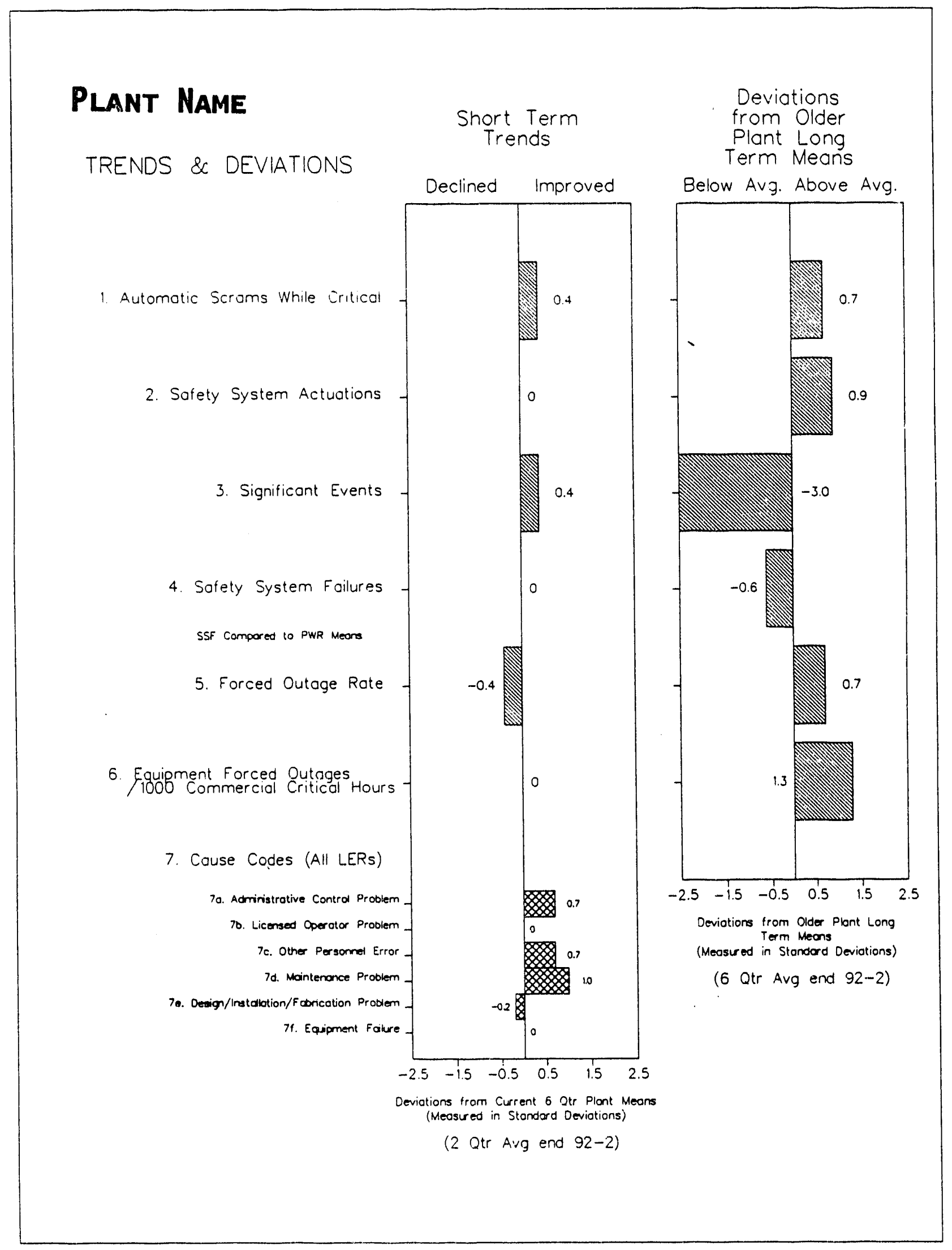

Figure A2. Illustration of plant specific trend and deviation data. 
the number of standard deviations by which the plant's moving average for the most recent six-quarter period varies from the newer plant industry's sixquarter moving average. These deviation charts are provided for all of the PIs except collective radiation exposure and cause codes.

In addition, the PI data are evaluated in the context of industry wide performance and reported annually (see Reference A2 for a typical annual report). The annual reports summarize the results of all of the AEOD programs to review and evaluate operating experience. Thus, these reports show how the information subset represented by the ?I program integrate with the other AEOD data collection and analysis programs to satisfy AEOD's independent monitoring role.

\section{A.6 U.S. NRC Announcement No. 200}

In the United States Nuclear Regulatory Commission Announcement No. 200 ${ }^{\mathrm{A3}}$, dated November 28, 1989, the purpose and specific criteria for the control and use of the Performance Indicator Program were described to the NRC staff. The purposes and specific criteria are as follows:

- The performance Indicator Program for operating reactors is a single, coordinated, overall NRC program under the direction of AEOD. NRC offices other than AEOD should not deviate from the NRC program without written permission of the EDO or the Director, AEOD.

- Performance Indicators are intended as a tool for senior NRC management to monitor trends in overall performance for a given plant. The performance indicators for a given plant should be viewed as a set. When viewed as a set, the performance indicators provide an additional measure of plant operational performance. However, they should not be used in communications with licensees as a measure of performance level.

- Performance indicators are intended to be one of several tools for use by senior NRC management in decision-making regarding $\mathrm{plant-specific}$ regulatory programs. Senior management in each NRC office should have access to performance indicators for their assigned unit(s).

Performance indicators are not to be overemphasized in relation to other measures of safety performance. For this reason, no regulatory action should be taken on the basis of Performance Indicator Program results alone.

- Performance indicators do not provide a valid basis for ranking individual nuclear power plants and should not be presented in such a way as to imply "problem facility" status for individual plants.

- The Performance Indicator Program is separate and distinct from the SALP program, although it is recognized that the indicators have relationships in varying degrees to SALP functional areas. Indicators, such as failures of a plant's safe y systems or frequent forced outages due to equipment failures, may be symptomatic of safety problems. Thus, the staff may recognize events and failures captured by certain indicators in SALP discussions and reports, but these SALP references 
are to be based on the underlying causes of poor performance and not on the results of the Performance Indicator Program, either individually or as a set. Regional Administrators should ensure that our decisionmaking process adheres to this guidance, especially in SALP discussions and documentation.

- NRC senior management should bear in mind when evaluating performance indicator results that the indicators are assessment tools and aid in identification of unanticipated performance, and the underlying causes should be carefully assessed, evaluated, and understood (factoring in other available information).

- Quarterly compilations of Performance Indicator Program results should be placed in the Public Document Room following dissemination to NRC management and the Commission.

In accordance with this announcement, the data are developed and presented in a format to clearly present the data trends. 


\section{A. 5 REFERENCES}

A1. U.S. Nuclear Regulatory Commission, Office for Analysis and Evaluation of Operational Data; Performance Indicators for Operating Commercial Nuclear Power Reactors, Report for Fourth Quarter 1991, Data through December 1991; Parts I and II.

A2. U.S. Nuclear Regulatory Commission, Office for Analys is and Evaluation of Operational Data; 1990 Annual Report, Power Reactors; NUREG-12.72, Vol. 5, No. 1 (July 1991).

A3. James M. Tayior, Acting Executive Director for Operations, Announcement 200 to all NRC employees on Revised Guidance on the Use of Performance Indicators, dated November 28, 1989. 


\section{APPENDIX B \\ Peer Group Analysis}

In the NRC Secretary's memorandum of August 10,1989, the Commission requested that the NRC staff assess the validity of comparing individual plants to their NSSS average groups. In response to this request, an evaluation was performed to identify the impact of different plant groupings on the performance indicator data. The evaluation resulted in an evaluation of combining plants into groupings named peer groups. This Appendix of the report documents the evaluation of these peer groups.

\section{B.1 Grouping Methodology}

The Peer Group Development Program resulted in nine peer groups being identified (Appendix D). The evaluation of the nine peer groups was performed and presented in an Oak Ridge National Laboratory (ORNL) report, ORNL/NOAC265. ${ }^{3}$ As presented in the referenced report, these nine peer group were identified based primarily on design factors with consideration given to NSSS supplier, product line, plant age, and reportability differences. In addition, the peer groups were established to ensure that the peer yroups were sufficiently large to provide statistically valid data but small enough to account for the individual plant design differences. The relevant elements considered for the design factors and plant population sizes are discussed in the following sections.

B.1.1 Plant Design Factors - To identify specific peer groups, the first criteria selected was general plant designs. This criteria were selected because if specific system or design criteria were used, since each plant is designed with different requirements, the peer groups would consist of one or two plants. Peer groups with one or two plants are too small to provide statistically valid data. For this reason the following general criteria were considered for the identification of peer groups:

- NSSS vendor - The nuclear steam supply system (NSSS) vendor is either Babcock \& Wilcox, Combustion Engineering, General Electric and Westinghouse. Each vendor has employed different design concepts; and therefore, each plant manufactured by the different NSSS vendors has difference operating characteristics.

- Product line - The design for each of the NSSS vendors has developed over the years. The changes have varied in areas such as thermal rating, number of coolant loops, containment design, emergency core cooling systems, and control and protection system technology.

- Age - The plant design relates to the age of the plant. Age criteria noted were: number of years of operation, year ordered, date of construction permit, date of operating license, year of intended operation, date of initial criticality, etc.

B.1.2 Peer Group Size - The peer group population size was studied to determine the minimum size acceptable for providing statistically valid data 
for performing PI deviation calculations. As presented in the ORNL report, the analysis of PI data began with estimating peer group parameters such as average number of events. For the use of these types of parameters, it was necessary to know the accuracy of the estimate of the parameter. A method often used to estimate the accuracy is to place a confidence interval on the parameter. The confidence interval was evaluated for this data and when the number of plants in a peer group was fewer than six, the confidence interval was wide and divergent. Peer groups with six or more plants tended to have relatively equal confidence intervals. Figure B-1 provides an example of how the confidence interval changed with the number of plants. The top plot shows the $\log$ of the factor and emphasizes the differences in the multiplication factor as the number of plants in the peer group changes. The bottom plot shows the linear plot of the factor and emphasizes how the factor converges across the confidence intervals as the number of plants increase. Figure B-1 illustrates how each peer group should have 6 or more plants.

\section{B.2 Peer Groups}

From the design factors and minimum peer group size the commercial nuclear power plants were separated into nine peer groups. The nine peer groups and the number of plants in each one are listed in Table B-1.

\begin{tabular}{|c|c|c|c|}
\hline Peer Group Designator & $\begin{array}{l}\text { No. of } \\
\text { Plants }\end{array}$ & Peer Group Designator & $\begin{array}{l}\text { No. of } \\
\text { Plants }\end{array}$ \\
\hline Small Westinghouse & 9 & GE - Pre-TMI 2, $3 \& 4$ & 23 \\
\hline 3-10op Westinghouse & 10 & GE - Post-TMI $5 \& 6$ & 14 \\
\hline 4-10op Westinghouse & 9 & $C E$ - Without CPC* & 8 \\
\hline $\begin{array}{l}\text { New } 3-\text { and } 4-100 p \\
\text { West inghouse }\end{array}$ & 24 & CE - With CPC* & 7 \\
\hline$B \& W$ & 7 & & \\
\hline
\end{tabular}

An analysis of variance of the PI data, by peer group, was performed. The results of the analysis noted that relationships could be established between the peer groups and the most frequently occurring indicators (administrative cause code, maintenance error cause code, other personnel error cause code, and safety systern failures). The relationships were not highly correlated but were related. It was noted that the PI data do not reflect the design differences within the peer groups. 


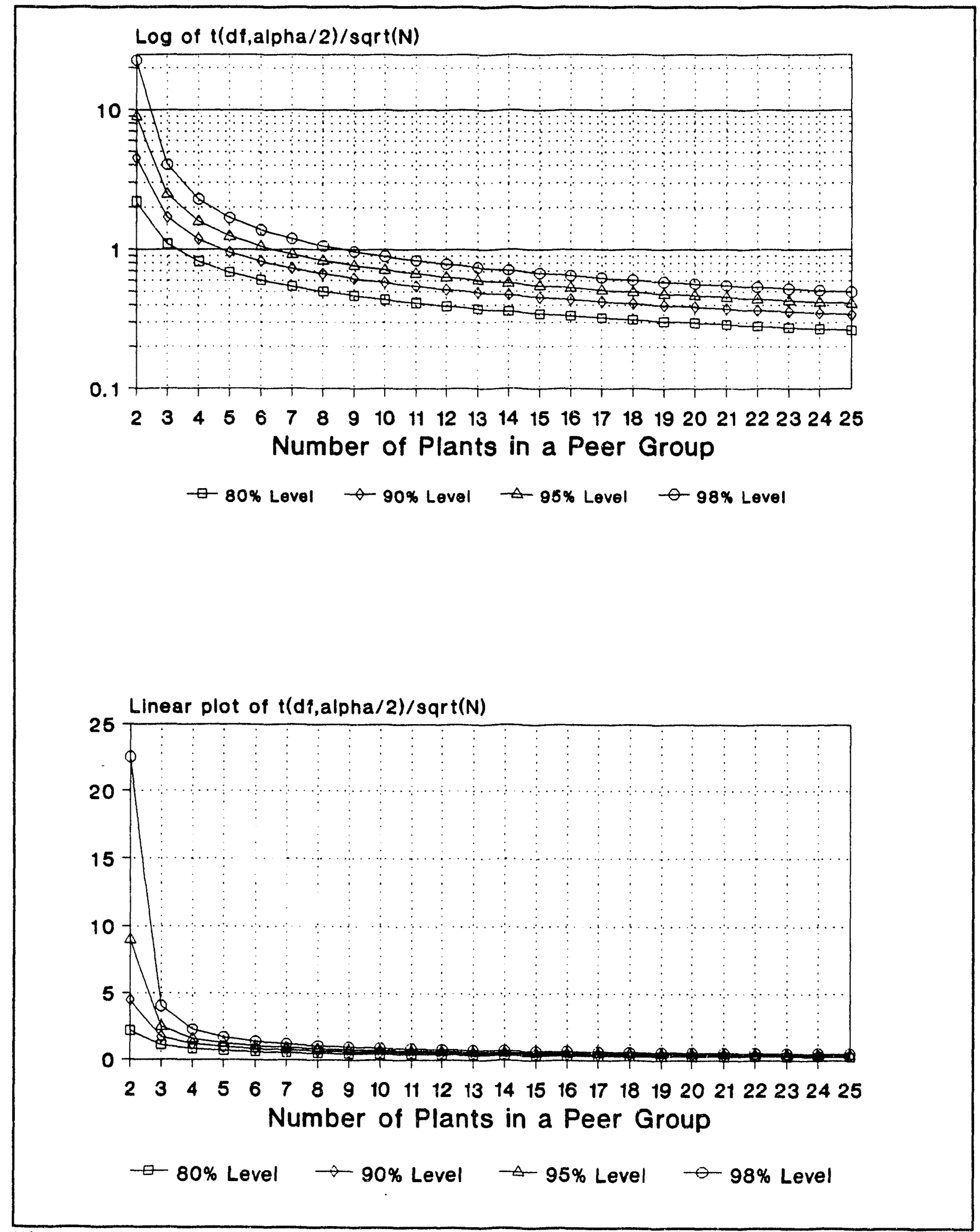

Figure B-1. Multiplying factors of the standard deviation for confidence intervals. 


\section{B.3 REFERENCES}

B1 Oak Ridge National Laboratory, Development and Evaluation of Proposed Modifications to the Nuclear Regulatory Commission's Performance Indicator Program, ORNL/NOAC-265, Martin Marietta Energy Systems, Inc. (July 1991). 


\section{APPENDIX C \\ Summary of Input from Other Organizations}

To minimize uncertainty and potential operational dissimilarities within the peer groups, input from other organizations in the commercial industry was solicited. Table $\mathrm{C}-1$ provides a summary of the responses and who provided the information.

\begin{tabular}{|c|c|}
\hline Organization & Summary of Information Provided \\
\hline $\begin{array}{l}\text { General Electric } \\
\text { (San Jose, CA) }\end{array}$ & $\begin{array}{l}\text { Plants are generally grouped by product line (l.e.. BWR/2s are grouped together, BWR/3s together, etc.). } \\
\text { Studies to evaluate specific hardware performance may result in different groups approprlate to those studies. } \\
\text { Comments from the BWR Scram Frequency Reduction Owner's Group generally centered on plant availability. } \\
\text { Other comments concerned reportablity differences among the large number of BW/2R/2, BWR/3, and BWR/4 } \\
\text { plants due, in part, to the age differences between the plants. The age difference affects both equipment and } \\
\text { dlstinguishes certain regulatory issues. Recommendations were made to incorporate a plant's age in its } \\
\text { current fuel cycle in the display of PI data. }\end{array}$ \\
\hline $\begin{array}{l}\text { Westinghouse } \\
\text { (Pittsburgh, PA) }\end{array}$ & $\begin{array}{l}\text { Comments from the Westinghouse Owner's Group Steering Committee centered on age differences between } \\
\text { the Westinghouse 3-Loop and 4-Loop plants and on reportability differences among the plants due to } \\
\text { dlfferences In technical speciflcations. The group also commented that technical specifications had a larger } \\
\text { effect on reportability than did the number of loops. }\end{array}$ \\
\hline $\begin{array}{l}\text { Combustion Englineering } \\
\text { (Windsor, } \mathrm{CT} \text { ) }\end{array}$ & $\begin{array}{l}\text { CE plants are generally classiffed in two groups: newer plants that utllize the Core Protection Calculators } \\
\text { (CPCS) and older plants that do not. These two groups are frequently used for general plant classifications. } \\
\text { Studles to evaluate speciffc hardware performance may group the CE plant differently so that attentlon can be } \\
\text { focused on the item of interest. }\end{array}$ \\
\hline $\begin{array}{l}\text { Babcock and Wilcox } \\
\text { (ORNL Personnel) }\end{array}$ & $\begin{array}{l}\text { It Is acceptable to group all B\&W plants into one group: however. Davis-Besse does have some major design } \\
\text { differences trom the others. }\end{array}$ \\
\hline $\begin{array}{l}\text { Stoller Power Corporation } \\
\text { (Boulder, CO) }\end{array}$ & $\begin{array}{l}\text { Stoller Identifled the following groups as typlcal of what they may use in plant studles: } \\
\text { 1) CE plants classified in two groups: those that have CPC and those that do not. } \\
\text { 2) GE plants grouped as follows: (a) BWR/2s, (b) BWR/3s and } 45 \text { grouped } \\
\text { together and (c) BWR/5s and } 6 s \text { grouped together. } \\
\text { 3) Group all B\&W plants together. } \\
\text { 4) Group Westinghouse plants according to the number of coolant loops with } \\
\text { some special exceptions for the very old or small 3-loop and 4-loop plants. }\end{array}$ \\
\hline $\begin{array}{l}\text { NRC Technical Training Center } \\
\text { (Chattanooga. TN }\end{array}$ & $\begin{array}{l}\text { The NRC Technical Training Center recommended the following peer groups: } \\
\text { 1) Group all B\&W plants together. } \\
\text { 2) Two groups of CE plants: those with dlgital RPS Instrumentation and those } \\
\text { without digital RPS instrumentation } \\
\text { 3) Westinghouse plants grouped according to the number of coolant loops with } \\
\text { speclal exceptions for certain 3-loop and 4-loop plants. } \\
\text { 4) GE plants based upon class: (a) BWR/2s as one group. (b) BWR/3s as } \\
\text { another, (c) BWR/4s as another, (they noted that this may cause a problem with } \\
\text { a few of the BWR/4s that have certain design similarities to the BWR/3s, and (d) } \\
\text { the BWR/5s and BWR/6s grouped together. }\end{array}$ \\
\hline $\begin{array}{l}\text { Statistician } \\
\text { (ORNL Personnel) }\end{array}$ & $\begin{array}{l}\text { ORNL recommended that the minimum number of plants in a group be at least six to maintain consistent } \\
\text { confldence intervals. }\end{array}$ \\
\hline
\end{tabular}

Using the information provided in Table $\mathrm{C}-1$ and the experience of the ORNL personnel, the peer groups were modified using this input. From the above input and the analyses describe in Appendix $B$, nine peer groups were developed. A listing of all plants in each peer group is provided in Appendix D. 


\section{APPENDIX D}

\section{Peer Group Plant Listing}

The peer groups used in the PI deviation analysis were selected to optimally satisfy two criterion:

1) Each peer group should be sufficiently large to contain statistically val id PI data, and

2) Each peer group should be sufficiently small to contain plants having significantly similar design and operational features.

The peer groups and specific plants included in each peer group are listed in Tables D-1 through D-8.

Table D-1. 2-Loop and small 3 and 4-Loop Westinghouse plants

\begin{tabular}{|c|c|c|c|c|}
\hline FID & DOCKET & PLANT NAME & VENDOR & $\begin{array}{l}\text { NUMBER } \\
\text { OF LOOPS } \\
\end{array}$ \\
\hline $\begin{array}{l}\text { REG1 } \\
\text { HNP1 } \\
\text { KNP1 } \\
\text { PBH1 } \\
\text { PBH2 } \\
\text { PIN1 } \\
\text { PIN2 } \\
\text { SOS1 } \\
\text { YKR1 }\end{array}$ & $\begin{array}{l}244 \\
213 \\
305 \\
266 \\
301 \\
282 \\
306 \\
206 \\
029\end{array}$ & $\begin{array}{l}\text { GINNA } \\
\text { HADDAM NECK } \\
\text { KEWAUNEE } \\
\text { POINT BEACH } 1 \\
\text { POINT BEACH } 2 \\
\text { PRAIRIE ISLAND } 1 \\
\text { PRAIRIE ISLAND } 2 \\
\text { SAN ONOFRE } 1 \\
\text { YANKEE-ROWE }\end{array}$ & $\begin{array}{l}\text { WE } \\
\text { WE } \\
\text { WE } \\
\text { WE } \\
\text { WE } \\
\text { WE } \\
\text { WE } \\
\text { WE } \\
\text { WE }\end{array}$ & $\begin{array}{l}2 \\
4 \\
2 \\
2 \\
2 \\
2 \\
2 \\
3 \\
4\end{array}$ \\
\hline
\end{tabular}

Table D-2. 01der 3-Loop Westinghouse plants

\begin{tabular}{lllll}
\hline FID & DOCKET & PLANT NAME & \multicolumn{2}{c}{ NUMBER } \\
\cline { 2 - 3 } BVS1 & 334 & BEAVER VALLEY 1 & WE & 3 \\
JMF1 & 348 & FARLEY 1 & WE & 3 \\
JMF2 & 364 & FARLEY 2 & WE & 3 \\
NAS1 & 338 & NORTH ANNA 1 & WE & 3 \\
NAS2 & 339 & NORTH ANNA 2 & WE & 3 \\
HBR2 & 261 & ROBINSON 2 & WE & 3 \\
SPS1 & 280 & SURRY 1 & WE & 3 \\
SPS2 & 281 & SURRY 2 & WE & 3 \\
TPS3 & 250 & TURKEY POINT 3 & WE & 3 \\
TPS4 & 251 & TURKEY POINT 4 & WE & 3 \\
& & & & \\
\hline
\end{tabular}


Table D-3. 01der 4-Loop Westinghouse plants

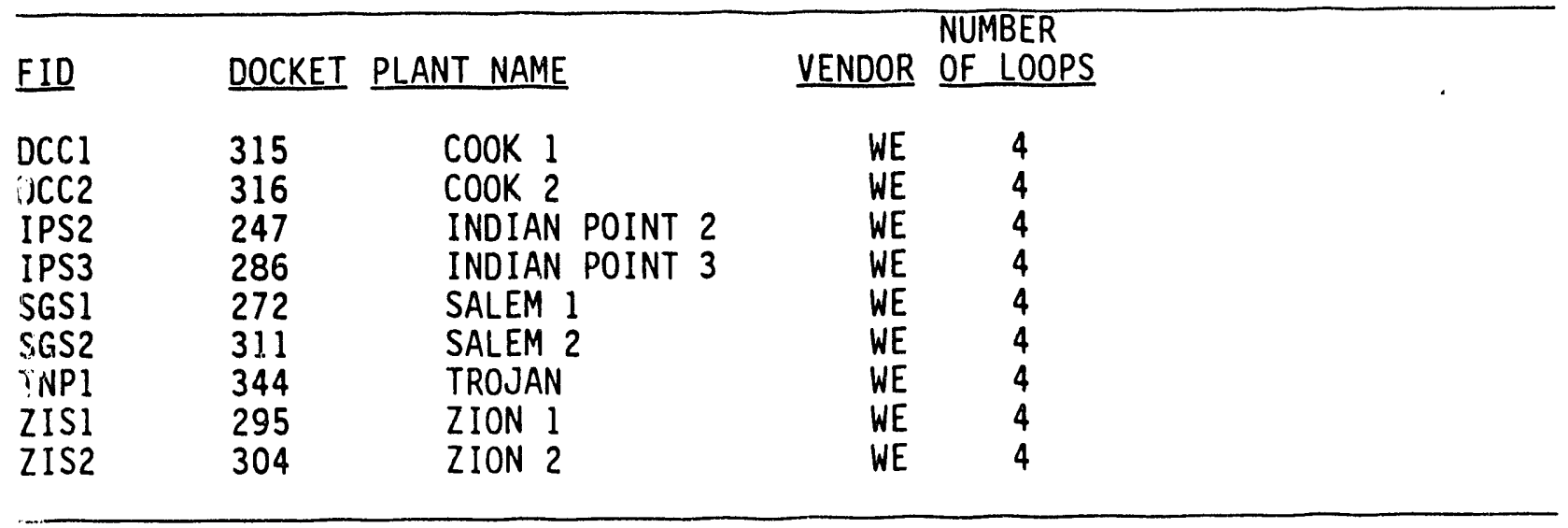

Table D-4. New 3- and 4-Loop Westinghouse plants

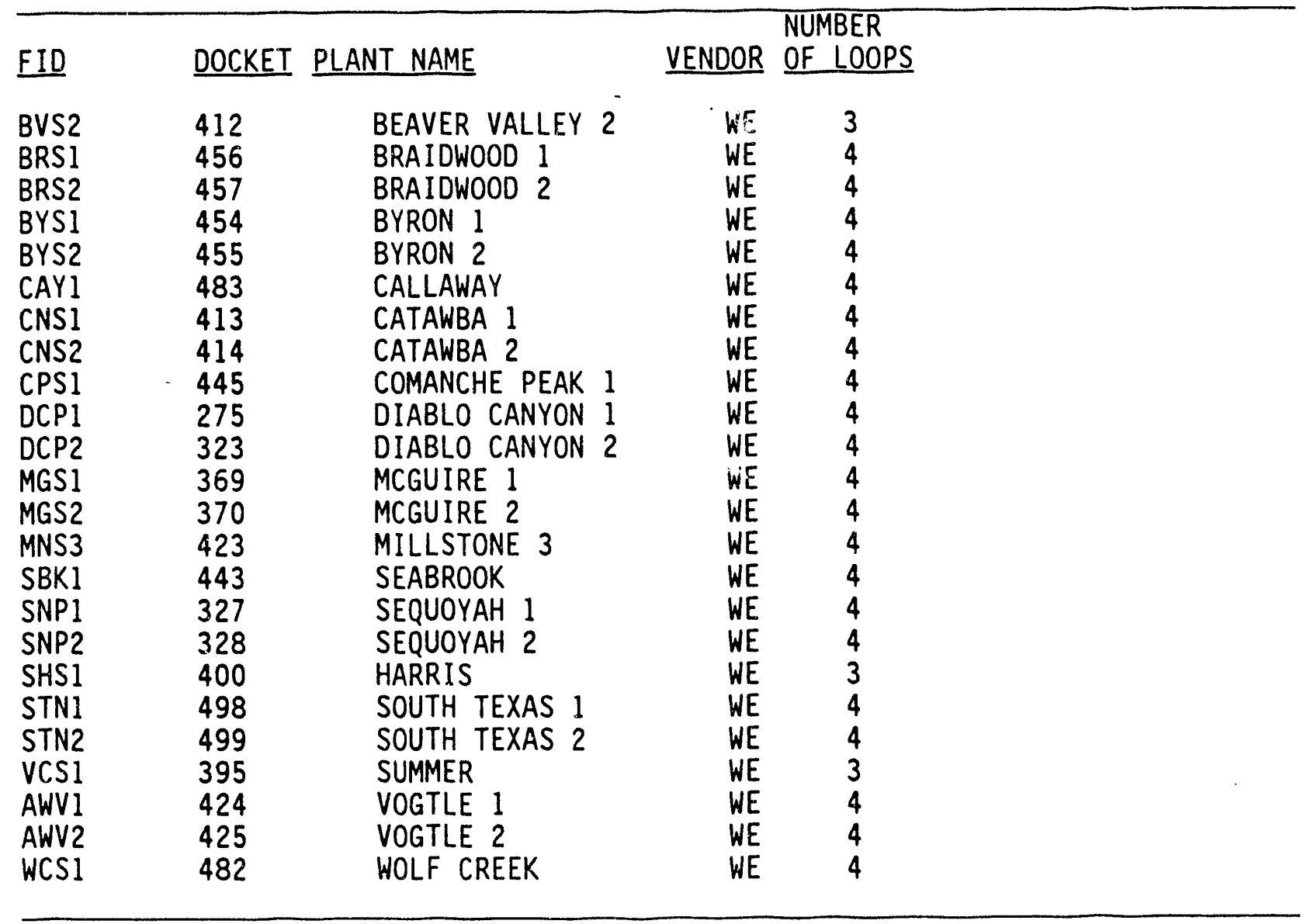


Table D-5. Pre-TMI General Electric plants

\begin{tabular}{|c|c|c|c|c|}
\hline FID & DOCKET & PLANT NAME & VENDOR & $\underline{\text { CLASS }}$ \\
\hline $\begin{array}{l}\text { BRP1 } \\
\text { BRF1 } \\
\text { BRF2 } \\
\text { BRF3 } \\
\text { BEP1 } \\
\text { BEP2 } \\
\text { CPR1 } \\
\text { DRS2 } \\
\text { DRS3 } \\
\text { DAC1 } \\
\text { JAF1 } \\
\text { EIH1 } \\
\text { EIH2 } \\
\text { MNS1 } \\
\text { MNP1 } \\
\text { NMP1 } \\
\text { OCP1 } \\
\text { PBS2 } \\
\text { PBS3 } \\
\text { PPS1 } \\
\text { QAD1 } \\
\text { QAD2 } \\
\text { VYS1 }\end{array}$ & $\begin{array}{l}155 \\
259 \\
260 \\
296 \\
325 \\
324 \\
298 \\
237 \\
249 \\
331 \\
333 \\
321 \\
366 \\
245 \\
263 \\
220 \\
229 \\
277 \\
278 \\
293 \\
254 \\
265 \\
271\end{array}$ & $\begin{array}{l}\text { BIG ROCK POINT } \\
\text { BROWNS FERRY } 1 \\
\text { BROWNS FERRY } 2 \\
\text { BROWNS FERRY } 3 \\
\text { BRUNSWICK } 1 \\
\text { BRUNSWICK } 2 \\
\text { COOPER STATION } \\
\text { DRESDEN } 2 \\
\text { DRESDEN } 3 \\
\text { DUANE ARNOLD } \\
\text { FITZPATRICK } \\
\text { HATCH } 1 \\
\text { HATCH } 2 \\
\text { MILLSTONE } 1 \\
\text { MONTICELOO } \\
\text { NINE MILE PT. } 1 \\
\text { OYSTER CREEK } \\
\text { PEACH BOTTOM } 2 \\
\text { PEACH BOTTOM } 3 \\
\text { PILGRIM } \\
\text { QUAD CITIES } 1 \\
\text { QUAD CITIES } 2 \\
\text { VERN JNT YANKEE }\end{array}$ & $\begin{array}{l}\mathrm{GE} \\
\mathrm{GE} \\
\mathrm{Gi} \\
\mathrm{GE} \\
\mathrm{GE} \\
\mathrm{GE} \\
\mathrm{GE} \\
\mathrm{GE} \\
\mathrm{GE} \\
\mathrm{GE} \\
\mathrm{GE} \\
\mathrm{GE} \\
\mathrm{GE} \\
\mathrm{GE} \\
\mathrm{GE} \\
\mathrm{GE} \\
\mathrm{GE} \\
\mathrm{GE} \\
\mathrm{GE} \\
\mathrm{GE} \\
\mathrm{GE} \\
\mathrm{GE} \\
\mathrm{GE}\end{array}$ & $\begin{array}{ll}0 \\
\text { B-CLASS } & 4 \\
\text { B-CLASS } & 4 \\
\text { B-CLASS } & 4 \\
\text { B-CLASS } & 4 \\
\text { B-CLASS } & 4 \\
\text { B-CLASS } & 4 \\
\text { B-CLASS } & 3 \\
\text { B-CLASS } & 3 \\
\text { B-CLASS } & 4 \\
\text { B-CLASS } & 4 \\
\text { B-CLASS } & 4 \\
\text { B-CLASS } & 4 \\
\text { B-CLASS } & 3 \\
\text { B-CLSS } & 3 \\
\text { B-CLASS } & 2 \\
\text { B-CLASS } & 2 \\
\text { B-CLASS } & 4 \\
\text { B-CLASS } & 4 \\
\text { B-CLASS } & 3 \\
\text { B-CLASS } & 3 \\
\text { B-CLASS } & 3 \\
\text { B-CLASS } & 4\end{array}$ \\
\hline
\end{tabular}

Table D-6. Post-TMI General Electric plants

\begin{tabular}{|c|c|c|c|c|}
\hline$\overline{\text { FID }}$ & DOCKET & PLANT NAME & VENDOR & CLASS \\
\hline $\begin{array}{l}\text { CPP1 } \\
\text { EFP2 } \\
\text { GGS1 } \\
\text { HCS1 } \\
\text { LSC1 } \\
\text { LSC2 } \\
\text { LGS1 } \\
\text { LGS2 } \\
\text { NMP2 } \\
\text { PNP1 } \\
\text { RBS1 } \\
\text { SES1 } \\
\text { SES2 } \\
\text { WNP2 }\end{array}$ & $\begin{array}{l}461 \\
341 \\
416 \\
354 \\
373 \\
374 \\
352 \\
353 \\
410 \\
440 \\
458 \\
387 \\
388 \\
397\end{array}$ & $\begin{array}{l}\text { CLINTON } 1 \\
\text { FERMI } 2 \\
\text { GRAND GULF } \\
\text { HOPE CREEK } \\
\text { LASALLE } 1 \\
\text { LASALLE } 2 \\
\text { LIMERICK } 1 \\
\text { LIMERICK } 2 \\
\text { NINE MILE PT. }{ }^{\circ} 2 \\
\text { PERRY } \\
\text { RIVER BEND } \\
\text { SUSQUEHANNA } 1 \\
\text { SUSQUEHANNA } 2 \\
\text { WASH. NUCLEAR } 2\end{array}$ & $\begin{array}{l}\mathrm{GE} \\
\mathrm{GE} \\
\mathrm{GE} \\
\mathrm{GE} \\
\mathrm{GE} \\
\mathrm{GE} \\
\mathrm{GE} \\
\mathrm{GE} \\
\mathrm{GE} \\
\mathrm{GE} \\
\mathrm{GE} \\
\mathrm{GE} \\
\mathrm{GE} \\
\mathrm{GE}\end{array}$ & 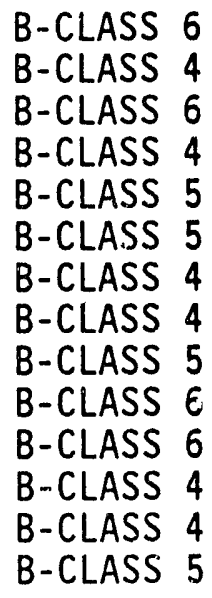 \\
\hline
\end{tabular}


Table D-7. All Babcock and Wilcox plants

\begin{tabular}{|c|c|c|c|c|}
\hline$\underline{F I D}$ & DOCKET & PLANT NAME & VENDOR & $\begin{array}{l}\text { NUMBER } \\
\text { OF LOOPS }\end{array}$ \\
\hline $\begin{array}{l}\text { AN01 } \\
\text { CRP3 } \\
\text { DBS1 } \\
\text { NEE1 } \\
\text { NEE2 } \\
\text { NEE3 } \\
\text { TMI1 }\end{array}$ & $\begin{array}{l}313 \\
302 \\
346 \\
269 \\
270 \\
287 \\
289\end{array}$ & $\begin{array}{l}\text { ARKANSAS } 1 \\
\text { CRYSTAL RIVER } 3 \\
\text { DAVIS-BESSE } \\
\text { OCONEE } 1 \\
\text { OCONEE } 2 \\
\text { OCONEE } 3 \\
\text { THREE MILE ISL } 1\end{array}$ & $\begin{array}{l}\mathrm{BW} \\
\mathrm{BW} \\
\mathrm{BW} \\
\mathrm{BW} \\
\mathrm{BW} \\
\mathrm{BW} \\
\mathrm{BW}\end{array}$ & $\begin{array}{l}2 \\
2 \\
2 \\
2 \\
2 \\
2 \\
2\end{array}$ \\
\hline
\end{tabular}

Table D-8. Combustion Engineering plants without a core protection calculator

\begin{tabular}{lllll}
\hline FID & \multicolumn{2}{c}{ DOCKET } & PLANT NAME & \multicolumn{2}{c}{ NUMBER } \\
\cline { 3 - 5 } CCN1 & 317 & CALVERT CLIFFS 1 & CE & 2 \\
CCN2 & 318 & CALVERT CLIFFS 2 & CE & 2 \\
FCS1 & 285 & FORT CALHOUN & CE & 2 \\
MYP1 & 309 & MAINE YANKEE & CE & 3 \\
MNS2 & 336 & MILLSTONE 2 & CE & 2 \\
PAL1 & 255 & PALISADES & CE & 2 \\
SLS1 & 335 & ST. LUCIE 1 & CE & 2 \\
SLS2 & 389 & ST. LUCIE 2 & CE & 2 \\
& & & &
\end{tabular}

Table D-9. Combustion Engineering plants with core protection calculators

\begin{tabular}{|c|c|c|c|c|}
\hline$\underline{F I D}$ & DOCKET & PLANT NAME & VENDOR & $\begin{array}{l}\text { NUMBER } \\
\text { OF LOOPS }\end{array}$ \\
\hline $\begin{array}{l}\text { ANO2 } \\
\text { PAV1 } \\
\text { PAV2 } \\
\text { PAV3 } \\
\text { SOS2 } \\
\text { SOS3 } \\
\text { WGS3 }\end{array}$ & $\begin{array}{l}368 \\
528 \\
529 \\
530 \\
361 \\
362 \\
382\end{array}$ & $\begin{array}{l}\text { ARKANSAS } 2 \\
\text { PALO VERDE } 1 \\
\text { PALO VERDE } 2 \\
\text { PALO VERDE } \\
\text { SAN ONOFRE } 2 \\
\text { SAN ONOFRE } 3 \\
\text { WATERFORD } 3\end{array}$ & $\begin{array}{l}C E \\
C E \\
C E \\
C E \\
C E \\
C E \\
C E\end{array}$ & $\begin{array}{l}2 \\
2 \\
2 \\
2 \\
2 \\
2 \\
2\end{array}$ \\
\hline
\end{tabular}




\section{APPENDIX E}

Further Development of Operational Cycle

Trend and Deviation Measures for the Performance Indicators 


\section{FURTHER DEVELOPMENT OF OPERATIONAL CYCLE TREND AND DEVIATION MEASURES FOR THE PERFORMANCE INDICATORS}

H. M. Stromberg

C. D. Gentillon

January 10, 1992

Idaho National Engineering Laboratory

EG\&G Idaho, Inc.

Idaho Falls, Idaho 83415

Prepared for the

U.S. Nuclear Regulatory Commission

Washington, D.C. 20555

Under DOE Contract No. DE-AC07-76ID01570

Under FIN D6152 


\section{ABSTRACT}

The presentations of the NRC/AEOD performance indicator program has undergone a number of enhancements. These enhancements allow a more accurate evaluation of the operating commercial nuclear power plants performance. Accurate performance evaluation and plant trending by the performance indicator program are integral parts of monitoring the operation of nuclear power plants. The diversity of the commercial nuclear plants, coupled with continued improvements in the performance indicator program, has resulted in the evaluation of plants in logical peer groups and highlighted the need to evaluate the impact of plant operational conditions on the performance indicators.

This report presents methods to enhance the presentation of the performance indicator data by displaying the trend and deviation data based on the operational status of the plants. Previously, in EGG-EAST-9107, Operational Cycle Effects on the Performance Indicators, and EGG-EAST-9445, Operational Cycle Adjustments to the Performance Indicators, preliminary development of the operational cycle displays of the performance indicator data was documented. This report extends the earlier findings and presents the continued development of the operational cycle trend and deviation data and displays.

This report describes enhancements to the operational cycle phase breakdowns, calculation methods, and presentation methods.

FIN NO. D6152--Special Projects 


\section{SUMMARY}

The U.S. Nuclear Regulatory Commission's (NRC's) Office for Analysis and Evaluation of Operational Data (AEOD) has been pursuing a method for enhancing the presentation of performance indicator trends and deviations. The efforts for this study have been directed at developing and verifying a methodology for presenting the performance indicator data that accounts for the impact of plant operating conditions experienced during an operational cycle. This development was a joint undertaking by the $\mathrm{NRC} / \mathrm{AEOD}$ and EG\&G Idaho, Inc. at the Idaho National Engineering Laboratory (INEL).

The operational cycle methodology was originally presented in the INEL report, EGGEAST-9107, Operational Cycle Effects on the Performance Indicators, and EGG-EAST-9445, Operational Cycle Adjustments to the Performance Indicators. The operational cycle trend and deviation calculation methodology begins with a file of all commercial nuclear power plant outages, uses the outages and identifies the dates when plant operating conditions change, aggregates a plant's performance indicator data by operating conditions, computes the number of days each plant spends in the different operating conditions, and computes peer group rates based on the aggregation. Using these data points, performance indicator trends and deviations adjusted for operational cycle effects are calculated.

The original reports were reviewed by numerous individuals. Based on the reviews, five enhancements were identified that could make the operational cycle methodology more effective. This report documents the enhancements mate to the operational cycle trend and deviation program.

The first of these enhancements was the modification of phase breakdown. The five operational cycle phases (startup, operations, pre-refueling, and refueling and non-refueling outages) were combined into two phase types: operational and shutdown.

The second enhancement was to study and display the performance in operational periods separately from performance in shutdown periods. This provides twice as many displays, but also twice as much information.

The third enhancement is that the frame of reference under evaluation is expanded. For trends, rather than the most recent two quarters (approximately 180 days), the most recent 270 days of power operation and the most recent 180 shutdown days are evaluated. For deviations, rather than the most recent six quarters (approximately 540 days), the most recent 720 days of power operation and the most recent 360 shutdown days are evaluated for deviations.

The fourth enhancement relates to the statistical significance of observed trends and deviations. The new methods employ specific significance tests for trends and deviations. The tests are based on the true nature of the data; that is, on the fact that the event performance indicators supply event counts which are not normally distributed. Since the statistical analysis is performed separately, the basic difference between plant-specific trend or deviation measures can be shown. The denominator then becomes a scaling factor used to display results from different performance indicators on a single set of axes.

Finally, enhancements were made to the methods for calculating trends and deviations. For trends, rates of change in counts (slopes) are used as the performance measure for trends instead of counts. The use of slopes has intuitive appeal; it shows the general pattern of each set of data. Since the focus for trend evaluation is on a longer period of time, and the method is as sensitive to changes early in the period as to changes late in the period, the new trend evaluations show long-term changes in plant performance.

For deviations, the enhancement was to scale the difference between peer group medians and plant-specific operational or shutdown performance indicator event rates for display. 


\section{CONTENTS}

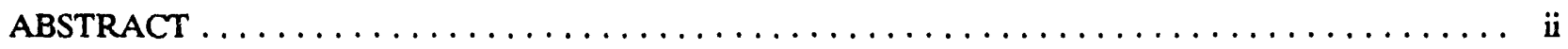

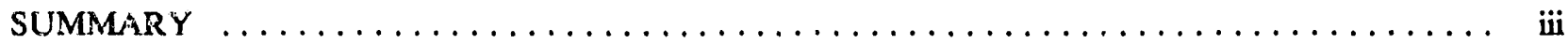

ACKNOWLEDGMENTS $\ldots \ldots \ldots \ldots \ldots \ldots \ldots \ldots \ldots \ldots \ldots \ldots \ldots \ldots \ldots \ldots \ldots \ldots \ldots$

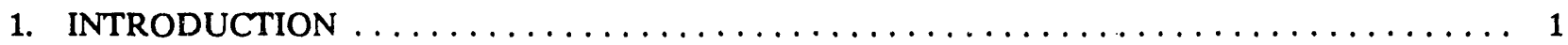

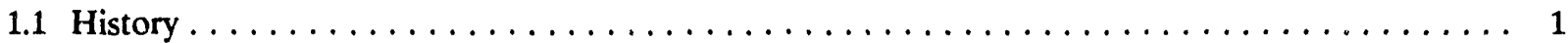

1.2 Overview of Operational Cycle Trends and Deviation Displays of the Performance Indicators . . 2

2. OPERATIONAL CYCLE PHASE BREAKDOWN $\ldots \ldots \ldots \ldots \ldots \ldots \ldots \ldots \ldots \ldots \ldots$

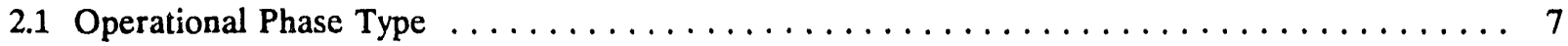

2.2 Shutdown Phase Type $\ldots \ldots \ldots \ldots \ldots \ldots \ldots \ldots \ldots \ldots \ldots \ldots \ldots \ldots \ldots \ldots$

3. CALCULATION METHODS $\ldots \ldots \ldots \ldots \ldots \ldots \ldots \ldots \ldots \ldots \ldots \ldots \ldots \ldots \ldots \ldots$

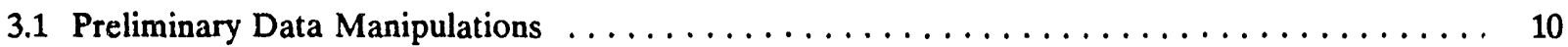

3.2 Trend Measure Numerators $\ldots \ldots \ldots \ldots \ldots \ldots \ldots \ldots \ldots \ldots \ldots \ldots \ldots \ldots \ldots \ldots$

3.3 Deviation Measure Numerators $\ldots \ldots \ldots \ldots \ldots \ldots \ldots \ldots \ldots \ldots \ldots \ldots \ldots \ldots \ldots$

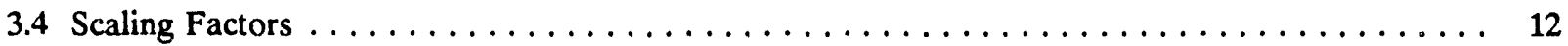

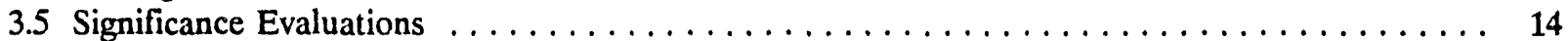

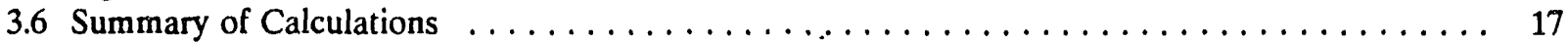

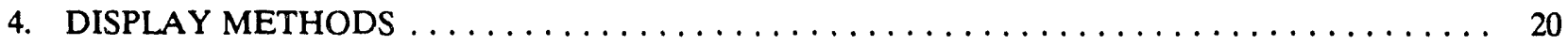

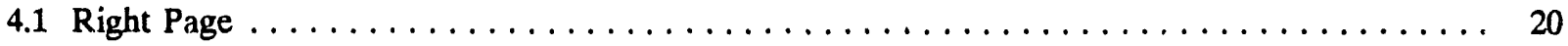

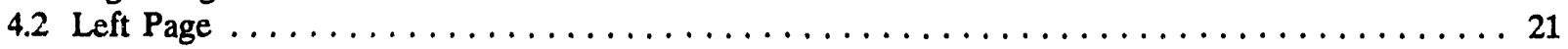

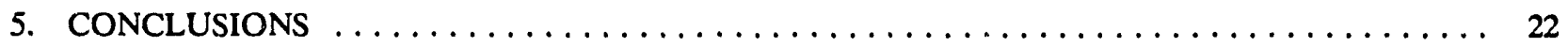

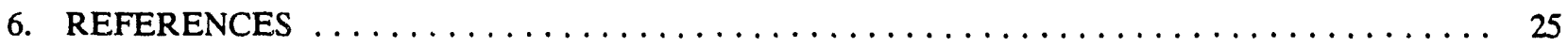

APPENDIX A. ADDITIONAL IMPLEMENTATION DETAILS $\ldots \ldots \ldots \ldots \ldots \ldots \ldots \ldots \ldots$

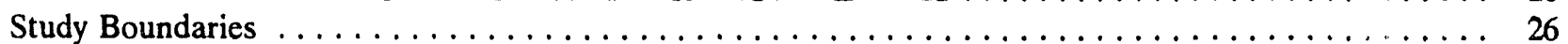

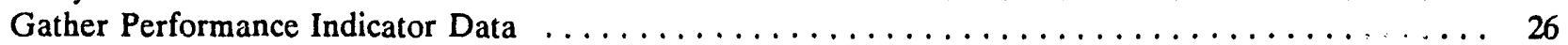

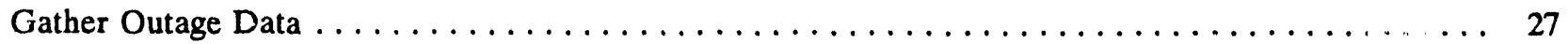

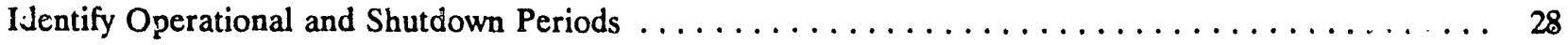

APPENDIX B. CALCULATION OF SLOPE THRESHOLDS $\ldots \ldots \ldots \ldots \ldots \ldots \ldots \ldots \ldots \ldots$

\section{FIGURES}

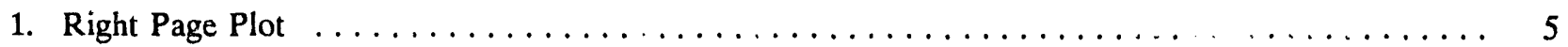

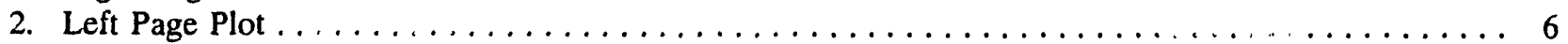




\section{TABLES}

1. Summary of performance indicator trend and deviation calculations $\ldots \ldots \ldots$

A-1. Use of LERs to adjust outage dates $\ldots \ldots \ldots \ldots \ldots \ldots \ldots \ldots$

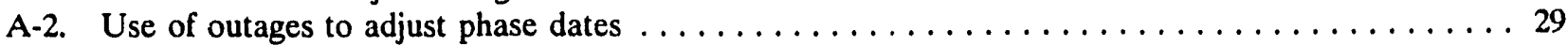

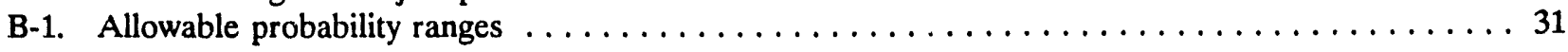




\section{ACKNOWLEDGMENTS}

This work would not be possible without the ongoing support of personnel in the U.S. NRC's Office for Analysis and Evaluation of Operational Data, Trends and Patterns Branch. Support and suggestions from the technical monitor, D. Hickman, and other members of the Trends and Patterns Branch staff including B. Brady, T. Wolf, and R. Prato are gratefully acknowledged.

R. Schmoyer from Oak Ridge National Laboratory is acknowledged for proposing methods for evaluating the significance of the PIs and for supplying the initial set of slope threshold values for the trend assessments.

J. Bryce and T. Smith from EG\&G Idaho, Inc. are thanked for their helpful suggestions and review comments. 


\section{Further Development of Operational Cycle Trend and Deviation Measures for the Performance Indicators}

\section{INTRODUCTION}

The U.S. Nuclear Regulatory Commission's (NRC's) Office for Analysis and Evaluation of Operational Data (AEOD) maintains the commercial nuclear power plant performance indicator program. As an output for the performance indicator program, the Performance Indicator Report is issued quarterly. Recently, the Performance Indicator Report has undergone a number of enhancements. This report presents a development of the most recently proposed enhancements to the operational cycle displays of the performance indicator trends and deviations. This evaluation was a joint undertaking by the NRC/AEOD and by EG\&G Idaho, Inc. at the Idaho National Engineering Laboratory (INEL).

\subsection{History}

The NRC has initiated a program where selected events experienced at commercial nuclear power plants are recorded and tracked as indicators of the effectiveness of plant operational performance. A description of the indicator events, trends, and comparisons is presented quarterly in a Performance Indicator Report. Since June 1990, the presentation of indicator data has undergone a number of enhancements. The goal of these enhancements has been to improve the presentation of the performance indicators to enable a more accurate evaluation of plant performance based on plant self-trends and a performance deviation with the plant's peers.

The first of these enhancements was to change the calculation technique from a four quarter moving average to a six quarter moving average for the industry deviation plots of the individual performance indicators. This change was implemented to remove the cyclic behavior experienced when short periods of time are used for evaluation. The enhancement was first presented in Performance Indicators for Operating Commercial Nuclear Power Reactors, Report for Second Quarter 1990. Data through June 1990. ${ }^{1}$
The second enhancement that has been initiated, and is currently under consideration, is the peer group categorization of the plants. In the past, the peer group calculations were performed by combining all plants in one of two categories, mature plants or new plants, and calculating the peer group average. This method allowed a comparison of each plant to a peer group of all mature plants or new plants depending on the number of years that the plant had been in commercial operation. However, a peer group categorization of new and mature plants does not allow each plant to be easily compared to plants with the same operating characteristics or designs. As an example, the boiling water reactors were considered in the same peer group as the pressurized water reactors for all but safety system failures and radiation exposure, even though the operating characteristics are significantly different. So that a comparison can be made between each plant and the plants with similar operating characteristics, a peer group study was initiated. The plant peer group categorization by more representative groups is currently being evaluated.

The third enhancement was to change the peer group calculations from a pooled average to a six quartèr moving average for indicators other than forced outage rate and equipment forced outage. This change was implemented so that the peer group calculation techniques would be consistent with the calculations performed for the plant. The enhancement was first presented in the Performance Indicators for Operating Commercial Nuclear Power Reactors, Report for Third Quarter 1990. Data through October $1990 .{ }^{2}$

A fourth proposed enhancement to the performance indicator report presentation has been identified. This enhancement is to display the performance indicator data based on the operational history of the plant. The first reporting on this effort was issued in June 1990 as EGG-EAST-9107, Operational Cycle Effects on the Performance Indicators. ${ }^{3}$ This report documented the results of 
a preliminary development of the operational cycle adjustments to the performance indicators and identified a number of areas that required further evaluation for the adjustments to be completely understood and implemented. The second reporting on this effort was issued in February 1991 in EGGEAST-9445, Operational Cycle Adjustments to The Performance Indicators. ${ }^{4}$ This report documented the results of further development of the operational cycle adjustments.

A treatise on the enhancements to the operational cycle calculations for the plant's performance indicator trend and deviation data, presented in the Performance Indicator Report, is the subject of this report. The operational cycle data have been developed for all indicators except forced outage rate, radiation exposure, and equipment forced outage.

A description of the operational cycle phase breakdown techniques is presented in Section 2. The presentation begins with a discussion of the segments of the operational cycle (termed operational cycle phases).

Section 3 presents a discussion of the calculation methods used in displaying the performance indicators for the operational cycle impact.

In Section 4 of this report, a discussion of the display is provided.

The conclusions are provided in Section 5.

\subsection{Overview of Operational Cycle Trends and Deviation Displays of the Performance Indicators}

A description of the operational cycle display and calculations of the performance indicator trends and deviations are the topics of this section.

\subsubsection{Objectives}

The trend and deviation presentation of the performance indicators are the primary contents of the Performance Indicator Report. Enhancements to the way the data is presented in the report is the purpose for this development program.
When the displays of the data were considered, the following criteria were identified as requirements to be addressed (i.e., objectives):

- Present the data.

- Show trends in a plant's performance compared to its prior performance.

- Show deviations between a plant's performance and that of its peers.

- Account for the fact that certain performance indicator events occur more often in certain operational plant states.

- Provide measures of the statistical significance of observed trends and deviations.

The first objective is met by bar chart displays on the left-hand page of each plant's presentation. The second and third objectives are met by the display of performance indicator displays on the right-hand pages. The right-hand displays are unitless measures of each plant's performance, as shown by each performance indicator, during a particular time period of interest. Four performance indicator displays exist for each performance indicator (given sufficient data): two trend displays comparing a plant with its own past performance, and two deviation displays contrasting a plant's performance indicator event count with that of plants in the same peer group. For both trend and deviation displays, separate displays show operational and shutdown experience. Statistically significant displays are shaded.

\subsubsection{Description of the Operational Cycle Methodology}

The operational cycle has discernible impact on the performance indicators. Some indicators are more sensitive to the operational cycle than others; however, data for the scrams, safety system actuations, safety system failures, significant events, and all cause code performance indicator trends and peer group deviation display have been developed. Using the display data, the effectiveness of plant performance can be kiore accurately characterized based on the operational history of the plant. 
The current Performance Indicator Report is based on quarterly event count differences divided by a normalizing factor. The trend value is a comparison between the plant's average counts for the past six quarters and the most recent two quarters. The deviation value is the comparison between the industry average counts for the most recent six quarters and the plant's average counts for the most recent six quarters.

The operational cycle method takes a similar approach for calculating the trend and deviation indications. However, separate indications are computed for operational and shutdown periods.

Another difference is that the trend indication is based on slopes of linear regression lines fitted to event counts in 20- or 30-day segments of the most recent, respectively, shutdown and operational time periods. The numbers of events each plant experienced in th $;$ most recent 270 days of operation are counted in 30-day increments. The numbers of events each plant experienced in the most recent 180 shutdown days are counted in 20day increments. Two linear regression lines are computed, and the resulting slopes are scaled to describe rates of change in counts per 90 days. These slopes form the basis for the trend indications. Thus, rather than forming a difference in two average counts, the single slope is evaluated for each plant, performance indicator, and phase type. The absolute value of the slope is small when no trends exist. In forming the indications, each slope is subtracted from zero and normalized so the different performance indicator slopes can be plotted on a single graph.

The deviation indication is based on the number of events each plant experienced in the most recent 720 days of operation and 360 days of shutdown. The total number of events in each of these periods for each plant and performance indicator is expressed in units of events per 30 days. In each peer group, the median event rate for each performance indicator and phase type is identified. The indications are normalized versions of the differences between the corresponding median rates and the plant-specific rates. This is similar to the current approach, except that medians are used, the comparisons are performed on a peer group level, and separate indications are computed for operational and shutdown periods.
The operational cycle indications have two other differences compared with those in the current performance indicator displays. First, statistical significance tests are performed. Since plants are compared with their own past performance and with the performance of other similar plants in the plant summaries, comparison of plant data with other data is the focus of the summaries. Knowledge of whether the data provides sufficient evidence to observe trends or between-plant deviations is important additional information in interpreting the importance of the data in the summaries. Further details of the calculations including the statistical tests are included in Section 3.

Performance indicator displays, for a sample plant, are presented in Figures 1 and 2. In Figure 1 , the plant self-trend is presented on the left side of the figure and plant deviation from the peer group is presented on the right side. As can be seen from the example, in the plant's self-trend indicators, when the plant's most recent operations and shutdown periods were compared to past operations and shutdown periods, it can be noted that, for operations, all indicators were improved except design/installation/fabrication problem cause code. For shutdown periods, all indicators were improved except for safety system actuations and administrative control problem cause code. In the deviation display, when the sample plant's performance indicator rates for the most recent operations and shutdown periods were compared to the peer group median event rates, for operations, the displays were above average for safety system failures, licensed operator error cause code, design/installation/fabrication problem cause code, and equipment failure cause code. For shutdowns, the displays were above average for all indicators except design/installation/fabrication problem cause code. The forced outage rate was improved for the plant self-trend and below average for the peer group deviation. Equipment forced outages per 1000 critical hours was improved for the plant selftrend and above average for the deviation. Note that the forced outage rate and equipment forced outage performance indicators are not calculated using the operational cycle methodology and that the scram trend and deviations displays are not presented for shutdown periods because the plant needs to be in operation for the scram to be a valid performance indicator. 
In Figure 1, it can be noted that three of the performance displays indicated a highly significant trend: from the plant self-trend display, the operations phase type maintenance problem, and from the deviation display the operations phase type safety system actuations and shutdown phase type maintenance problem.

Figure 2 presents the sample plant's quarterly counts of the performance indicator events. The different shading shows the number of events that occurred during startup operation, power operations (including pre-refueling), and shutdown periods. Note that the forced outage rate, equipment forced outage, and radiation exposure indicators are not shown separately, by operational phase type, because these indicators describe information over intervals of time and are not discrete events. Also, no scram indicators will be indicated for the shutdown periods because the plant needs to be in operation for the scram to be a performance indicator.

A more detailed discussion of the display is presented in Section 4 of this report.

\subsubsection{Non-Operational Cycle Trend and Deviation Displays}

There are two trends and deviations displays on the right page that have not been calculated considering the impact of the operational cycle. These two displays are the equipment forced outages per 1000 commercial hours and the forced outage rate. The trends displays are calculated by computing the difference between the plant's average rate for the most recent two quarters and the plant's average rate for the most recent six quarters and dividing the difference by the standard deviation based on the plant's most recent sixquarter period data. The deviation displays are calculated by computing the difference between the plant's average rate for the most recent six quarters and the industry's average (without outliers) for the most recent six quarters and dividing the difference by the standard deviation based on the industry's most recent six quarters of data (without outliers). 
FIGURE

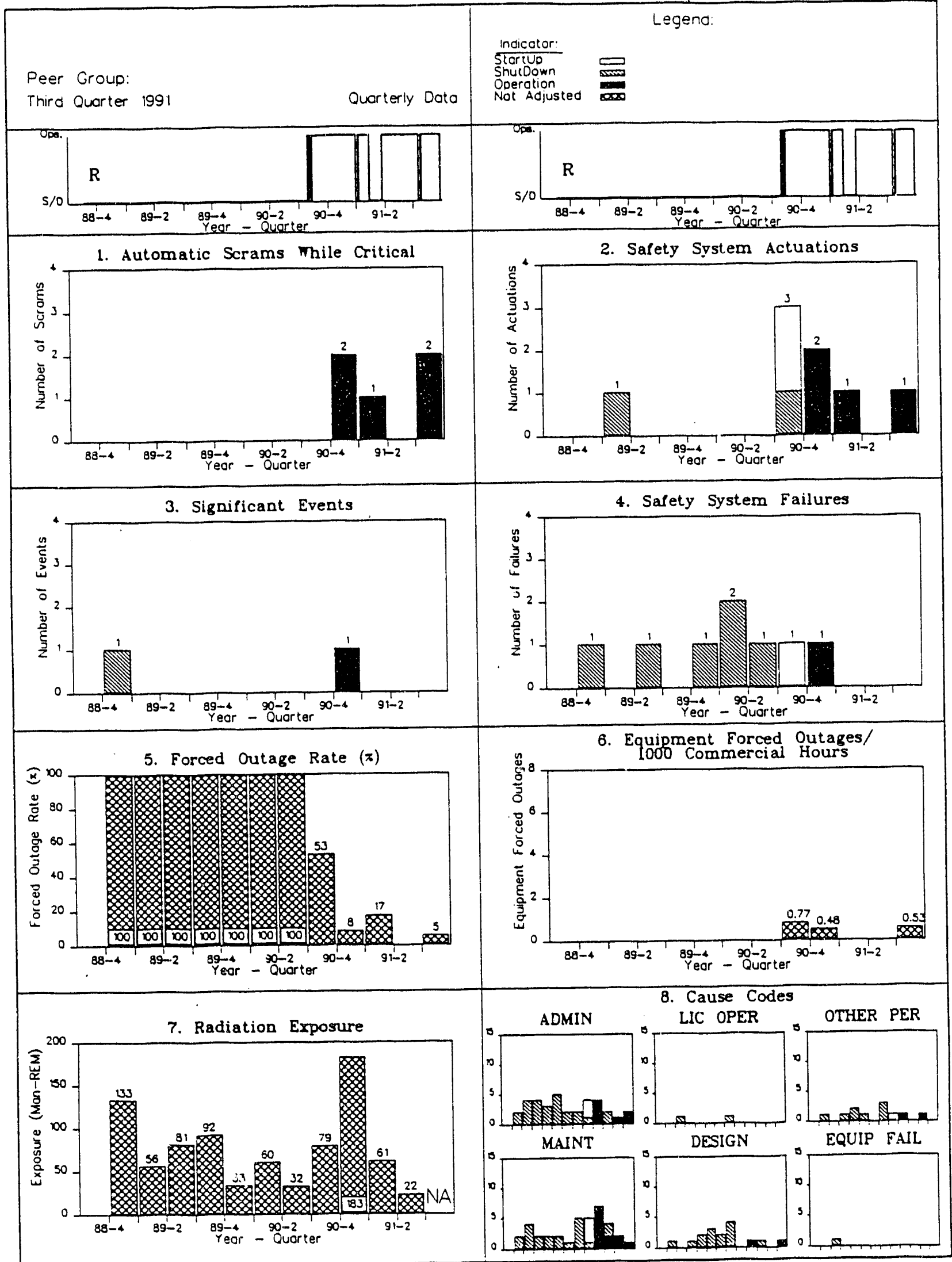

Figure 1. Right Page. 


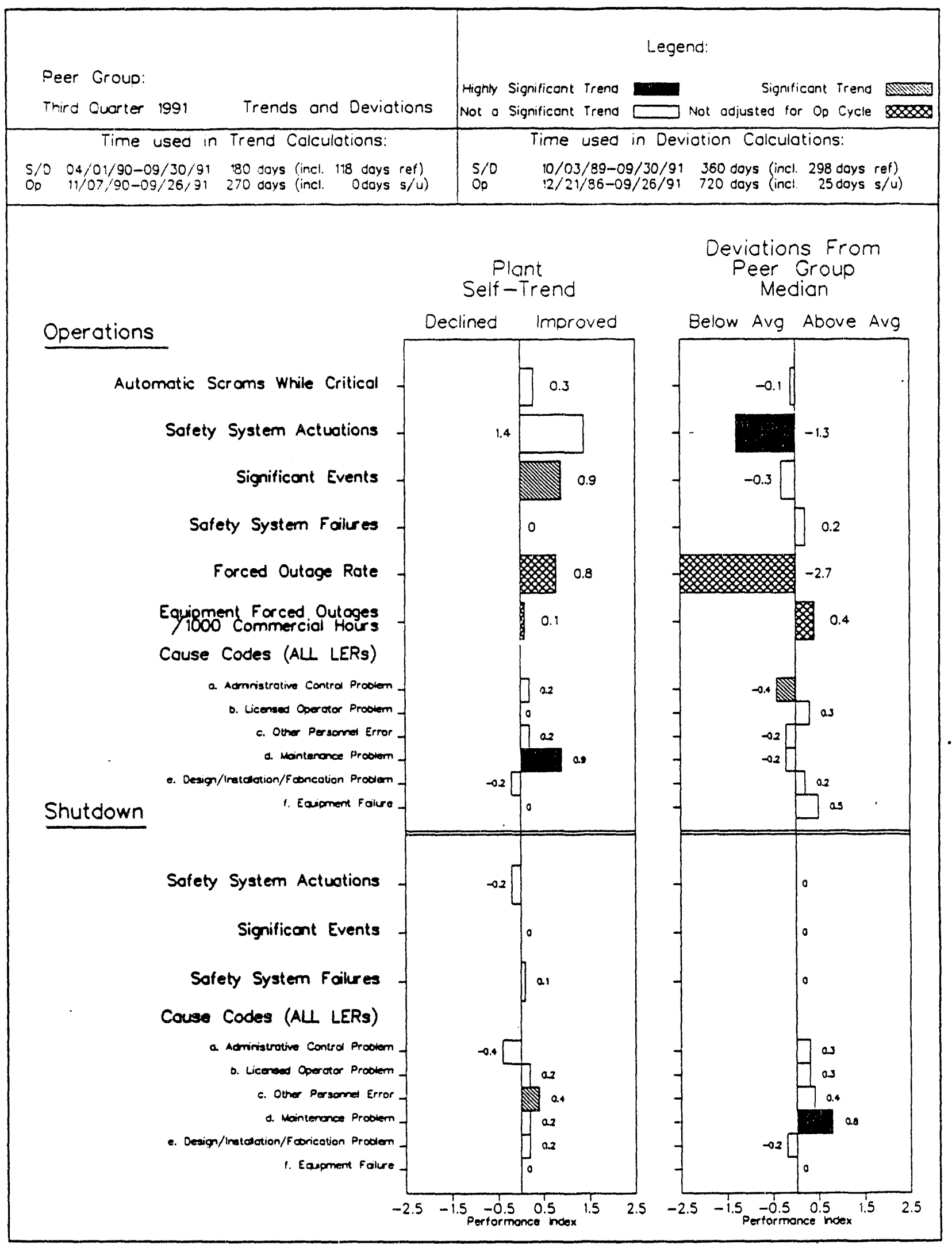

Figure 2. Left Page. 


\section{OPERATIONAL CYCLE PHASE BREAKDOWN}

The operational cycle methodology calculates the performance indicator trend and deviation in a manner that accounts for operational cycle effects. The operational cycle phase types on which the calculations are based, and the use of the phase types in implementing the displays are discussed in detail in this section of the report.

The operational cycle is defined as plant operations following recovery from a cold shutdown, after a refueling outage, to ready for recovery from cold shutdown in the next refueling outage. This cycle was studied in detail. The study evaluated the most optimum way for subdividing the operational cycle to facilitate event analysis. The divisions were defined giving consideration to the different operating conditions in a plant's operational cycle. The development of the operational cycle divisions, termed operational cycle phases, resulted in five phases being identified.

The goal of dividing the operational cycle into phases was to divide each plant's operational cycle into periods of operations where the operating characteristics and activities performed within each period were similar, but differ from that of the previous or subsequent periods. The operational cycle was ultimately resolved into five phases: startup, operations, pre-refueling, refueling outages, and non-refueling outages. One of the enhancements to be discussed in this report is the combination of the phases in a manner that reduces the number of phases while maintaining the phase identity and allowing a logical presentation of the trend and deviation data.

The phase enhancement was made by combining the phases by type. There are two types of phases in the phase breakdown structure: operational and shutdown phases. The operational type phases are: startup, operations, and prerefueling. The shutdown type phases are the refueling and non-refueling outages.

The five individual phases are maintained as part of the available information. However, the phase type breakdown was used for the calculation methods presented in Section 3 and display methodology discussed in Section 4. More detailed discussions of the phase types are provided in the following subsections.

\subsection{Operational Phase Type}

This section of the report provides a definition of the operational phase type and major considerations for the definition.

Operational Phase Type Definition - The operational phase type is defined as the period of the operational cycle that begins as the plant leaves the cold shutdown mode, following a refueling outage, and continues until a plant enters cold shutdown for the next refueling outage. The periods of time where the plant experiences significant plant shutdowns or extended outages are not considered to be part of the operations phase type. The operational phase type is an aggregation of three phases: start-up, operations, and prerefueling.

Previous studies ${ }^{3}$ of performance indicator occurrence rates have shown that the start-up phase is statistically significantly different from power operations, particularly for scrams and maintenance cause events. The pre-refueling phase was not found to have a discernable impact on the event rates. However, the largest difference in occurrence rates was between operations and shutdown. Therefore, the plant summary data is based on combining experience across all three operational phases. However, the number of days in start-up is listed in the descriptions of the times used in the plant summary, and the detailed quarterly counts on the left pages are separately labelled for start-up.

A definition of each phase is provided below so that the bounds of the operational phase type can be clearly understood.

Start-up Phase Definition - The start-up phase is the period of the operational cycle that begins as the plant leaves the cold shutdown mode, following a refueling outage, and continues for 25 days with the plant in either start-up or power operation mode. Periods of time, if any, when the plant is shutdown for four or more days are not considered to be part of the start-up phase.

Power Operations Phase Definition - The power operations phase is the period of the operational cycle that begins at the completion 
of the start-up phase and continues until the beginning of the pre-refueling phase. The segments of the phase where the plant is shutdown for four or more days are not considered to be part of the power operations phase.

Pre-refueling Phase Definition - The prerefueling phase is the period of the operational cycle that begins 25 days prior to entering cold shutdown for a refueling outage and ends when the plant enters the cold shutdown for refueling. Periods of time where other significant plant shutdowns are experienced, if any, are not considered to be part of the prerefueling phase.

\subsection{Shutdown Phase Type}

This section of the report provides a definition of the shutdown phase type and major considerations for the phase.

Shutdown Phase Type Definition - The shutdown phase type is the periods of the operational cycle that begins when a plant shuts down and is shut down for four or more days and periods when a plant is in cold shut down for a refueling outage. The shutdown phase type is an aggregation of two phases: refueling outage and non-refueling outage phases.
Refueling is important because all plants routinely require such outages and because some refueling activities are performed by virtually all plants. Among non-refueling outages, less event homogeneity exists. However, the event occurrence rates for refueling has been shown to be significantly statistically different than for nonrefueling outages for just one peer group for three indicators (see Reference 3, p. 34). Thus, combining non-refueling and refueling data for the plant summaries seems reasonable. Furthermore, the number of days in refueling is listed in the descriptions of the times used in the plant summary.

A definition of each phase is provided below so that the bounds of the shutdown phase type can be clearly understood.

Refueling Phase Definition - The refueling phase is the period of the operational cycle that begins when a plant shuts down and enters cold shutdown for a refueling outage and ends when the plant leaves the cold shutdown mode following the refueling.

Non-refueling Outage Phase Definition - The non-refueling outage phase is an aggregation of outages, other than refueling outages, during the start-up, power operations, and prerefueling phases where the plant is shut down for four or more days. 


\section{C.LCULATION MFTHODS}

The purpose of this section is to describe the calculation of operational cycle trend and deviation measures for the performance indicators. Steps leading up to and including the computation of trend and deviation values for the plant summaries are described in subsections below.

The following requirements were considered in the development of the trend and deviation calculation methods:

- The methods must, as a minimum, distinguish between operational and shutdown periods, since certain performance indicators occur more often in shutdown periods and others occur more often in operational periods.

- The methods must generate both trend and deviation performance measures.

- The trend values must reflect short term plant performance. A display of longterm trends would also be desirable, but is of lower priority; such a display may at some time be developed.

- The deviation calculation must reflect long term performance. In the current Performance Indicator Report, the most recent six quarters of data are used in the deviation displays and six-quarter moving averages are plotted with the raw data. The current methods consider the most recent two years (720 days) of operational experience.

- The methods must use shorter time periods in the evaluation of shutdown experience, since plants spend less time in shutdowns. The most recent 180 days of shutdown experience are used for the trend values and the most recent 360 days for the shutdown deviation values.

- The methods must scale the performance indicator trend and deviation indications to plot data for all performance indicators on one set of axes.
An important assumption that underlies all the current operational cycle performance indicator data evaluation methods is the validity of examining a fixed number of days of operational experience and a fixed number of days of shutdown experience for each plant's evaluation. In this process, separate operational times are regarded as a continuum and separate shutdown periods are treated as a continuum. Such periods of evaluation may in fact be made of several separate pieces of experience separated by lengthy operational or outage periods. Future refinements to the methodology will include special treatment of plants with insufficient data and plants coming out of extremely long outages.

The methods described herein pertain to event-related performance indicators; that is, performance indicators that are counts of events that occurred on particular dates. The methods do not apply to other types of performance indicators, such as forced outage rates or radiation exposures which indicate monthly or quarterly performance and are not separate events.

In all cases, the trend and deviation measures that result from the operational cycle methods are differences divided by scaling factors. That is,

Trend or deviation measure $=[$ (comparison value) - (plant-specific performance attribute)] / scaling factor.

The differences are plant-specific event counts or other performance attributes subtracted from nominal, average numbers of events or other measures. The resulting trend and deviation indications more accurately reflect plant performance than the performance indicator plant summary displays currently used in the NRC's quarterly Performance Indicator Reports because they compensate for operational cycle effects.

Preliminary data manipulations are described in the next section. Then, in a subsection describing trend performance measures and a subsection describing deviation measures, the plant-specific performance attributes and the nominal (comparison) values are described. These calculations are performed separately for operational and shutdown period data. The final subsections describe the calculation of scaling factors and the assessment of 
statistical significance for each event type. The calculation methods are then summarized.

\subsection{Preliminary Data Manipulations}

The following are initial steps for the computation of both trend and deviation performance measures.

- Each plant's history is split into operational and shutdown periods. Operational periods are power operations, start-up, and pre-refueling. Shutdown periods comprise both refueling and non-refueling outages. Regulatory shutdown periods are excluded. Appendix A contains further information on which plants are included in the analysis and how their plant histories are split up.

- A period for evaluation is selected for each phase type (operations or shutdown) and analysis type (trends or deviations); e.g., the most recent 270 days in operations for trend studies. Regard such a period as a continuum (even though it may be made of several separate pieces of experience separated by lengthy outages or operational periods).

- Each study period is partitioned into equal-length segments (e.g., 30-day operational periods or 20-day shutdown periods). The resulting segment lengths for operational periods and for shutdown periods may differ.

- The number of events is counted for each particular plant and performance indicator for each segment in the time spanned by the trend or deviation studies.

In accordance with the requirements stated above, the periods selected for evaluation are as follows:

\section{Trends Deviations}

Operational periods

Shutdown periods

$\begin{array}{ll}270 \text { days } & 720 \text { days } \\ 180 \text { days } & 360 \text { days }\end{array}$

The selection of partitions for the operational and shutdown periods is particularly crucial for the trend evaluations. For deviations, the period under evaluation is treated as a single contiguous period of operation, and counts for different segments are summed. For trend analysis, the counts are examined to see if they increase or decrease. The selection of partitions for trends was based on qualitative evaluations of the results of different segment length choices. Thirty-day and twenty-day partitions were selected for operational and shutdown periods, respectively, so that each complete trend analysis period would be split into nine segments for evaluation.

\subsection{Trend Measure Numerators}

The plant-specific performance attribute for studying trends is based on the slope of a line fitted to the count versus time segment data. For example, the nine 30-day operational segments are numbered from one to nine, and each has a corresponding event count (some of which could be zero). Consider a plot of the (segment number, event count) data with the first time segment as the oldest and the ninth as the most recent time period under study. The slope of the line that minimizes the sum of the squares of the deviations between the observed event counts and the y-axis values on the line is the basis for the plant-specific trend performance measure.

The slope is computed as follows. $S N$ is defined as the number of segments ( 9 in this case), $S X$ is the sum of the segment numbers (45), $S X X$ is the sum of the squares of the segment numbers (285), $S Y$ is the sum of the observed counts for the nine segments, and $S X Y$ is the sum of the cross-products, i.e., the sum of segment number times event count terms. Then, from standard statistics techniques, the computed slope is

$$
B=\left(S X Y-S X^{*} S Y / S N\right) /\left(S X X-S X^{*} S X / S N\right) \text {. }
$$

This slope describes the rate of change in the event count as time changes across the nine thirty-day intervals.

Note that, for some plants, less than nine full intervals of data are available. The 9,45 , and 285 figures cited above are not required in the calculations; these apply to the full-data cases. At least two intervals are required to compute a slope. 
This slope is multiplied by a factor to compute the actual plant-specific performance measure used for the plant summary trend values. The factor is based on the fact that a computed slope value depends on the choice of partitions for the period under study. For nine thirty-day periods, the slope is the rate of change in thirty-day counts as a function of changes in the segment count index as it goes from one to nine. If the same 270 operational days were divided into three 90 -diny periods, the slope computed as above would be the change in 90-day counts as a function of changes in the segment count index as it goes from one to three, and would be much higher. In the ninety-day analysis, changes in the counts would be three times as much as such changes for thirty-day periods. On the other hand, in the ninety-day analysis, changes in the $x$-axis time segment index would be one-third as much (from one to three instead of from one to nine). The net change in the slope (change in $y$ divided by change in $x$ ) would thus be a factor of nine. More generally, the difference in slope values as a function of the size of the intervals compared to a baseline interval size is

$$
\begin{aligned}
& \text { Computed slope }=\text { Baseline slope }{ }^{*} \\
& (\text { computed interval size } / \text { baseline interval size })^{2} .
\end{aligned}
$$

Since ninety days represents approximately one quarter, changes in count rates per ninety days was selected as the output unit for the slope calculations. Thus, the baseline interval size is ninety days, but for operations the interval size used in the computations is thirty days. The thirty-day computed slopes were multiplied by a conversion factor of nine to obtain rates of change per ninety days. For shutdown data, 180-day evaluation periods were divided into nine 20-day periods for the calculations. Thus, the conversion factor for shutdown data slopes was $(90 / 20)^{*}(90 / 20)$, or 20.25 .

The choice of the partition of the trend study periods into intervals deserves further comment. With more and shorter intervals, more of the actual date information is used. However, the data sequences then become strings of mostly zeros and ones and the conversion factor needed to convert the results into rates of change per 90 days becomes very large. Additional studies to optimize the choice of interval sizes would be desirable. These studies would try to maximize the power of the trend tests. That is, they would identify the interval sizes that optimize the probability that particular performance indicator trends would be flagged as statistically significant.

As stated in the introduction to the calculations, the trend and deviation numerators are plantspecific performance attributes subtracted from nominal comparison values. For trend evaluations, the nominal slope, reflecting no trends, is zero. Thus, the trend indication numerator is zero minus the scaled slope. Alternately, the numerator is another scaling of this slope; i.e., (-1) times the slope. Positive slopes show increasing count rates, which represent declining performance. Conversely, negative slopes show decreasing count rates and improving performance. Thus, the converted slopes were multiplied by $(-1)$ to obtain numerators for which positive values show improved performance.

\subsection{Deviation Measure Numerators}

The plant-specific performance attribute for studying deviations between a plant's performance and that of its peer group for a performance indicator and phase type is a simple quantity: the event rate for the selected performance indicator during the operational or shutdown period under evaluation for deviations. The rate is measured in events per 30 days. That is, the measure is the total number of events divided by the number of available 30day periods under study. This unit applies to both operational and shutdown data. As explained above, long-term rates are computed, based on 24 operational periods and 12 30-day (18 20-day) shutdown periods. For plants lacking 720 days of operational experience or 360 days of shutdown period experience, the available data are used.

The nominal value against which the plantspecific long term event rate is compared for deviations is based on the performance of all the plants in the peer group. Specifically, it is the median event rate for the peer group, performance indicator, and phase type. It is the center value from each set of rates, or the average of the two center values if an even number of values is present. Medians are used to consolidate the experience of plant units within each peer group for each performance indicator and phase type because:

1. Medians are not heavily influenced by outliers in the data, and 
2. The median calculation weighs each plant having data equally.

Each of these considerations is discussed further below.

The current (not operational cycle based) rate calculation method is to sum the number of events across plants and divide by the corresponding total time, after first excluding plants regarded as outliers. This method corresponds to a weighted average of the event rates considered, each weighted by the corresponding time. However, averages are heavily influenced by outliers, and the current method provides little assurance that actual outliers are identified. The current method excludes rates that differ from the arithmetic mean of the rates by a multiple of at least 2.5 estimated standard deviations. For normally distributed data, values exceeding 2.5 standard deviations from the mean are in the upper or lower $0.6 \%$ of the distribution and could indeed be considered as outliers. However, actual standard deviations are not known; based on a Student's $t$ distribution with six degrees of freedom, 2.5 times the standard deviation estimated from at least 7 data points excludes as much as $2.5 \%$ of each tail of the distribution. With approximately 20 plants in some peer groups, some of these excluded values may not be outliers. Furthermore, the performance indicator rates are always positive and are often heavily skewed, with a large probability of a rate being identically zero. For distributions in general, including data that are not normally distributed, the "Chebyshev Inequality" states that as much as $16 \%$ (2.5 to the -2 power) of the distribution can differ from the mean by more than 2.5 times the true standard deviation. Thus, the discarded rates may in fact be part of the population that should be considered. However, the average is sensitive to these rates, particularly if they are large. Medians, on the other hand, show where half of the data lie and are not heavily influenced by outliers.

The other advantage of the use of medians is that all plants are weighted equally. For the purpose of historical reporting of the performance of nuclear power plants over a specified time period, weighting the data by the amount of time each plant spends in a phase is reasonable. If one plant dominates such a calculation, the plant also dominated, historically, in the experience being represented by the reported value. However, comparing all plants with a value heavily influenced by one plant biases the comparison. The rate difference for the plant dominating the calculation would be small. If that plant's performance were poor, the other plants would have positive rate differences; if it were good, the other plants would have negative differences. For between-plant comparisons, having certain plants dominate the standard against which the plants are being compared is not desirable. Each plant should be weighted equally, assuming enough data are present from each included plant to be representative of the plants' operational experience.

The deviation performance indicator display numerator is thus the plant-specific performance indicator event occurrence rate subtracted from the corresponding median peer group rate. Note that, with the use of the median, the interpretation of a positive rate difference is simply that the plant's rate is among the lower half of the data being observed for a particular peer group.

\subsection{Scaling Factors}

Both trend and deviation numerators are divided by scaling factors to obtain the plotted plant summary values. The purpose of such factors is to allow the display of data from all performance indicators and all plant units on a common set of plotting axes.

Data are combined for plants across the entire industry to compute scaling factors. Peer group differences in occurrence rates are anticipated, but these should be reflected in the standard rates used for comparison in the deviation indications. Peer group differences are not expected in the rate of change data being evaluated for trends. Also, using the entire industry provides more data for characterizing the populations. The resulting denominators do not disturb the ordering of plant performance determined from the numerator slope or rate differences. The basic plant performance assessments come from these slope and rate differences. The scaling factors affect neither the sign nor the among-plant ordering of these values.

Two pieces of information are needed to scale the performance measures. The first is the range of such measures for each performance indicator, plant summary display type (trends and deviations), and phase type. The second is the desired range for the performance indicator report plotting scale. The 
range of measures for each performance indicator is observed from the data across plant units. The desired range for the plotting scale is (arbitrarily) selected to be from minus one to plus one. ${ }^{a}$

To scale the data, each positive numerator may be divided by the maximum of such numerators across the industry, and then multiplied by the desired maximum plotting value. Similarly, negative numerators would be scaled by dividing by the minimum of such numerators across the industry and multiplying by the desired minimum plotting value. This procedure scales all the performance indications to lie strictly within the desired plotting range.

However, if outliers exist among the calculated rate or slope differences, the scaling factors that bring such values in line with the desired plotting positions may be so large that the resulting scaled performance indications for the other plants are quite small. For example, if a single positive outlier is three times as large as the nearest other performance measure numerator for a particular indicator, type of display, and operational state, then the scaled positive indications for all other plant units for this case will be less than 0.34 .

Because of the potential effect of such large outliers, a slight modification of the above procedure is used for the performance indicator data. Instead of scaling the maximum and minimum to lie between minus one and plus one, the 2 and 98 percentiles of each set of numerators are scaled to lie between -0.9 and 0.9 . This choice ensures that most of the trend and deviation performance measures will lie in the desired interval without a few outlier values compressing the plotted values.

a. The scales in Figure 1 are from -2.5 to 2.5 in order to show the forced outage rate and equipment forced outage data.
The specific details of the scaling factor calculations are as follows. For each performance indicator, plant summary display type, and phase type, the U.S. commercial nuclear power plant industry forms a population with a range of numerator measures of plant performance. With approximately 100 plant units, this method allows, at most, two positive and two negative values from each performance indicator and plant summary display type to be "pegged" with normalized values that exceed 0.9 or are less than -0.9. The denominators are computed as follows:

Denominator $=98$ th percentile for numerator

$$
\text { / (0.9) }
$$

or

Denominator $=2$ nd percentile for numerator

$$
/(-0.9)
$$

Equation (a) is used for positive numerators and Equation (b) is used for negative numerators. As required, both of these denominators are positive.

The percentiles are computed as follow: Define $n$ as the number of performance indicator numerators in a population, with $d_{(1)}, d_{(2)}, \ldots, d_{(\mathrm{i})}$, $\ldots, d_{(\mathrm{n})}$ as the ordered values of the numerator slope or rate differences (from minimum to maximum). Corresponding to these values, consider the sequence $\{1 / n, 2 / n, \ldots, i / n, \ldots, n / n\}$. Define $p$ as the fraction corresponding to the percentile being sought $(2 / 100$ for the second percentile and $98 / 100$ for the 98 th). If $p$ (e.g., 0.02 ) is less than $1 / n$, the minimum sample value is used as the second percentile and all negative rate differences are scaled in the interval from -0.9 to 0 . If one of the values in the $\{i / n\}$ sequence equals $p$, and $p$ is less than one, the corresponding $d_{(\mathrm{i})}$ and the next value $\left(d_{(\mathrm{i}+1)}\right)$ are averaged to obtain the desired percentile. Otherwise, the greater of the two $d$ values whose sequence values most closely bracket $p$ is the desired percentile. Another way to state these rules is to consider the product $n^{*} p$. With $j$ as the integer part of this product and $g$ as the fractional part, the desired percentile is estimated as 


$$
\begin{aligned}
& \left(d_{(j)}+d_{(j+1)}\right) / 2 \text { if } g=0, \text { and } \\
& d_{(j+1)} \text { otherwise. }^{6}
\end{aligned}
$$

(In this expression, $n^{*} p=j+g, j$ is an integer from 0 to $n$, and $g$ is less than 1 ).

In summary, there are a total of eighty possible scaling factors. With ten performance indicators, two plant summary display types, and both operational and shutdown period assessments, forty populations of plant summary performance measures exist. A scaling factor for positive values and for negative values exists for each of these.

The option of not using scaling factor adjustments for trends is a part of the analysis system. They are less crucial there since the variation in rates of change in counts across time for various performance indicators is not as large as the variation in rate differences.

\subsection{Significance Evaluations}

For both trends and deviation displays, and for operational and shutdown data, the plant performance measures were compared with threshold values in order to evaluate their statistical significance. That is, they were evaluated to see if sufficient evidence exists in the data to reject the idea that the slopes might be zero or that a plant is like its peers. These tests show the ability of the data to discern such differences. They do not show the actual magnitude of the slopes or between-plant deviations. Details of these assessments for trend and deviation measures are described below.

\subsubsection{Significance Evaluations for Trends}

Although the trend evaluation slopes are computed using ordinary statistical methods, use of the ordinary statistical method to evaluate the significance of the slopes is not appropriate for the event count data. In paragraphs below, the ordinary method will be briefly described in order to show how it must be adjusted to obtain a method applicable to the performance indicator data.
The ordinary method is based on the assumption that the dependent or response variable (the yaxis variable; here, the counts) is normally distributed. Under this assumption, coupled with the assumption that the true slope is zero, the estimated slope divided by its estimated standard deviation can be shown to have a Student's $t$ distribution with $S N-1$ degrees of freedom, where $S N$ is the number of data points (segments). The slope divided by its standard deviation is called the test statistic. If the computed test statistic is in the center of this $t$ distribution, the data give no reason to reject the no trend hypothesis. On the other hand, if the test statistic is unusually large or small and thus is in the tails of the reference $t$ distribution, either a trend does exist, or a rare event, namely the observance of an unusual slope/standard deviation ratio, has occurred. If, for example, the reference t distribution tail probability for observing a value as large or larger than the observed test statistic is 0.01 , either the true slope is statistically different from zero, or the slope is zero and an event that occurs once every 100 times has occurred. In this case, the associated slope is regarded as statistically significant, with significance level 0.01 . The significance level or tail probability associated with the reference distribution is a measure of how statistically significant the corresponding slope estimate is.

The slope significance tests are one-sided; that is, positive slopes are tested with reference to the right tail probability in the reference distribution and negative slopes are tested with reference to the left tail probability. Reference distribution tail probabilities for large negative test statistics are probabilities for the occurrence of values less than or equal to the observed value. For large positive test statistics, they are exceedance probabilities (i.e., probabilities of equalling or exceeding the observed value). In both of these cases, significant slopes will be called "large" in the remainder of this discussion.

The use of $t$ distributions for reference to obtain probability values for assessing whether the slopes are large enough to be statistically significant is heavily dependent on the assumption that the response data are normally distributed. The performance indicator counts, however, are not normally distributed. The counts have a discrete distribution. For many of the performance indicators, the counts for 30-day periods are often zero, and they are never .cegative. Thus, the counts do not follow a typical "bell-shaped" distribution. This means that 
$t$ distributions are not suitable for evaluating the performance of the slopes.

The behavior of the slopes can be observed by studying the behavior of the underlying event counts. Simulation is a recognized method for observing how well-understood phenomena behave. When no trends exist, the long term average number of events in each interval should be the same for a plant, phase type and performance indicator. Thus, the total number of events for a plant/phase type/performance indicator should be spread randomly across the time intervals for the plant and phase type. Recall that $S N$ is the number of intervals. As in Section 3.2, $S Y$ is defined as the total number of events. Then the number of events in any particular time interval would be expected to follow a binomial distribution with $1 / S N$ as the probability parameter and $S Y$ as the parameter for the total number of events. More generally, the multinomial distribution describes how $S Y$ events fall among $S N$ intervals. By simulating many instances of typical counts on a computer, and computing the slope for each set of counts, the behavior of the slopes unter the assumption of no trends can be assessed.

Thus, the trend significance evaluation method selected for the performance indicator data is the method described above, with $t$ distributions replaced by distributions derived in computer simulations. A separate reference distribution is generated for each possible $S N, S Y$ combination, and the slope itself is used as the test statistic. (In the ordinary method, a different $t$ distribution is used for plants with less than nine full intervals of data, so the $S N$ parameter was considered. The $S Y$ parameter was also considered, since the slopes were divided by standard deviation estimates.)

Use of the simulated reference distributions requires further explanation. Over 1300 such distributions were generated (with $S N$ going from two to 27 and $S Y$ going from 1 to 50 for each case). Each simulated distribution contains as many as 10,000 simulated slope values. Clearly, not all these simulated slope values are important. The important values are those that allow the probability values associated with the observed slopes to be categorized. To preserve some flexibility in evaluating the data, the following categories of significance levels were sought:

\author{
Reference Distribution \\ Label Tail Probability Range \\ $001 \quad$ Probability values less than or equal \\ to 0.001 \\ 010 Probability values $>0.001$ and less \\ than or equal to 0.01 \\ 050 Probability values $>0.01$ and less \\ than or equal to 0.05 \\ 100 Probability values $>0.05$ and less \\ than or equal to 0.10
}

The capability to flag probability values less than 0.20 but greater than 0.10 (with label "200") and values less than 0.30 but greater than 0.20 (with label "300") was retained. Appendix B explains how the the simulated slope values were processed in order to identify slope thresholds for each of these significance levels.

The slope threshold values for this sequence decrease; for example, the value a slope must equal or exceed to be in the upper 0.001 tail of the reference distribution is strictly greater than the value it must equal or exceed to be in the upper 0.01 tail. The significance label assigned to a particular observed slope is the label associated with the largest simulated slope threshold that the observed slope equals or exceeds.

Note that, with many hypothesis tests being performed, occurrences that happen once in every ten or twenty opportunities are not rare. Considering two types of tests for each of two phase types for each of 10 performance indicators, forty significance tests are being performed for each plant unit. Purely by chance, and with no actual trend or deviation being present, such occurrences could occur on average for two to four tests for each plant unit. Thus, many of these indications will be spurious; that is, the true trend slopes or rate differences could be zero for many of these shaded bars. For this reason, they are labelled as "possibly" statistically significant. With over four thousand tests being performed for the industry as a whole, even some of the "statistically significant" bars will be spurious.

Note also that the procedure described above is not the only method that could be used to evaluate whether trends exist in the performance indica- 
tor data. In hypothesis testing, statisticians seek methods that have optimal power; that is, that have the highest probabilities of detecting trends when they exist. The method adopted for the performance indicator program has intuitive appeal. It mimics the thought process of an analyst trying to assess the slopes of lines passing through the data. However, it is not sensitive to certain nonlinear variations in the performance indicator occurrence rates, and no studies have been conducted to compare the power of methods based on slopes with that of other count data trend analysis methods.

\subsubsection{Significance Evaluations for Deviations}

The deviation performance measures are a scaled version of the difference between a plant's rate for a performance indicator and operational state and the median of such rates for the plant's peer group. The significance of such a difference should reflect whether the data show that the plant's rate is noticeably different than that of its peers. As with the trend significance evaluations, the evaluations show whether sufficient evidence exists in the data to reject the idea that a plant is like its peers. These tesis show the ability of the data to discern such differences; not the actual magnitude of the deviations.

The method currently implemented for this assessment is based on the assumption that all plants in the peer group have the same occurrence rate for the performance indicator and operational state under consideration. With this assumption, the total number of events occurring for the peer group would be expected to be spread among the plants in proportion to the experience (time) from each plant included in a peer group. If all the plants have the full 720 or 360 days of experience, the events would be expected to be spread equally among the plants in the peer group. In peer groups containing newer plants, some plants have less experience than others. In any case, the average number of events that would be expected for any particular plant is the total number of events for the peer group times the fraction of the total peer group's time that occurred at that plant. With $S Y$ as the total number of events for the peer group, and $P$ as the probability that one of these events will occur at a particular plant, the number of events (under the hypothesis of a constant event rate across plants) is expected to have a binomial distribution with parameters $S Y$ and $P$. Note that this is the same distribution as the one used for the counts in the trend evaluations. Here, the "cells" containing the counts are different plants instead of different time periods for a single plant.

The basic principle used for the significance evaluations is the same for deviations as for trends. The test considers whether a test statistic is in the tails of an established reference distribution that applies when between-plant deviations do not exist. For the deviations test, the number of events occurring at a particular plant is the test statistic, and the binomial distribution described above is the reference distribution.

The deviation significance tests are also onesided. Relatively high plant counts are tested with reference to the right tail probability in the reference distribution and relatively low ones are tested with reference to the left tail probability. More specifically, counts that exceed $S Y^{*} P$ are tested for high rates; others are tested for low rates.

To perform the tests, binomial distribution tail probabilities are required. Let $Y$ be the number of events observed at a plant. The upper tail probability is the probability that a binomial count will equal or exceed $Y$. Thus, it is the sum, from $x=Y$ to $\mathrm{x}=S Y$, of binomial probabilities of the form

$$
\begin{gathered}
\mathrm{P}[\text { Count }=\mathrm{x}]=S Y !^{*}(P)^{\mathrm{x} *}(1-P)^{S Y-\mathrm{x}} \\
/\left[\mathrm{x} !^{*}(S Y-\mathrm{x}) !\right] .
\end{gathered}
$$

In this equation, $x$ ! (read: " $x$ factorial") is $x$ * $(x-1)$ * $(x-2)^{*} \ldots * 1$. The lower tail probability is the probability that a binomial count would be less than or equal to the observed value, and is the sum of binomial probabilities but from $\mathrm{x}=0$ to $\mathrm{x}=Y$. To perform a test on the significance of a particular $Y$, the appropriate tail probability is evaluated to see if it is unusually small.

To develop a data base program to perform the above factorials and summations for every test seemed prohibitive. Therefore, tables of binomial distribution tail probabilities were generated using functions contained in SAS. ${ }^{a}$ Even here, the number of events for a peer group ranges from 0 to over 400 and plant time fractions may be as large as 0.15 , so many relevant binomial distributions exist. The following steps were taken to limit the problem: 
1. Distributions were tabulated for $P$ ranging from 0.05 to 0.20 in steps of 0.05 . In application, the plant probabilities were rounded to the nearest 0.05 to select a reference distribution for consideration.

2. When $S Y^{*} P$ is large, the binomial distribution can be approximated by a Poisson distribution. Table look-ups are simplified for the Poisson distribution, since it has a single parameter, the long term average expected count rate for the plant $\left(S Y^{*} P\right)$. Poisson distribution-based tail probabilities were used whenever $S Y^{*} P$ is greater than or equal to 5.0. These probabilities were summarized for the Poisson parameter going from 5 to 100 in steps of 0.5. In application, the plant expected count $\left(S Y^{*} P\right)$ was rounded to the nearest 0.5 to select a distribution for consideration.

3. Not all cumulative probabilities frort each bincmial or Poisson distribution are relevant. Binomial tail probabilities for peer group counts $(S Y)$ going from 1 to 500 and for plant counts $(Y)$ going from 1 to 30 or $S Y$, whichever is smallest, were tabulated. Poisson tail probabilities were tabulated for expected counts $\left(S Y^{*} P\right)$ going from 5 to 500 and for plant counts $(Y)$ from 1 to 100. Binomial and Poisson low tail probabilities included the $(Y=0)$ case. High and low tail probabilities lying between 0.0005 and 0.35 were tabulated.

Four tail probability tables were generated: binomial upper and lower tail probabilities, and Poisson upper and lower tail probabilities. Each binomial table entry contains $P, S Y, Y$, and a corresponding tail probability. Each Poisson table entry contains

a. SAS is a software system developed by SAS Institute, Inc. Mention of specific products and/or manufacturers in this document implies neither endorsement or preference, nor disapproval, by the U. S. Government, any of its agencies, or EG\&G Idaho, Inc., of the use of a specific product for any purpose. an expected count $\left(S Y^{*} P\right), Y$, and a corresponding tail probability. In the binomial tables, $S Y^{*} P$ was less than 5.0 in all cases.

The tables were applied as follows. First, $S Y^{*} P$ for a plant, performance indicator, and phase type was evaluated to determine whether to reference the detailed (binomial) or approximate (Poisson) tables. In each of these cases, the next decision was whether a plant's count should be tested as being high or as being low. Then the $S Y$ and $P$ data were rounded as required to identify a specific binomial or Poisson distribution in the selected reference distribution table. Finally, a match was sought for the plant-specific count, $Y$. In testing for high counts, the label '999' (not significant) was assigned if $Y$ was less than the tabulated counts and the label ' 001 ' was assigned for Ys exceeding the tabulated counts. The opposite situation occurs for testing for low counts. When matching records are found in the reference tables, significance labels ("001," "010," "050", etc.) are assigned in accordance with the reference tail probabilities, as described in the trend significarce evaluation section above.

The assignment of shading to the deviation bars based on the significance labels is the same as for the slope significance evaluations. The same caution applies in the interpretation of the significances: with many hypothesis tests being performed, occurrences that happen once in every ten or twenty opportunities are not rare. Many of the significance indications will be spurious and will not show true deviations.

The assumption that all plants in the peer group have the same occurrence rate for the performance indicator and operational state under consideration is unduly restrictive. Even within a peer group, plant data tend not to be homogeneous. The current method flags a higher number of plants than would be expected from the stated significance levels. For example, among 2,192 deviation tests (across plants and performance indicators and two phase types), $9 \%$ were flagged with "010" $(1 \%)$ or "001" $(0.1 \%)$ labels. Other methods are currently under consideration that would allow some variation for occurrence rates among plants in a peer group.

\subsection{Summary of Calculations}

Table 1 below provides a summary of the calculations. 
Table 1. Summary of performance indicator trend and deviation calculations.

Action
Parse the operational history
into segments of operational
and shutdown experience for
each plant

Compute plant-specific performance attributes

Compute nominal values against which to compare the plant-specific performance attributes.

Compute the performance indication numerators

Compute the performance indication denominator, and perform the division to obtain values for the plant summary displays.

\section{Detail for Trends Detail for Deviations}

Identify date ranges for the most recent 24 thirty-day segments of operational shutdown experience for each plant and for the most recent 18 twenty-day segments of shutdown experience. Count cyents for each performance indicator for both sets of time segments (i.e., for each phase type).

Compute the slope of the least squares fit line thru the most recent 9 (time segment number, performance indicator count) data points for each performance indicator, for both operations and shutdown data.

$B=F^{*}\left(S X Y-S X^{*} S Y / S N\right) /$ $\left(S X X-S X^{*} S X / S N\right)$,

where $F$ is a conversion factor for rate of change in event count per $90 \mathrm{~d}$.

(See Section 3.2 for further explanations.)

The "no trend" slope is 0 .

0 minus the plant-specific slope.

Compute pooled long term event rates for each performance indicator, plant, and phase type. Use the most recent 24 30-day operational segments and the most recent 18 20-day shutdown segments.

Rate $=30 \mathrm{~d}$ * (Tot. count)/(Tot.days), for each phase type (operational and shutdown).

Identify the median or center plantspecific event rate within each performance indicator, phase type, and plant peer group combination.

Peer group median minus the plantspecific rate.

The calculation is the same for both trends and deviations. For positive numerators,

Denom. $=98 \mathrm{th}$ percentile of numerators $/(0.9)$.

For negative numerators,

Denom. $=-(1) * 2$ 2nd percentile of numerators $/(0.9)$.

Percentiles are computed as follows: Sort the, say, $n$ numerators $\left(d_{(j)}\right)$ for a performance indicator, plant summary display type, and phase type. Let $p$ be the fraction corresponding to the percentile being sought. Let $j$ be the integer part of $n^{*} p$, and $g$ the fractional part. The percentile is $\left(d_{(j)}+\right.$ $\left.d_{(j+1)}\right) / 2$ if $g=0$, and $d_{(j+1)}$ otherwise. 
Action

Evaluate the statistical significance of each trend or deviation indication

\section{Detail for Trends}

Select a set of slope thresholds based on the total number of events (SY) and the number of time intervals $(S N)$. Identify the significance label corresponding to the largest slope threshold that the computed slope equals or exceeds.
Detail for Deviations

Let $P$ be the fraction of the peer group time associated with the plant of interest, and let $S Y$ be the total number of peer group events for a performance indicator and phase type. Select a binomial or Poisson distribution tail probability reference table, based on whether $S Y^{*} P$ exceeds 5 and on wheth the plant count exceeds $S Y^{*} P$. I dentify the matching reference distribution tail probability and assign the smallest sought significance level that it meets or exceeds. 


\section{DISPLAY METHODS}

A description of the display of the performance indicator data is the topic of this section. The performance indicator data are presented on two pages, for each plant, in volume one of the Performance Indicator Report. The following two sections present a description of the contents of these two pages. Examples of the displays are presented in Figures 1 and 2.

\subsection{Right Page Display}

The right page of the performance indicator report consists of five specific areas: plant information, legend, time used in trend calculations, time used in deviation calculations, and trends and deviations values for each indicator. See Figure 1 for an example of the display. Each area of the display is discussed separately in the following subsections.

\subsubsection{Plant Information}

In the plant information section of the right page, three items of information are provided: plant name, peer group, and the quarter. The plant name provides the name of the plant for which the data are being presented. The peer group information provides the peer group name for the group to which the plant belongs. The quarter information provides the last quarter of the data included in the display.

\subsubsection{Legend}

The legend provides a description of the shading plan for the trend and deviation indications. As described in Section 3, statistical significance tests are performed. The shading shows report reviewers whether statistically significant or possibly statistically significant trends or deviations have been observed. A solid black bar indicates that the slope is significant, nominally at at least the $1 \%$ significance level. (Recall that the significance level is a measure of how rare the observed data were under the hypothesis of no trend or no betweenplant differences. Low significance levels show either that real trends or deviations exist, or that rare events have occurred; with over 4000 tests being performed, there is opportunity for rare events.) A slashed bar indicates that the slope is possibly significant; the nominal significance level was found to be $10 \%$ or less. An unshaded bar indicates that the slope or plant evert count was not found to be statistically significant. However, no statistical test proves that trends and deviations do not exist. Conversely, with many tests being performed, many of the flagged indications are flagged by chance rather than actually showing data differences.

A cross hatched bar indicates that the indicator is not directly based on event counts and thus was not analyzed separately by phase types. For these indicators, the methods in the current Performance Indicator Report were retained and no statistical significance tests were performed.

\subsubsection{Time Used in Trend Calculations}

The time used in trend calculations are provided to give the report reviewer information on the time spanned for the trend calculations. The time used in the trend calculations are provided on two lines: one for shutdown (S/D) and one for operations $(\mathrm{Op})$. Each line provides three items of information. The first is the dates spanned for the trend calculations. In Figure 1, the shutdown dates spanned from April 1, 1990 to September 30, 1991; the operations dates spanned from November 7 , 1990 to September 26, 1991. The second piece of information is the number of days covered by the calculations. Again from Figure 1, 180 shutdown days and 270 operations days were covered by the calculations. Note that the calendar time spanned by the calculations is longer than 180 or 270 days since it includes both operations and shutdown periods. The third item of information is the number of days during the recent 180 shutdown days that were spent in refueling or the number of days during the recent 270 operations days that were spent in startup. From Figure 1, 118 days of the most recent 180 shutdown days were in refueling and 0 days of the most recent 270 operations days were in startup.

For plants with sufficient history, the total times for trend calculations are 270 operational days and 180 shutdown days. The 270 figure represents approximately 390 -day quarters. Three quarters were sought instead of the current performance indicator report's two quarters in order to provide one quarter of overlap with the performance 
indicator report describing data as of six months ago. For shutdowns, the 270 days were multiplied by two-thirds since plants typically spend over twothirds of their time in operations.

\subsubsection{Time Used in Deviation Calculations}

The time used in deviation calculations are provided in the same format used in the time used in trend calculations section above. These data are interpreted in the same manner as the times for the trends displays. However, the times for deviation calculations are longer, because long-term evaluations are sought.

\subsubsection{Trends and Deviations}

The trends and deviations section provides bar charts of the trend and deviation values. The trends and deviations section of the right page consists of two parts: operations and shutdown. The operations section contains the trends and deviations values for all indicators. The trends and deviation values are calculated as described in Section 3 and printed on the right page as bar charts. Note that the forced outage rate and equipment forced outages per 1000 commercial hours have not been computed accounting for the operational cycle. These two indicators are computed as described in Section 3.

The shutdown section contains trend and deviation displays for all indicators except scrams, forced outage rate, and equipment forced outages per 1000 critical hours. Scrams are not applicable during shutdown periods since a plant needs to be critical and in operation in order for a scram to be a performance indicator. Forced outage rate and equipment forced outages per 1000 critical hours are not adjusted for the operational cycle and therefore, can not be separated into operations and shutdown.

\subsection{Left Page}

The left page of the performance indicator report consists of five specific areas: plant information, legend, plant status, performance indicator counts, and cause code indicator counts. See Figure 2 for an example of the display. Each area of the display is discussed separately in the following subsections.

\subsubsection{Plant Information}

In the plant information section of the left page, the same information as provided in the plant information section of the right page (described in Section 4.1.1).

\subsubsection{Legend}

The legend provides a description of the shading plan for the performance indicator and cause code indicator count plots. An unshaded bar indicates the events that occurred during startup, a slashed bar, the events that occurred during shutdown, a solid bar the events that occurred during power operations (operations and prerefueling phases), and a cross hatched bar is used for the indicators that cannot be separated by phases.

\subsubsection{Plant Operational Status}

The plant operational status is presented on the left page. The plant status is provided in both columns so that the report reviewer can identify the periods of time where the plant was shutdown for greater than four days. The plant status presents a three year plot, where the operational condition is indicated. When the line is at the top of the plot, the plant was in an operating phase type and whea the plot is at the bottom, the plant was in a shutdown phase type. Load reductions or low power operations are not indicated.

\subsubsection{Indicator Counts}

The numbers of events are presented in the indicator counts section by calendar quarter and phase type.

\subsubsection{Cause Code Indicator Counts}

The numbers of cause code events are presented in the cause code counts indicator counts section by quarter and phase type. The bars are shaded in the same manner as the other indicator plots. 


\section{CONCLUSIONS}

The operational cycle trend and deviation measures are based on simple calculations that use the event counts. In this section, the calculations are compared with the tretids and deviations in the current Performance Indicator Report plant summaries. Strengths and weaknesses of the analysis approach are addressed, as well as areas for further research.

The current trend values are calculated using the following expression:

\section{[Comparison [Current value] - 2-quarter count $] / 2$}

[a standard deviation term].

In this expression, the current two-quarter count for an indicator is the performance attribute being evaluated, the comparison value is an average that describes one quarter's counts based on the plant's past experience, and the standard deviation term is a plant-specific standardizing or normalizing factor describing variation in one-quarter counts.

The current industry deviation values are computed in a similar manner:

$\frac{\left.\begin{array}{c}\text { [Comparison } \\ \text { value] }-6 \text {-quarter count] }\end{array}\right] 6}{\text { [a standard deviation term] }}$

Here, the current six-quarter count for an indicator is the performance attribute being evaluated, the comparison value is an average for the industry that describes one quarter's counts, and the standard deviation term is again a standardizing or normalizing factor (this time describing a six-quarter count average).

Compared to the current Performance Indicator Report trend and deviation values, the operational cycle trend and deviation values are of a similar form. They employ a comparison value, a plant-specific performance attribute for evaluation, and a normalizing factor.

However, four significant differences apply to the operational cycle trend and deviation values. First, performance in operational periods (power operations, start-up, and pre-refucling) is studied separately from performance in shutdown periods (refueling or non-refueling outages). This provides twice as many plots, but also twice as much information. Since many of the indicators occur at different rates during shutdown than during operations, separate evaluations based on these operational states is worthwhile. Consideration has been given to further breakdowns of the data, such as distinguishing start-up from power operations and distinguishing refueling outages from other outages.

The second significant difference is that the frame of reference under evaluation is expanded. For trends, rather than the most recent two calendar quarters (approximately 180 days), the most recent 270 days of power operation and the most recent 180 shutdown days are evaluated. For deviations, rather than the most recent six calendar quarters (approximately 540 days), the most recent 720 days of power operation and the most recent 360 shutdown days are evaluated. This difference could have a significant impact on the results of the performance indicator report. With longer periods of time, more data are available hut the ability to quickly respond to changes in the data is lessened.

The third significant difference relates to the statistical significance of the trend and deviation indications. The new methods employ specific significance tests for trends and deviations. The tests are based on the true nature of the data; that is, on the fact that the performance indicators under consideration supply event counts which are not normally distributed. In the current performance indicator methods, the use of standard deviations in the denominators is an attempt to scale the performance indications so that the statistically significant ones are large. In the new methods, since the statistical analysis is performed separately, the basic difference between comparison measures and plantspecific trend or deviation measures can be shown. The denominator then becomes a scaling factor rather than (especially for trends) a plant-specific factor intended to show significance.

Finally, a significant difference applies to the methods for calculating trends and deviations. For trends, rates of change in counts (slopes) are used as the performance attribute instead of counts. The use of slopes has intuitive appeal; it shows the general pattern of each set of data. Since the focus for trend evaluation is on a longer period of time, and the method is as sensitive to changes early in 
the period as to changes late in the period, the new trend evaluations have a different interpretation than the current trend indications.

For deviations, the most significant difference is the processing of data for plants within welldefined peer groups. Plant performance is thus assessed by comparison with similar plants instead of with the industry as a whole. This change makes these comparisons more meaningful.

The use of a longer time period for the evaluations will lessen differences in the deviation results from successive quarterly performance indicator reports. In the current method, one-sixth of the data changes from one report to the next. With the current time frames, one-twelfth of the deviation data will change. Flexibility exists in the data processing methods for selection of these periods, however.

Several issues remain for further investigation with the proposed performance indicator trend and deviation calculation methods:

1. The methods are dependent on the idea that separate operational or shutdown periods can be analyzed as a continuum. For example, operational time prior to a refueling outage is combined with operational time after such an outage. This practice was carefully avoided in the FY1990 and FY-1991 operational cycle processing of the performance indicator data. In that processing, the usage of data from incomplete outage periods was restricted and data was never combined across operational cycles. The validity of combining these data should be checked.

2. The selection of overall time periods for the evaluations needs further study.

3. The selection of a study period partition for the trend data needs further study.

4. The identification and treatment of data from new plants with little historical data and from plants coming out of long outages needs further study.

5. Consideration should be given to more powerful methods for significance tests for trends in the performance indicator data.

6. The current hypothesis testing for deviations is based on the unrealistic assumption that all plants within a peer group have the same rates for a given operational state and performance indicator. A more appropriate method should be employed.

The use of statistical significance tests deserves further comment. At issue is the question of what makes a particular indicator value important. Statistical evaluations flag whether differences can be discerned from the data, without regard to the actual magnitude of such differences. However, the computation of comparison values for the trend and deviation indications based on plant data in itself shows that the standards for significant (i.e., important) event counts are based on how the counts compare with a plant's prior experience and that of the plant's peer group. The focus is not on an external standard used to evaluate the magnitude of the counts themselves. If the actual importance of the data is based on comparison with other data, the statistical evaluations become very important. Furthermore, since the data for most performance indicators are rather sparse, such differences generally must be large in order to show statistical significance.

What then is the significance of the performance indications that are not flagged? Why bother to display such data? And, how much data should be flagged? Answers to these questions hinge on the following principles:

1. The fact that a particular performance indication is not flagged means it is not statistically significant, but does not mean that it is not significant. No statistical test ever proves that no trend exists, or that no deviation exists. Therefore, all the trend and deviation values should be displayed.

2. With any statistical test, there is a possibility that a large trend or deviation exists and is not flagged. Conclusions are not possible when the data are insufficient, even though actual differences may exist. This is called a Type II error, and is 
minimized by choosing the statistical test that has been shown to be most powerful for the attribute under study.

3. Among performance indications that are flagged as being statistically significant, cases of no trends or no deviations may exist. This is the Type I error. Most statistical tests are designed to control the magnitude of this error. However, in this study, unless higher significance levels are sought and fewer values are flagged, this error can be expected to be rampant.
The large number of hypothesis tests being performed provides many opportunities for such occurrences. From a statistical point of view, the presence of many "false alarms" dilutes the effectiveness of the testing.

4. All the data should be displayed in order to provide a complete picture of the operational performance. As in all of human experience, data must be viewed in an appropriate context in order to truly appreciate the significance. 


\section{REFERENCES}

1. Performance Indicators for Operating Commercial Nuclear Power Plants, Nuclear Regulatory Commission Office for Analysis and Evaluation of Operational Data, June 1990.

2. Performance Indicators for Operating Commercial Nuclear Power Plants, Nuclear Regulatory Commission Office for Analysis and Evaluation of Operational Data, October 1990.

3. H.M. Stromberg, J.H. Bryce, C.D. Gentillon, C. Kido, Operational Cycle Effects on the Performance Indicators, EGG-EAST-9107, June 1990.

4. H.M. Stromberg, J.H. Bryce, C.D. Gentillon, C. Kido, Operational Cycle Adjustment to the Performance Indicators, EGG-EAST-9445, February 1991.

5. Outage Information Data File, EG\&G Idaho, Inc., Idaho National Engineering Laboratory, Idaho Falls, 、 ID.

6. SAS Language Guide for Personal Computers, Version 6 Edition, Cary, NC: SAS Institute Inc., 1985.

7. FoxPro, Revision 2.0, Fox Software, Inc. Perrysburg, $\mathrm{OH}$. 


\section{APPENDIX A. ADDITIONAL IMPLEMENTATION DETAILS}

Operational cycle-based calculations for the performance indicators are accomplished by adding steps to the existing quarterly performance indicator report generation procedures. Additional details for the initial setup of the operational data are provided below.

\section{Study Boundaries}

The first step in the operational cycle performance indicator calculations is to establish initial values for the following sets of parameters that control the analysis of the performance indicators: the study start and study end dates, and the particular plants to be analyzed. Each of these are discussed in more detail below.

For the performance indicators, the fourth quarter of 1985 was selected as the study start date. The initial operational cycle methods were developed in 1990 and were based on exactly two operating cycles ofexperience. Four years of historical outage data were sought at the outset of this study.

Performance indicators are analyzed through to the end of quarter 91.3 for the demonstration operational cycle analysis.

For each plant, the current study bounds are from the commercial operation date or study start date, whichever is later, to the study end date. Thus, one requirement for the selection of plants to analyze is that they be in commercial operation. Comanche Peak 1, Seabrook and Shoreham were omitted from the current demonstration analysis on these grounds. The plant data base used to control the operational cycle analysis must be updated with the latest commercial operation dates. A standard data base application ${ }^{a}$ exists to update the plant data using the UNITINFO.DBF data base maintained for NRC/AEOD by EG\&G's Plant Operations Analysis Unit.

The operational cycle plant data base also contains peer group acronyms that influence the formation of the deviation performance measures. Certain atypical plants that lack peer groups are omitted from the operational cycle analysis study: Dresden 1, Fort St. Vrain, Humboldt Bay 3, La Crosse, Rancho Seco, and Three Mile Island 2.

\section{Gather Performance Indicator Data}

As in the existing Performance Indicator Program, data bases with records containing dates for each performance indicator event are needed. All the procedures currently in place to obtain these data will be retained, including the steps that provide assurance that the performance indicator data are complete and accurate.

For the operational cycle methods, historical performance indicator data are needed for the time period spanned by the study start and end dates.

a. Throughout this appendix, the term "data base application" refers to programs or procedures written for manipulation of data bases on IBM-compatible PCs. The data bases are in the format established in AshtonTate's dBase III + system. In practice, most of the applications are developed using Fox Software, Inc.'s FoxPro Relational Database Management System, Version 1.02. Note, however, that mention of specific products and/or manufacturers in this document implies neither endorsement or preference, nor disapproval, by the U. S. Government, any of its agencies, or EG\&G Idaho, Inc., of the use of a specific product for any purpose. 
A data base application is used to prepare the data base of cause code data received from the Oak Ridge National Laboratory (ORNL) for operational cycle trend and deviation calculations. This application splits the data into separate files for each cause code, including the maintenance cause subcodes. In addition, it makes "FID" the key field for plants instead of the docket number and eliminates duplicates in data prior to 1989.

The operational cycle analysis of the performance indicator data assumes that each record in the performance indicator data input files corresponds to one event. At one time, each safety system actuation record could describe both a diesel generator actuation and an emergency core cooling system actuation. These are now in separate records.

The final additional step in preparing the performance indicator data is to complete the data base that controls processing. Performance indicators to be included in the analysis must be selected by setting the "USED" field to true, and the data base file names associated with each performance indicator must be placed in the "INDB" field.

\section{Gather Outage Data}

Two types of outages drive the operational cycle calculations: refueling outages and non-refueling outages. These are described briefly in the main text (Section 2). To correctly categorize start-up phases that occur at the start of a plant's study period and any pre-refueling phases that occur at the end of the study period, the outage data set should extend from one month before the study start date for each plant to one month after the end of the study period.

For this study, outage data were initially obtained from two sources. The first is the Operating Plant Evaluation Code (OPEC), a data base maintained by Stoller Power Division, RCG/Hagler Bailly, Inc. of Boulder, CO. This source provided data through the first quarter of 1990 . Ongoing outage data, starting with the second quarter of 1990 , is derived from the Monthly Operating Reports submitted by the licensees to the NRC and summarized in the Monthly Operation Report Tracking Data File maintained by EG\&G for AEOD. A series of data base and SAS Institute Statistical Analysis System application programs were developed to compute outage end dates from start dates and durations and combine separate entries from long outages into single outage descriptions in each input data file, and then append the two sources.

Accounting for the operational differences that occur during shutdown conditions is a major objective of the methods. The outages of concern are those in which the plant is not at power. The presence of an operational event such as a scram during such outages indicates an attempt to return to power operations; such periods should be included in the operational phases. To ensure that such events would not be included in the outage data set, the outage data were compared with Licensee Event Reports for all plant units. The LER comparison also provides further assurance that no outages were missed since data base checks were made for LERs showing plants in a cold shutdown mode during operational phases. The outage data set was adjusted as needed; Table A-1 summarizes these checks.

A data base application program checks the adjusted outage data base to ensure that there are no overlaps among the non-refueling and refueling outages for each plant.

The final stage in preparation of the outage data base is to include records describing periods in which plants have been in regulatory outages, requiring Commission approval for restart. For the operational cycle methods, these outage are treated as special phases that are excluded from the analysis. Records describing these outages were added on a case-by-case basis. They may overlap other outages.

The result of this step is a data base $e^{5}$ containing starting and ending dates for refueling, non-refueling, and regulatory outages for each plant. 
Table A-1. Use of LERs to adjust outage dates

\begin{tabular}{|c|c|c|}
\hline $\begin{array}{l}\text { Plant } \\
\text { Status on } \\
\text { LER Date } \\
\end{array}$ & $\begin{array}{l}\text { LER Status Leading } \\
\text { to Outage Data } \\
\text { Review } \\
\end{array}$ & $\begin{array}{c}\text { Nature of } \\
\text { Outage Data Adjustment }\end{array}$ \\
\hline \multirow[t]{2}{*}{ Refueling outage } & Reports a scram ${ }^{b}$ & $\begin{array}{l}\text { Move outage dates inward (shorten outage } \\
\text { phase). }\end{array}$ \\
\hline & $\begin{array}{l}\text { Reports some other } \\
\text { operational event (at } \\
\text { power) }\end{array}$ & $\begin{array}{l}\text { Check accuracy of LER; if needed, move } \\
\text { refueling dates inward. }\end{array}$ \\
\hline \multirow[t]{2}{*}{ Non-refueling outage } & Reports a scram & $\begin{array}{l}\text { Move outage dates inward, or split into two } \\
\text { periods separated by a } 2 \text {-day operational period. }\end{array}$ \\
\hline & $\begin{array}{l}\text { Reports some other } \\
\text { operational event (at } \\
\text { power) }\end{array}$ & $\begin{array}{l}\text { Check. If generator output breaker was closed, } \\
\text { then move outage dates or split the outage as for } \\
\text { scrams in non-refueling. }\end{array}$ \\
\hline $\begin{array}{l}\text { Operational period (not } \\
\text { within a refueling outage } \\
\text { or non-refueling outage) }\end{array}$ & $\begin{array}{l}\text { Reports plant not at } \\
\text { power }\end{array}$ & $\begin{array}{l}\text { Check that LER does not show the plant in a 4- } \\
\text { day or longer outage. If such a state is indicated } \\
\text { from the LER, check the corresponding monthly } \\
\text { operating report to determine why the outage is } \\
\text { not shown there. If needed, add an outage } \\
\text { record to the outage data. }\end{array}$ \\
\hline
\end{tabular}

a. Based on dates in the outage data base. The dates on which a plant enters or leaves an outage are treated as operational periods.

b. This situation occurs particularly at the end of refuelings. The data sources generally report the date of synchronization to the grid as the refueling end date. Startup tests and low-power operation often precede this date.

\section{Identify Operational and Shutdown Periods}

The next step in the implementation procedure is to partition the operating history of each plant into a series of phases (refueling, start-up, one or more operating periods, one or more non-refueling outage phases, and pre-refueling) during each operational cycle. These phases are briefly defined in the Section 2 of the main report; previous reports provide further information. A data base application program uses the outage data to identify phase start dates for each plant. The program results in a file containing a series of database records for all plants, providing the required information for the study period.

The outage data file has information on refueling, non-refueling, and regulatory impact outages. The application program that identifies specific phase dates performs the following tasks:

- Arranges the dates so that the phase start date for the first phase record for each plant is that plant's start date (i.e., either the plant's commercial start date or the study start date, whichever is later)

- Arranges the dates so that the phase end date for the last phase record for each plant is the study end date 
- Screens out all non-refueling outages that are less than four days long

- Inserts power operations phases between each remaining outage. The 24 hours of days on which the plant enters or leaves an outage are treated as part of the operations phase.

- Creates a plant fuel cycle index for each record and increments it after each refueling

- Inserts records for regulatory impact outages, if any. In this process, records providing dates covered by the regulatory outages are truncated or, if covered entirely, are eliminated. Records with dates spanning such outages are split,creating records describing phases before and after the outage.

- Inserts records for start-up phases after each refueling. As explained in the Terminology section, these phases are taken to be 25 days long. These records override the first 25 days of the power operations phases that follow the refuelings. If non-refueling or regulatory impact outages are present within these 25 days, the start-up phase is split into segments and multiple start-up phase records are created. The presence of such outages makes the ending date of the final start-up segment more than 25 days after the refueling.

- Inserts records for pre-refueling phases before each refueling. This process is entirely analogous to the process for the start-up phase. Other outages within 25 days before the refueling cause the insertion of multiple pre-refueling phase records; the starting date of the final pre-refueling segment added to the data base is then more than 25 days before the refueling.

Table A-2 shows the interaction between various outage types and phases in the development of the phase dates.

Table A-2. Use of outages to adjust phase dates

\begin{tabular}{ll}
\hline \multicolumn{1}{c}{ Phase } & \multicolumn{1}{c}{$\begin{array}{c}\text { Effect of Non-Refueling and } \\
\text { Regulatory Impact Outages Initially in the Phase }\end{array}$} \\
$\begin{array}{ll}\text { Transitional phases (start- } \\
\text { up and pre-refueling) }\end{array}$ & $\begin{array}{l}\text { Split phase into segments and extend total duration of phase (extends end } \\
\text { date of start-up phases and starting date of pre-refueling) }\end{array}$ \\
$\begin{array}{l}\text { Power operations and the } \\
\text { shutdown phases (refueling } \\
\text { and non-refueling) }\end{array}$ & $\begin{array}{l}\text { Interrupt the phase (for regulatory impact outages, the time is excluded) } \\
\text { (note that only regulatory impact outages can impact refueling phases) }\end{array}$ \\
\hline
\end{tabular}




\section{APPENDIX B. CALCULATION OF SLOPE THRESHOLDS}

The use of simulation to identify distributions for slopes of the performance indicator count data for trend tests is described in Section 3.5.1 of the main text. This appendix provides further details on the generation and use of these distributions.

For each combination of number of intervals and total performance indicator events, multinomial counts are generated under the assumption that no trend exists. A slope is computed from each set of counts. The slope distributions are symmetric; e.g., if $b$ is the slope from the count sequence $\{1,1,2,1,5\}$, then $-b$ is the slope from the sequence $\{5,1,2,1,1\}$. Furthermore, each of these sequences is equally likely under the hypothesis of no trend. Thus, each generated count sequence can be used twice; or, alternately, just the distribution of the absolute value of the slope needs to be observed. The slopes were simulated using a SAS program. ${ }^{\mathrm{a}}$

Additional considerations are involved in the computation of slope thresholds. From the each set of 10,000 slopes, as many as six values are retained which show how large slopes must be to be in, respectively, the 0.300 , $0.200,0.100,0.050,0.010$, and 0.001 fraction tails of the simulated slope distribution. These values approximate the thresholds of the actual slope distributions, since a large sample is used for the simulations. ${ }^{b}$ For cases with large numbers of counts and many intervals, many possible slopes can arise from the data and the set of possible slopes acts like a continuum. In these cases, the raw percentiles of the observed slope distribution approximate the desired thresholds. For example, the 9000 th of 10000 such slopes is an estimate of the 90 th raw percentile. Observed slopes equalling or exceeding this value, but remaining less than the 95 th percentile, would be flagged as significant at the $10 \%$ level and shaded as possibly significant. ${ }^{c}$

The sparsity of counts for certain indicators introduces additional complications; raw percentiles, in general, do not suffice. Cases occur in which the, say, 95th percentile is also the 94 th or even the 90.05 th percentile. Such a 95th percentile should be used to evaluate whether the tail probabilities are greater than or equal to 0.10 , not 0.05 . The actual significance of a positive observed slope that equals any particular simulated slope is the biggest tail probability that corresponds to that simulated slope. Effective thresholds are those whose maximum exceedance probabilities are closest to the desired tail probabilities.

Equivalently, the actual significance is one minus the smallest cumulative probability associated with a simulated slope value. To assign the desired thresholds, the SAS program seeks simulated slope values for which the minimum cumulative probabilities lie within specified bounds and are closest, among simulated slope probabilities, to the desired target cumulative probabilities. More specifically, the algorithm is as follows.

1. Sort the observed slopes from small to large.

2. Assign to each unique computed positive slope its minimum cumulative probability. This is defined to be $(k+1) / 10000$, where $k$ is the number of sample values strictly less than the particular slope.

a. Mention of specific products and/or manufacturers in this document implies neither endorsement or preference, nor disapproval, by the U. S. Government, any of its agencies, or EG\&G Idaho, Inc., of the use of a specific product for any purpose.

b. Note that the standard deviation of a the estimate of the qth percentile based on a simulation with sample size $s$ is the square root of $\left[(\mathrm{q} / 100)^{*}(1-\mathrm{q} / 100) / s\right]$. With $s=10,000$ and $\mathrm{q}=0.1$, the standard deviation is 0.001 . This standard deviation is in the same units as the slopes.

c. Recall that, with many hypothesis tests being performed, occurrences that happen once in every ten opportunities are not very rare. Considering two types of tests for each of two phase types for each of 10 PIs, forty significance tests are being performed for each plant unit. Purely by chance, and with no actual trend or deviation being present, they could occur on average for four tests for each plant unit. 
3. Start with the lowest sought cumulative probability (e.g., 0.700 for the 0.300 significance level). Scan the list of unique slopes to find the first such slope whose minimum cumulative probability exceeds the target value. Identify also the prior slope value in the list. The minimum cumulative probabilities for these two slope values bracket the desired target probability. If neither of these probability values are in a specified allowable range around the target value, assign zero as the target threshold (this means that this significance level will not be assigned). ${ }^{a}$ Otherwise, assign as the desired slope threshold the slope (among the two flagged slopes) whose cumulative probability is within the allowed range and is closest to the target probability.

4. Change the target to the next sought cumulative probability (e.g., 0.800 ) and continue the scan of the slope file, repeating Step 3.

In Step 3, when zero is assigned, Step 4 is performed and the two identified slope values are assessed to see if the current slope is suitable for the next higher significance level.

The table below contains the allowable ranges used in this algorithm. Note that these limits only have an effect for sparse slope distributions. With nine time segments and four events, 495 unique assignments of the counts to the time segments exist. Enough unique slopes exist among these assignments to estimate even the 99.9 slope percentile without invoking these approximations.

Table B-1. Allowable probability ranges.

\begin{tabular}{cccc}
\hline & \multicolumn{3}{c}{ Minimum Cumulative Probability } \\
\cline { 3 - 4 } $\begin{array}{c}\text { Significance } \\
\text { Label }\end{array}$ & Target & Allowed Values & Minimum \\
\hline 300 & 0.700 & 0.675 & 0.775 \\
200 & 0.800 & 0.775 & 0.875 \\
100 & 0.900 & 0.875 & 0.925 \\
050 & 0.950 & 0.925 & 0.975 \\
010 & 0.990 & 0.975 & 0.995 \\
001 & 0.999 & 0.995 & 1.000
\end{tabular}

a. In the allowable range, the selected minimum cumulative probability must strictly exceed the specified minimum but may equal the specified maximum. 


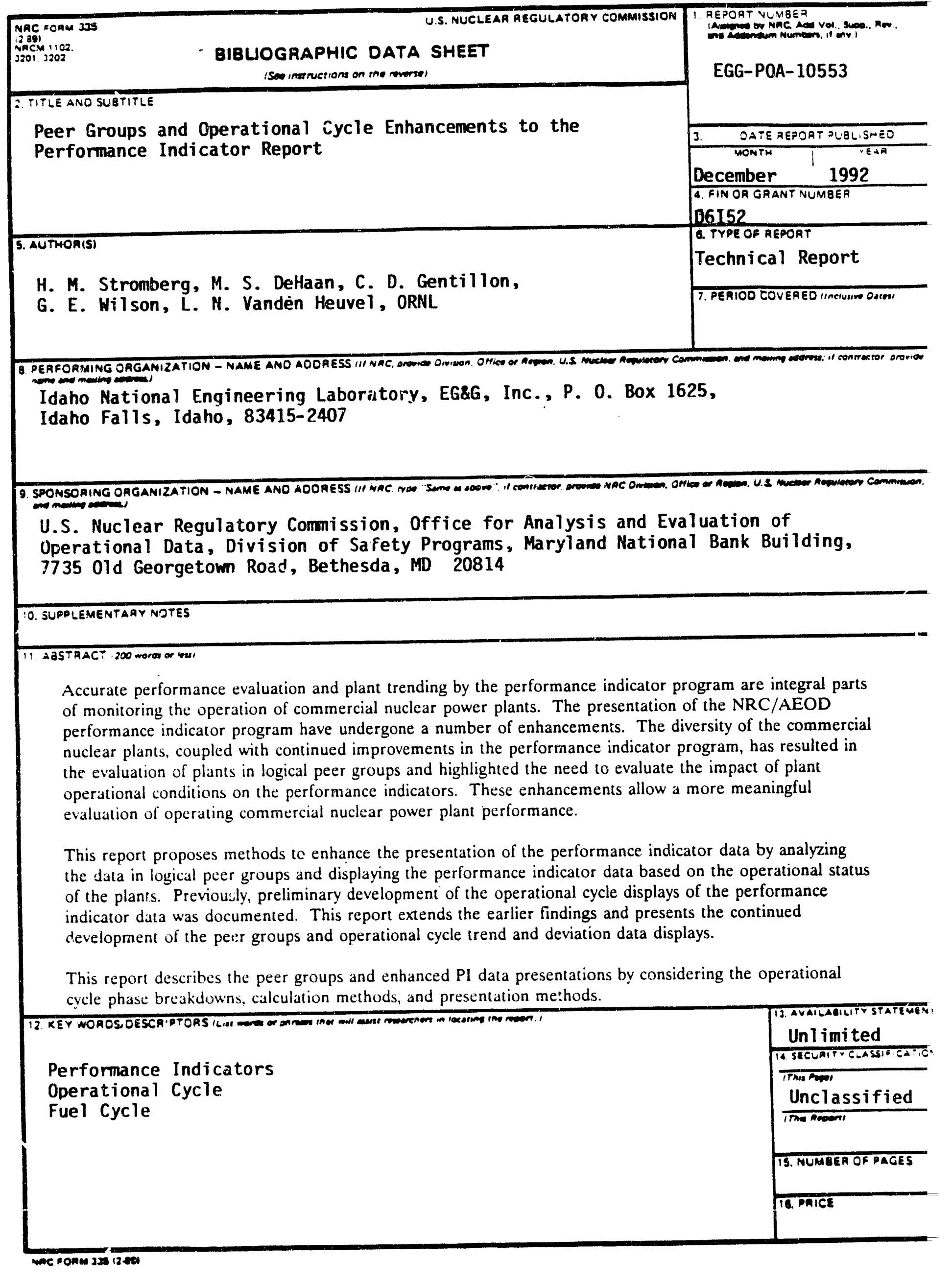



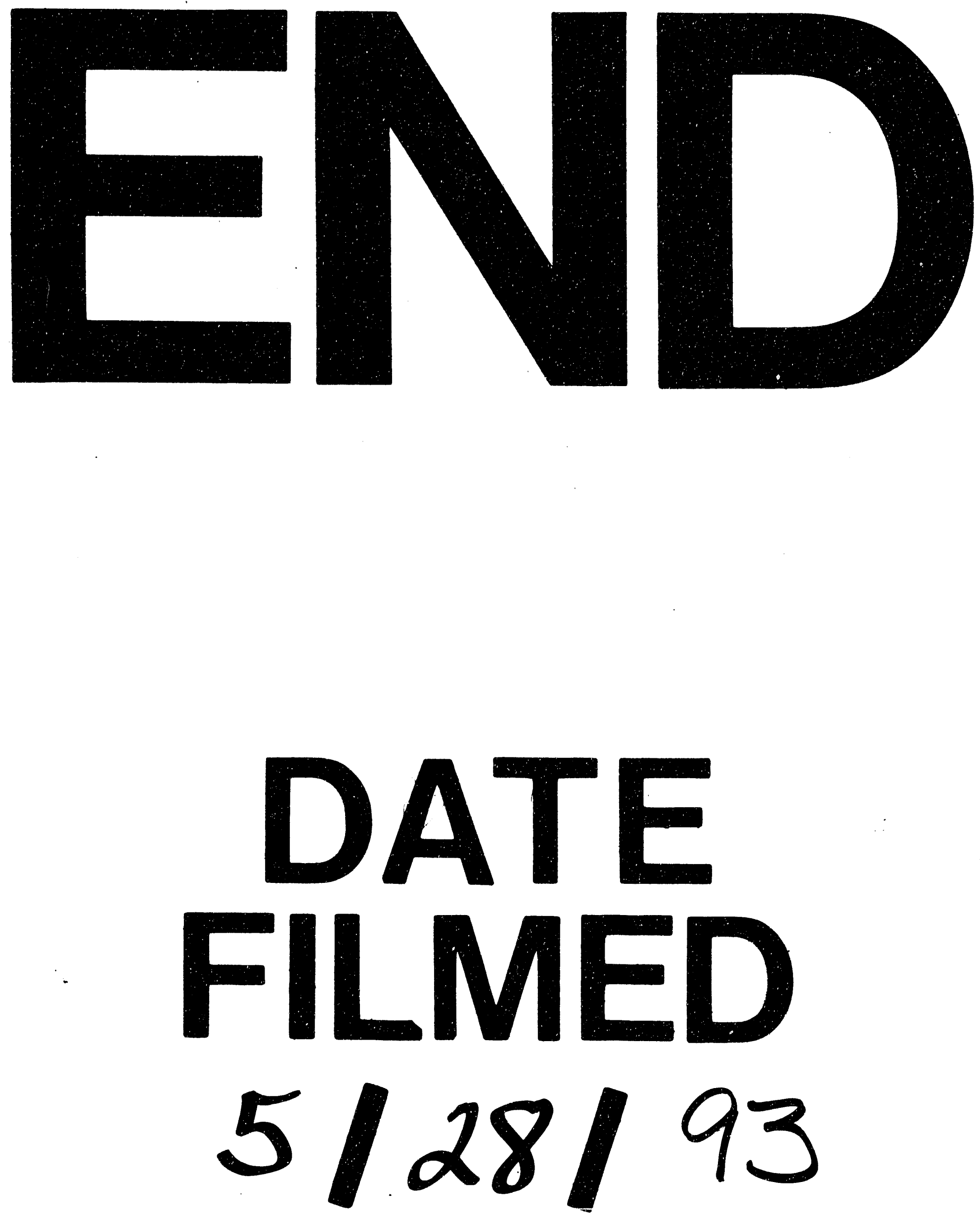

1 
